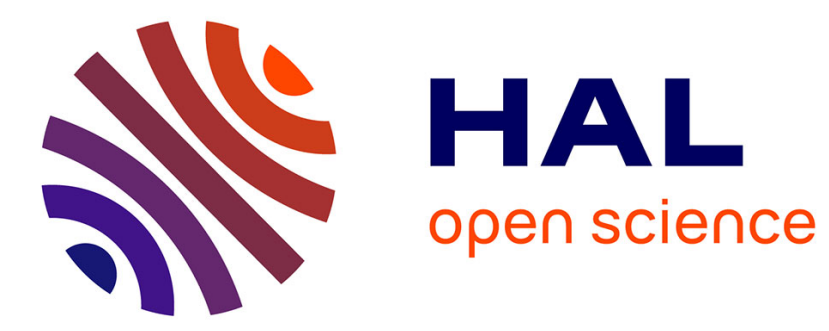

\title{
Extracellular Vesicles: Mechanisms in Human Health and Disease
}

\author{
Marine Malloci, Liliana Perdomo, Maëva Veerasamy, Ramaroson \\ Andriantsitohaina, Gilles Simard, M. Carmen Martínez
}

\section{To cite this version:}

Marine Malloci, Liliana Perdomo, Maëva Veerasamy, Ramaroson Andriantsitohaina, Gilles Simard, et al.. Extracellular Vesicles: Mechanisms in Human Health and Disease. Antioxidants and Redox Signaling, 2019, 30 (6), pp.813-856. 10.1089/ars.2017.7265 . hal-02323323

\section{HAL Id: hal-02323323 \\ https://hal.science/hal-02323323}

Submitted on 16 Dec 2020

HAL is a multi-disciplinary open access archive for the deposit and dissemination of scientific research documents, whether they are published or not. The documents may come from teaching and research institutions in France or abroad, or from public or private research centers.
L'archive ouverte pluridisciplinaire HAL, est destinée au dépôt et à la diffusion de documents scientifiques de niveau recherche, publiés ou non, émanant des établissements d'enseignement et de recherche français ou étrangers, des laboratoires publics ou privés. 


\section{COMPREHENSIVE INVITED REVIEW}

\section{EXTRACELLULAR VESICLES: MECHANISMS IN HUMAN HEALTH AND DISEASE}

Marine Malloci ${ }^{1 *}$, Liliana Perdomo ${ }^{1 *}$, Maëva Veerasamy ${ }^{1}$, Ramaroson Andriantsitohaina ${ }^{1,2}$, Gilles Simard $^{1,2}$, M. Carmen Martínez ${ }^{1,2}$

${ }^{1}$ INSERM UMR 1063, Stress oxydant et pathologies métaboliques, UNIV Angers, Université Bretagne Loire, F-49933, Angers, France; ${ }^{2}$ Centre Hospitalo-Universitaire d'Angers, F-49933, Angers, France

*These authors contributed equally in this work

Running head: Microvesicles/exosomes: biomarkers and effectors

Corresponding author: M. Carmen Martínez, PhD, INSERM UMR 1063, Stress oxydant et pathologies métaboliques, Institut de Biologie en Santé, 4 rue Larrey, F-49933 Angers, France; Phone: +33 2446885 79; E-mail: carmen.martinez@univ-angers.fr

Word count: 18425

Number of references: 351

Numbers of greyscale illustrations: 2

Number of color illustrations: 15 (for online only)

Keywords: Microvesicles, exosomes, biomarkers, miRNA

Reviewing Editors: Haike Antelmann, Markus Bachschmid, Donald Becker, Gregg Semenza and Chandan K Sen 
I. INTRODUCTION

II. MICROVESICLES (MVs) 5

A. MV formation and shedding $\quad 6$

$\begin{array}{lr}\text { B. MV composition } & 8\end{array}$

$\begin{array}{lr}\text { C. Isolation and characterization } & 9\end{array}$

$\begin{array}{lr}\text { D. MV uptake by target cells } & 9\end{array}$

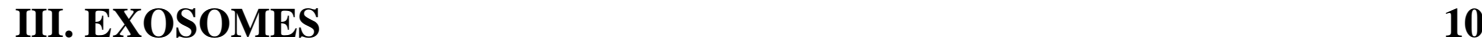

$\begin{array}{lr}\text { A. Exosome formation } & 11\end{array}$

$\begin{array}{lr}\text { B. Exosome release } & 13\end{array}$

$\begin{array}{lr}\text { C. Exosome composition } & 14\end{array}$

$\begin{array}{ll}\text { D. Exosome uptake } & 17\end{array}$

$\begin{array}{lr}\text { E. Biodistribution and clearance of exosomes } & 18\end{array}$

$\begin{array}{lr}\text { F. Isolation of exosomes } & 19\end{array}$

$\begin{array}{lr}\text { G. Characterization methods } & \mathbf{2 0}\end{array}$

$\begin{array}{ll}\text { IV. EVS in DIABETES } & 20\end{array}$

$\begin{array}{ll}\text { V. EVs in OBESITY } & 25\end{array}$

$\begin{array}{ll}\text { VI. EVs in ATHEROSCLEROSIS } & 27\end{array}$

A. EVs and atherosclerotic type I/ II and III lesions 28

B. EVs and atherosclerotic type IV to VIII lesions 32

VII. NEURODEGENERATIVE DISEASES and EVs 36

A. Characteristics of EVs from CNS 36

B. Functional roles of EVs in CNS 38

C. EVs as biomarkers of neurodegenerative diseases 42

D. Implication of EVs in neurological disorders 43

$\begin{array}{ll}\text { VIII. EVs AND CANCER } & 47\end{array}$

A. EVs as biomarkers for cancer diagnosis and prognosis 48

B. EVs as shuttle of information involved in the growth of tumors 
$\begin{array}{lr}\text { IX. EVs as THERAPEUTIC TOOLS } & 57\end{array}$

A. EVs as tools for drug delivery

B. EVs as therapeutic tools in pathophysiological contexts 62

X. FUTURE DIRECTIONS 


\section{Abstract}

Significance: Secreted extracellular vesicles (EVs) have now considered as veritable entities for diagnosis, prognosis and therapeutics. These structures are able to interact with target cells and modify their phenotype and function.

Recent advances: Since composition of EVs depends on the cell type of origin and the stimulation that leads to their release, the analysis of EV content remains an important input in order to understand the potential effects of EVs on target cells.

Critical issues: Here, we review recent data related to the mechanisms involved in the formation of EVs and the methods allowing specific EV isolation and identification. Also, we analyze the potential use of EVs as biomarkers in different pathologies such as diabetes, obesity, atherosclerosis, neurodegenerative diseases and cancer. Besides, their role in these diseases is discussed. Finally, we consider EVs enriched in miRNA or drugs as potential therapeutic cargo able to deliver desirable information to target cells/tissues.

Future directions: We underline the importance of the homogenization of the parameters of isolation of EVs and their characterization that allow considering EVs as excellent biomarkers for diagnosis and prognosis. 


\section{INTRODUCTION}

Cells are able to release various types of vesicles from different biogenesis into the intracellular space. Long considered as simple cell debris, there is now enough evidence that extracellular vesicles (EVs) participate in intercellular communication and, thus modulate many cellular processes. Surrounded by a phospholipid bilayer, EVs are loaded with proteins and nucleic acids from donor cells, which are grouped in the database Vesiclepedia (http://www.microvesicles.org) that contains molecular data identified in all classes of EVs. Furthermore, it is described in numerous pathologies that EVs could be potential biomarkers, since they are easy to detect, more stable than other soluble biomarkers and accessible in a noninvasive manner in most biological fluids (216).

Although the interest in EV research is increasing, there is still no real nomenclature to classify the different types of vesicles. Many terms are used, varying from ectosomes, microparticles, microvesicles (MVs), nanovesicles, exosomes and membrane particles to exosome-like particles and exovesicles (314). Currently, EVs are commonly classified based on their intracellular origin. Thus, three principal populations of EVs are considered: apoptotic bodies, MVs and exosomes (299). The apoptotic bodies (size between 50-5000 nm) which are released by cells undergoing apoptosis, and characterized by permeable membrane, will not be covered in this review. This review focuses on the role of EVs as possible biomarkers and/or therapeutic targets in diabetes, obesity, atherosclerosis, neurodegenerative diseases and cancer. Also, we develop the use of EVs as therapeutic tools in these diseases.

\section{MICROVESICLES (MVs)}

MVs were originally identified by Peter Wolf in 1967 as "platelet dust" (334) and, for a long time, they were considered as cellular debris resulting from cell damage or dynamic plasma membrane incomings (117). They are characterized by preset of surface markers indicative of 
their cellular origin (118). Indeed, MVs are rich in negatively charged phospholipids (e.g. phosphatidylserine (PS)) at their surface.

MVs are distinguished of exosomes by their size and the mechanisms involved in their generation. MVs are directly shed from the plasma membrane of cells and measure approximately 100-1000 $\mathrm{nm}$ (90) (Figure 1). The size range of MVs and exosomes (see below) may possibly overlap, for that reason high-sensitivity technics and novel instruments including nanoparticle tracking analysis, are used to characterize and distinguish both populations (342).

\section{A. MV formation and shedding}

The shedding of MVs is preceded by the budding of small cytoplasmic protrusions, which then detach by fission from different cell types. Platelets, leukocytes, erythrocytes, endothelial cells, and tumor cells are availed to induce in vitro MV shedding $(13,141,187,189,279)$. MVs have also been described in atherosclerotic plaques (250) and liver (238). Regarding MVs on fluids, MVs derived from platelets represent approximately 70-90\% of circulating MVs (91), while in urine, MVs are mainly from renal cells including podocytes, juxtaglomerular and mesangial cells. The mechanisms that lead to the formation of MVs are not completely elucidated even if quantity and phenotype of shed MVs are depending on the method of production. Nevertheless, numerous studies have shown that shedding of MVs follows chemical and physical cell activation or apoptosis (reviewed by (201)).

Distinct stimuli such as tumor necrosis factor (TNF- $\alpha$ ) (35) or actinomycin D (213) trigger an increase in cytosolic calcium concentration, which leads to MV formation (152, 205, 223, 233). This influx of extracellular calcium is associated with calcium-dependent calpain activation, a proteolytic enzyme, which induces changes in the actin cytoskeleton stability $(152,233)$. In addition, the inhibition of cytosolic calcium increase might prevent MV formation (41). The asymmetry of the lipid bilayer is regulated by three types of enzymes: translocases, flippases and scramblases. These enzymes are responsible for the transport of PS and 
phosphatidylethanolamine to the external layer and the rapid "flip-flop" of phospholipids between the membrane leaflets. Under basal conditions, PS is found preferentially, if not exclusively, on the inner leaflet of the plasma membrane of cells. Evidence suggests that PS exposure is a key mediator of the formation of MVs. However, some reports suggest that PS is not externalized in certain MV populations (324).

Nevertheless, shedding of MVs is induced by prolonged high intracellular calcium concentration, which involves different mechanisms such as the activation of tyrosine kinases. Martinez and colleagues have reviewed several molecular targets linked to the increase in intracellular calcium concentration and, MV formation and shedding (201). Some targets include extracellular signal-regulated kinase (ERK) pathway, small GTPase Rho A, myosin light chain and Rho-associated kinase (ROCK I), NADPH oxidase, and reactive oxygen species (ROS) (Figure 1). However, calcium is not the only second messenger involved in MV shedding. Indeed, in dendritic cells (DCs), macrophages and microglia, activation of protein kinase $\mathrm{C}(\mathrm{PKC})$ by a calcium-independent mechanism, is also effective to induce the shedding of MVs (reviewed by (55)).

On the other hand, during apoptosis, MV formation and shedding are associated with the activation of ROCK I and caspase 3, which might lead to the disruption of the membrane skeleton structure and consequently, to the MV formation (56). During apoptosis-dependent MV formation, disturbed membrane follows cell contraction and DNA fragmentation (274). Stimuli such as TNF-related apoptosis-inducing ligand or Apo2 ligand, a cytokine belonging to the TNF- $\alpha$ superfamily, promote endothelial MV release by initiating the recruitment of adaptor

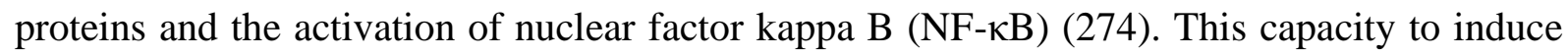
MV production has been attributed to the activation of different signaling cascades, including caspase, RhoA/ROCK, and the p38-MAPK pathways (188). Interestingly, TNF- $\alpha$ treatment has a dual effect on the endothelial release of MVs. TNF- $\alpha$ can induce both miRNA-rich and 
miRNA-poor MVs displaying anti-apoptotic or pro-apoptotic effects, respectively, depending on the activated signal pathway. Indeed, TNF- $\alpha$ induces miRNA-rich MV release through the inhibition of caspase pathway, whereas when RhoA/ROCK pathway is suppressed, TNF- $\alpha$ induces miRNA-poor MV generation (5). This dual effect results in the anti-atherogenic and the pro-atherogenic effects of endothelial MVs on target cells.

\section{B. MV composition}

Proteomic analyses of several MV populations have been performed in order to improve MV molecular profile knowledge $(69,167)$. The different reports have confirmed that MV composition depends, not only on the origin of cell type, but also on the conditions of cell stimulation $(29,280)$. In terms of composition, MVs present elements of their membrane origin, such ligands and receptors, miRNA and proteins from mitochondria $(3,72)$, nucleus and cytosolic compartments (69). There are not a lot of specific protein markers of ubiquitous expression in all MV membranes, since protein composition depends on origin cell. However, a proteomic study of marker comparison has been recently performed in order to characterize heterogeneous populations of EV subtypes released by human DCs. This study has shown that MVs from DCs are specifically enriched in proteins such as actin-4 and -1 , the chaperone endoplasmin, mitofilin, the eukaryotic translation elongation factor 2 and major vault protein. Nevertheless, MVs can express proteins shared by other types of EVs such as actin, tubulin, endoplasmin, glyceraldehyde-3-phosphate dehydrogenase and annexin II (167). However, as stated above, since the composition of MVs strongly depends on the cell type of the origin and the stimuli used for their generation, it is not possible to establish a list of specific MV proteins. It should be noted that MVs express proteins related to the function of mother cells. Thus, MVs derived from neutrophils and tumors are enriched with matrix metalloproteinases (MMPs) and other proteolytic enzymes, which have a function in the digestion of the extracellular matrix necessary for the progress of inflammation and for cancer growth. MVs derived from platelets 
harbor various integrins, the plasma membrane glycoproteins GPIb and GPIIb-IIIa and Pselectin, playing a role in coagulation. The MVs shed from macrophages carry the ligand-1 of the P-selectin glycoprotein, which helps with their binding to platelets (reviewed by (55)).

Furthermore, the lipid composition of MVs can vary depending on the environment nearby to cells. Thus, it has been shown that, after a high-fat meal, individuals display circulating MVs with higher apoB expression and weaker apoCII and ApoE expression when compared to preprandial conditions (278).

\section{Isolation and characterization}

Different biophysical and biochemical properties can be used to isolate EVs, including size, mass density, and shape, charge, and antigen exposure in order to distinguish MVs from exosomes or other type of EVs (Figure 2). The most common methods to isolate EVs are based on size, density, and immunophenotype separation. They include differential centrifugation, density gradient centrifugation, size exclusion chromatography, ultrafiltration, immunocapture assays and precipitation. Some of these methods may be used alone or in combination (reviewed by (30). However, methods to obtain highly pure and well-characterized vesicle populations are not well standardized.

Overall, MVs are isolated from cell culture supernatants or body fluids by a series of centrifugation steps in order to remove dead cells, large debris, and other cellular contaminants resulting from cell lysis (131). Isolation of circulating MVs includes processes that remove blood cells from anticoagulated whole blood by low-speed centrifugation, at room temperature, in order to avoid in vitro platelet activation. However, time and speed of centrifugation change between protocols.

\section{MV uptake by target cells}

Although the mechanisms by which MVs transfer biological information to target cells are not completely elucidated, several ways for MV uptake have been proposed (215). It has been 
described that receptor-ligand interaction is an important mechanism to internalized MVs (289). Other mechanisms involved in MV interaction to the target cells are the transfer of components, the fusion of MVs and target-cell membranes and MV internalization (reviewed by (201)). Concerning internalization, it has been reported that endothelial MV uptake by endothelial cells is inhibited in the presence of annexin V indicating a major role of phospholipids (298). The same group and others have shown that milk fat globule-epidermal growth factor 8 (Mfge8) protein on the MV membrane may serve as a bridge between the PS expressed by MVs and $\alpha v \beta 3$ integrin by endothelial cells and macrophages $(66,298)$. Jansen et al (140) have described that endothelial MVs are internalized by endothelial cells in an annexin I/PS receptor-dependent manner. Also, developmental endothelial locus-1 can act as a bridge between platelet-derived MVs and endothelial cells (67) suggesting that different mechanisms can take place for MV uptake.

The receptor-ligand interaction leads to activation or inhibition of a transduction signal in target cells. However, the above-mentioned mechanisms can change the phenotype of target cells (310). Indeed, interaction by the transfer of MV components includes the transfer of surface receptors, proteins, mRNA, miRNA and bioactive lipids (reviewed by (55)).

\section{EXOSOMES}

Exosomes were described, for the first time three decade ago, as nanoscaled vesicles of endosomal origin, released as a result of the fusion of the multivesicular bodies (MVBs) with the plasma membrane in reticulocytes from rats (116) and sheeps (230). Indeed, by studying the intracellular traffic of transferrin receptor by electronic microscopy, it has been observed that transferrin receptor could be internalized to be recycled and, then, found on the surface of the exosomes in the extracellular medium. Since, in vitro release of exosomes is observed in most of the cells, such as hematopoietic (B-, T- and mast cells, DCs, platelets), epithelial and neural cells, adipocytes, fibroblasts, stem cells and many types of tumor cells (311). In addition, 
exosomes are found in several biological fluids, such as blood, saliva, urine, seminal fluid, amniotic liquid, ascites, bronchoalveolar lavage fluid, synovial fluid, breast milk and cerebrospinal fluid (CSF) (311). Since then, the multiple functions of exosomes in immune and cardiovascular diseases (CVD), tumorigenesis, and the propagation of neurodegenerative diseases have become evident. This has sparked interest in exosomes as biomarkers and therapeutic targets.

Exosomes can be defined by their size comprised between $30-150 \mathrm{~nm}$. The size of exosomes seems to depend on their cell origin type, being $\sim 50 \mathrm{~nm}$ in reticulocytes $(230), \sim 100 \mathrm{~nm}$ in Bcell lymphoma cells (229), or 80 to $120 \mathrm{~nm}$ in adipocytes (76). To identify exosomes, the analysis of at least three specific markers is advised in order to better identify exosome populations (191). In fact, several proteins commonly enriched in exosomes from different origin cell types, can be considered as exosomal markers. Among them, we can find the tetraspanins CD9, CD81, CD63, the endosomal proteins tumor susceptibility gene 101 (TSG101) and ALG-2-interacting protein X (ALIX), or Mfge8 (191). However, the relevance of these markers is currently discussed because they can be also found in MVs (167).

\section{A. Exosome formation}

In contrast to MVs (see above), exosomes come from the endosomal compartment and are formed as intraluminal vesicles (ILVs). ILVs are formed by inward budding of the early endosomal membrane, sequestering proteins, lipids, and cytosol, in order to degrade, recycle or exocytose their content. Early endosomes then mature into late endosomes and the accumulation of multitude of ILVs leads to the formation of MVBs. The main fate of MVBs is to fuse with lysosomes, ensuring the degradation of their content. However, MVBs can also fuse with the plasma membrane to release their sequester ILVs as exosomes in the extracellular space (146) (Figure 1). Several mechanisms have been proposed to participate in the exosome 
formation, and they can be classified into two groups depending on the endosomal sorting complex required for transport (ESCRT).

ESCRT-dependent exosome formation (Figure 3): Involvement of ESCRT machinery in exosome biogenesis is initially inferred from proteomic studies showing the presence, in exosomes from different cell types, of ESCRT-associated proteins, TSG101 and ALIX (301). The role of the ESCRT complexes is to ensure the transport of ubiquitinated proteins from endosomes to lysosomes, leading to their degradation. Thus, ESCRT proteins are responsible to sort proteins into ILVs by inward budding of the membrane and, by the way, exosome release. It has been suggested that ESCRT-0, -I and -II complexes form stable hetero-oligomers that function together to recognize and sequester ubiquitinated proteins in the endosomal membrane. Then, ESCRT-I together with ESCRT-II could initiate the budding process of the endosomal membrane. In addition, ESCRT-II initiates the assembly of the ESCRT-III complex, which in turn, mediates membrane budding and scission to form ILVs (266).

ESCRT-independent exosome formation (Figure 3): Alternative ESCRT-independent pathways have also been proposed. MCF7 tumor cells secrete exosomes through a syndecansyntenin-ALIX pathway (14). Indeed, the syndecan heparan sulfate proteoglycans and their cytoplasmic adaptor syntenin can control the formation of exosomes by direct interaction with ALIX and support the intraluminal budding of endosomal membranes. These syndecan-positive exosomes are also enriched in CD63 and ceramide. Downstream of ALIX, charged MVB proteins, and vacuolar protein sorting-associated protein 4 knockdowns block their biogenesis (14), suggesting that these ESCRT III-associated proteins are also involved in this formation way, although it is independent of the entire classical ESCRT pathway. Moreover, the enzymatic digestion of heparan sulfate chains on syndecans by heparanase facilitates both the endosomal membrane budding and the biogenesis of exosomes, and stimulates their release (254). Thereafter, it has also been described that both the GTPase ADP ribosylation factor 6 
(ARF6) and its effector phospholipase (PL) D2 can regulate this exosome biogenesis pathway (100). Both, ARF6 and PLD2, can affect exosomes by controlling the budding of ILVs into MVBs.

In oligodendroglial cell lines, Trajkovic and colleagues (306) have found that exosome release is diminished after inhibition of neutral sphingomyelinase (nSMase), an enzyme responsible for ceramide production. This lipid can facilitate the membrane invagination of ILVs through its cone-shaped structure and induce exosome formation. Exosomes derived from this way are enriched in proteolipoprotein (PLP), CD63, CD81 and TSG101.

In addition, the tetraspanins CD9 and CD63 have also been directly implicated in exosome formation. Indeed, DCs generate major histocompatibility complex (MHC)-II-exosomes through the CD9-dependent pathway, without ESCRT machinery implication (37). In melanosome, CD63 directly participates in the ESCRT-independent sorting of luminal domain of the premelanosome protein, a protein enriched in melanosomes, to ILVs (316).

Thus, the formation of exosomes seems to involve many mechanisms and remains incompletely elucidated. Moreover, these different ways of production influence exosome composition and, thus induce the formation of different populations of exosomes. This also underlines the molecular and mechanical heterogeneity of the types of exosomes secreted by different cells.

\section{B. Exosome release}

To release exosomes, MVBs must be transported, docked and fuse with the plasma membrane to liberate ILVs in the extracellular space. It has been suggested that proteins of the Rab family are involved in this process. These small GTPases are implicated in the trafficking of intracellular vesicles, their docking and fusion with the plasma membrane (281) (Figure 4). Indeed, Savina and colleagues (263) have shown that, in erythroleukemia cells, Rab11 regulates exosome secretion by acting in docking and fusion of MVBs which requires also the presence of calcium. Beside, in oligodendrocytes, the inhibition of Rab35 function impairs exosome 
secretion (126). In addition, Rab27a and Rab27b promote exosome secretion in HeLa cells. These two Rab27 isoforms are involved in MVB docking at the plasma membrane (229). Exosomes released via this way are enriched in late endosomal proteins (e.g. CD63, ALIX, and TSG101) (2). Furthermore, Rab7 has also been described as implicated in the release of exosomes containing ALIX and syntenin in breast tumor cells (14). However, other authors have shown that depletion of Rab7 does not affect exosome release in Hela cells (229), suggesting this way can be dependent on the cell type. Different studies have suggested that MVB formed by the ESCRT-independent ways carry Rab11 and Rab35 whereas those formed by the ESCRT-dependent mechanisms are rich in Rab27a and Rab27b, and Rab7 (27). Otherwise, Fader et al (82) have shown that the soluble N-ethylmaleimide sensitive factor attachment protein receptor ( $\mathrm{v}-\mathrm{SNARE})$ protein, vesicle-associated membrane protein 7 , may also be implicated in the fusion of MVB with plasma membrane to release exosomes in the extracellular space.

Once again, the mechanisms allowing the secretion of the exosomes seems to be multiple, depending on the origin cells and are not yet completely elucidated.

\section{Exosome composition}

Like MVs (see above), exosomes carry multiple proteins and nucleic acids, protected by a lipid bilayer (Table 1). However, their composition is a consequence of their formation through the endosomal compartment as well as the various mechanisms associated with their secretion. Thus, the composition of exosomes differs from MVs and source cells. For example, a proteomic and lipidomic study has compared the composition of exosomes, MVs and source cells for the three different cell lines: U87 glioblastoma cells, Huh7 hepatocellular carcinoma cells and human bone marrow-derived mesenchymal stem cells (MSCs) (115). The authors have found that protein patterns of exosomes are more likely different from their mother cells than are the protein patterns of MVs. Moreover, exosomes seem enriched in proteins of 
extracellular matrix, heparin-binding, receptors, immune response and cell adhesion functions, whereas MVs are enriched in proteins from endoplasmic reticulum, proteasome and mitochondria. Exosomes and MVs also differ in their types of lipid contents. Furthermore, EV composition differs from one cell line to another, for instance, Huh7 and MSC exosomes are specifically enriched in cardiolipins whereas U87 exosomes are enriched in sphingomyelins (115).

Additionally, the composition of the vesicles may depend on the cell type of origin but also on their specific function. Indeed, Conde-Vancells and colleagues (59) have compared exosomes from a mouse hepatic cell line and from a primary culture of rat hepatocytes, and they have reported that hepatic-derived exosomes comport several common exosomal proteins as well as proteins not previously described in exosomes, such as proteins specifically found in hepatocytes and associated with the function of these cells. In adipocyte-derived EVs, it has been shown that exosomes and MVs exhibit specific protein signature and suggest that the differences in their content could predict the specific biological functions of the EVs (76).

Proteins carried by exosomes: Commonly found proteins in exosomes are logically those associated with the mechanisms responsible for their biogenesis and secretion, including proteins associated with the endosomal compartment. Thus, exosomes are enriched in proteins associated with ESCRT complexes (ALIX, TSG101), involved in the MVB structure (lysosomal-associated membrane protein (Lamp)1 and Lamp2, CD9, CD81 and CD63 tetraspanins), proteins of membrane traffic (Rab GTPases, annexins), fusion proteins (vSNARES), heat-shock proteins (HSP 90/70) or proteins of MHC-I and II, but also proteins from plasma membrane (flotillin-1, Mfge-8, caveolin-1) (for review see (58)).

In general, proteins associated with the endoplasmic reticulum, Golgi and nucleus are not found in exosomes (191); however exosomes carry transcription factors e.g. Notch, Wnt, that are normally found in the nucleus (2). 
Lipid components in exosomes: Comparison of exosome composition produced in vitro from guinea pig primary reticulocytes and their parent cells show that exosomes and reticulocytes have a similar cholesterol composition, but phosphatidylethanolamine content is lower in exosomes than in parent cells (321). Since then, numerous studies have reported the lipid composition of exosomes derived from different cell types such adipocytes (76), MSCs (115), or cancer cells (190), mast cells and DCs (179). These comparisons show that, although lipid content of exosomes is distinct from that of the cell of origin, exosomes display some common lipid features independently of their origin. Indeed, exosomes are mainly enriched in cholesterol, sphingomyelin, ceramide and exposed PS at the membrane surface. Otherwise, the endosomal specific phospholipid, essentially localized in MVBs, bis(monoacylglycero)phosphate could be a specific lipid marker of exosomes (179).

Moreover, fatty acids of exosome membranes are mainly saturated or monounsaturated reflecting a lateral segregation of these lipids in exosomes during maturation of MVBs (286). In addition, exosomes can also contain bioactive lipids. In exosomes from RBL-2H3 basophil cells, it has been shown that enzymes involved in lipid metabolism including PLA2, PLC, and PLD, are responsible for the release of signaling mediators from membrane phospholipids (285). Exosomes can also contain a large panel of free fatty acids or derivatives such as arachidonic acid and prostaglandin E2.

Interestingly, lipid composition of exosomes can also serve as biomarkers and be involved in different diseases (for review see (251)). Recently, it has been shown that lipid content of urinary exosomes changes in patients with prostate cancer (276).

Nucleic acids in exosomes: Exosomes have the capacity to convey and to transfer genetic information, and thus to modulate the gene expression of the target cells. In a small number of cases, DNA has been found, including genomic and mitochondrial DNA (mtDNA), but 
exosomes contain mostly small RNAs, with many derived from ribosomal $18 \mathrm{~s}$ and $28 \mathrm{~s}$ rRNAs and tRNAs (2).

For the first time, mRNA and miRNA are found in exosomes from human and murine mastocytes (312). Montecalvo and colleagues (207) have described the transfer of functional miRNA between DCs through exosomes. Also, the different miRNA cargo profile observed according to the DC maturation suggests that cells could select miRNA content. In this context, in rats, it has also been shown that exosomal miRNA profile can be modulated by stimuli, such as chronic ingestion of sucrose (34).

It has also been described that exosomes can contain many types of RNA such as long and short non-coding RNA, piwi-interacting RNA, vault RNA or Y RNA (2). In this respect, the packaging of RNA in the exosomes within the lipid bilayer membrane allows protecting it from RNAse digestion once released into the extracellular environment. However, due to the variations in isolation techniques and the different cell types and culture conditions used to analyze exosomal content, the comparison of the existing results on the composition of these vesicles has to do with a critical eye.

\section{Exosome uptake}

Once released, exosomes can interact with recipient cells and trigger intracellular signaling pathways, by conveying messages through the delivery of their content. Firstly, binding of exosomes to the cell surface can be possible through a simple interaction with several contact proteins, surface receptors or ligands of target cells (Figure 5). Among all those which have been described, it is possible to retain the role of lymphocyte function-associated antigen 1 (LFA-1) on DCs to capture intercellular adhesion molecule-1 (ICAM-1)-bearing dendritic exosomes (267). Moreover, a decrease of dendritic exosome uptake by DCs is observed after blockage of ICAM-1 and CD9 or CD81 tetraspanins, and their respective receptors, LFA-1 and $\alpha v$ or $\beta 3$ integrins, decrease (210). Secondly, exosomes can also transmit their cargo by the 
direct membrane-membrane fusion as described in DCs (207) and melanoma cells (232). Finally, exosome content can be internalized by different ways of endocytosis: caveolaedependent endocytosis in epithelial cells (222), clathrin-dependent endocytosis in neurons (95) and PC12 cells (303), clathrin-independent but cholesterol- and lipid raft-dependent endocytosis in endothelial and some tumor cells (290), macropinocytosis by microglia (89) and tumor cells (221) or phagocytosis by macrophages (85) and PC12 cells (303).

To improve exosomes uptake, Nakase and colleagues (220) have proposed to combine cationic lipids and a $\mathrm{pH}$-sensitive fusogenic GALA peptide which increase exosome binding at the plasma membrane and improve uptake via the endocytic pathway. Interestingly, heparin blocks both binding to the membrane or recipient cells and uptake of glioblastoma-derived exosomes by human endothelial cells (12). Although the exact mechanism is not advanced, these authors suggest that exosomes contain ligands which bind directly with heparin and impede the binding of exosomes to the receptors on recipient cells.

\section{E. Biodistribution and clearance of exosomes}

Independent studies indicate that the half-life of purified exogenous exosomes from splenocyte supernatants (292), after intravenous injection in mice, is about 2 minutes. Several biodistribution studies of intravenously injected exosomes demonstrate those vesicles are accumulated mainly in liver, spleen, and lungs $(176,197,292,332)$. However, it has been shown that the distribution of exosomes is different after an injection in mice of the same amount of exosomes through three different systemic delivery routes: intravenous, intraperitoneal, and subcutaneous (332).

Thus, biodistribution of exosomes depends on their origin, the administration protocol and the availability of different types of target cells to internalize specific exosomes. Moreover, the slower uptake of exosomes in mice with an impaired innate immune system and a complement 
deficiency suggest that the clearance of exosomes can be regulated by the innate immune system, likely mediated by complement opsonization (277).

\section{F. Isolation of exosomes (Figure 2)}

Exosomes are usually purified from a culture supernatant and biological fluids by serial steps of centrifugation and ultracentrifugation performed at $4{ }^{\circ} \mathrm{C}$ and classically recovered at $100,000 \mathrm{~g}$ during 70 minutes as pellets. However, the intensity or the duration of ultracentrifugation may vary depending on the type of original fluid. For further purification, ultracentrifugation on linear sucrose gradient is recommended, with exosomes floating to a density ranging from 1.13 to $1.19 \mathrm{~g} / \mathrm{mL}$. Some steps of serial centrifugations can be skipped through filtration on $0.22 \mu \mathrm{m}$ pore filters (300). Other methods have been developed to isolate exosomes, such as immunoprecipitation or the use of antibody-loaded magnetic cell beads directed against proteins exposed on exosomal membranes (54). However, this approach allows isolating only a subpopulation of marker-positive exosomes. Finally, once captured on beads, exosomes retaining full functionality may not be successfully eluted from the bead surface (300). Otherwise, the size-exclusion chromatography technique, based on the separation of particles according to size, allows a better elimination of the possible contaminants isolated with the exosomes, while conserving their integrity and biological activity with no loss of sample (28). Moreover, this approach can easily be scaled for isolating large volumes of exosomes. It is described that chromatography allows to recover a more uniform population of vesicles in terms of size and vesicle components (proteins and RNA) than centrifugation (297). There are also different commercial kits, like more expensive, allowing the extraction of exosomes. It has been shown that when circulating exosomes are isolated by ExoQuick precipitation, exosomal RNAs and proteins present greater purity and quantity than chromatography and ultracentrifugation (297). Thus, extraction kits appear to be a good alternative when limited amounts of biological samples are available. 


\section{G. Characterization methods}

Simple purification by differential ultracentrifugation is not sufficient to qualify vesicles as exosomes and a combination of quantitative protein composition, morphological and physical criteria must be used to identify exosomes among other EVs. Morphology and size of exosomes can be determined by transmission electron microscopy, which remains the only method that allows to direct and detailed visualization of these vesicles. Employing immuno-gold labeling provides biochemical information regarding the exosome surface. Moreover, by using cryoelectron microscopy, samples are analyzed in frozen conditions without being stained or fixed (206). Nanoparticle tracking analysis (NTA) allows determining not only size (30-1000 nm), but also the exosome concentration of EVs at a concentration range of $10^{8}-10^{9}$ (206). NTA software is then able to track individual EVs moving under Brownian motion, relates the movement to a particle size and calculates the total concentration. By combining NTA with fluorescence measurement, it is also possible to determine EV phenotype with specific antibodies (75). Finally, specific markers of exosomes can be identified and quantified by classical methods like Western blot, global proteomic analysis using mass spectrometry techniques, or flow cytometry.

\section{EVs in DIABETES (Figure 6, Table 2 and 3))}

Diabetes is a disease characterized by a blood glucose increase, which is associated with several complications, mainly cardiovascular alterations. There are two main types of diabetes: Type 1 diabetes (T1DM) is an autoimmune disease characterized by the destruction of pancreatic $\beta$ cells, which leads to a total failure of the insulin secretion (19), whereas Type 2 diabetes (T2DM) is characterized by failure of insulin action and/or secretion and, frequently, is associated with obesity and aging (148).

Sabatier and colleagues (257) have shown that both T1DM and T2DM are associated with increased levels of circulating MVs, mainly from, endothelial cells $\left(\mathrm{CD} 51^{+}\right)$and platelets 
$\left(\mathrm{CD} 41^{+}\right)$. These MVs from diabetic patients display different pro-coagulant activity being the pro-coagulant activity of circulating MVs increased in T1DM patients but not in T2DM patients. Interestingly, the pro-coagulant activity of MVs from T1DM positively correlates with HbA1c levels, suggesting that this activity of MVs is associated with glucose imbalance. Even more, a recent meta-analysis that consists of 48 studies has shown that patients with T2DM display higher levels of circulating EVs, in particular MVs, than non-diabetic patients (186). Interestingly, enhanced endothelial-derived MV levels are reduced by anti-diabetic treatments such as pioglitazone but not by metformin. It suggests that although both drugs have similar effects on glycemic control, only pioglitazone is able to correct the imbalance between glucose and endothelial damage, as well as, to reduce circulating MVs derived from endothelial cells (81).

Even though some studies have shown the secretion of EVs under high glucose conditions, there is still a lack of knowledge regarding the role of EVs from tissues involved in insulin resistance. An excessive consumption of refined carbohydrates, saturated fat and trans-fatty acids contribute to both weight gain and dyslipidemia, leading to insulin resistance and development of T2DM (155). Under this situation, the storage capacity of white adipose tissue can become saturated which causes abnormal redistribution of lipids in other tissues (260). The effects of EVs from adipocytes have been poorly studied. However, it has been suggested that obesity-dysregulated microRNAs in visceral adipocyte-derived exosomes are predicted to impair insulin receptor signaling in obese subjects (86). Furthermore, circulating adipocytederived exosomal microRNAs targeting the canonical insulin receptor pathway are altered following bariatric surgery-induced weight loss (130). Additionally, white adipose tissue produces a wide variety of adipokines (leptin, resistin, adiponectin, interleukin (IL-6), TNF- $\alpha$ ) which play a significant role in the development of peripheral insulin resistance. Likewise, elevated circulating levels of saturated free fatty acids (e.g. palmitic acid) induce inflammatory 
responses and cause insulin resistance in peripheral tissues. In this context, adipose tissue constitutes an important source of circulating exosomal miRNAs, which can regulate gene expression in distant tissues and thereby serve as a previously undescribed form of adipokines (302). Indeed, mice with Dicer adipose-specific knockout suffer from a severe metabolic phenotype with lipodystrophy which is associated with a huge decrease in serum exosomal miRNAs. Moreover, patients with congenital generalized lipodystrophy, who have been found to have decreased Dicer levels in adipose tissue, display a decreased expression of miRNAs in exosomes (302). Nevertheless, it has been described that exosomes from human adipose tissue, generated ex vivo, decrease or increase insulin-induced Akt phosphorylation depending on their adipokine content (170).

In individuals with T2DM, the prevalence of chronic liver disease is increased since the liver is a key organ in maintaining glucose homeostasis. EVs released by hepatocytes in response to palmitic acid and TNF- $\alpha$ might contribute to local macrophage activation, inflammation, and fibrosis. Even more, lipid-induced toxicity stimulates hepatocytes to release angiogenic MVs suggesting that, under lipotoxicity, MVs from hepatocytes may be critical signals to liver damage in steatohepatitis (239). Likewise, adipose-derived EVs may act into the liver and modulate signaling pathways associated with metabolism, inflammation and fibrosis, which may contribute to the initial stages of non-alcoholic steatohepatitis (NASH) (129). NASH has been described as a significant predictor factor for future T2DM in middle-aged health population, especially in women (305). In this respect, both exosomes and MVs enriched in miR-122 and miR-192 have been identified into the bloodstream during experimental NASH, suggesting an association between T2DM and these miRNA (238).

On the other hand, pancreatic $\beta$ cells secrete insulin, which regulates the hepatic production of glucose. However, when there is resistance to insulin in this tissue, there is a deregulation of hepatic gluconeogenesis contributing to the development of hyperglycemia (203). It has been 
demonstrated that EVs derived from endothelial progenitor cells (EPCs) enhance neoangiogenesis in transplanted pancreatic islets through mRNA and microRNA transfer (44). Figliolini and colleagues (88) suggest that pancreatic islet-derived EVs transport several miRNAs and mRNAs which may play a role in $\beta$ cell-endothelium cross-talk. EVs derived from pancreatic islets carry several mRNAs (vascular endothelial growth factor (VEGF), endothelial nitric oxide ( $\left.{ }^{*} \mathrm{NO}\right)$ synthase (eNOS) and microRNAs (miR-27b, miR-126, miR-130 and miR296) involved in $\beta$-cell function, insulin secretion and angiogenesis, suggesting that their compartmentalization within EVs is not a random process. Some studies have shown that miRNAs carry on $\beta$-cells-derived EVs might modulate glucose homeostasis and interfere with the typical complications of diabetes. For instance, miR-375 (240) and miR-15a (288) are found to be positive regulators of insulin production in pancreatic $\beta$-cells by targeting myotrophin and UCP-2, respectively. Furthermore, Kamalden and colleagues (149) have provided data, in vivo and in vitro, which support the concept that miR-15a contributes to the pathogenesis of diabetes. miR-15a from the rat pancreatic $\beta$-cell line INS-1 can be packaged into exosomes, under high glucose culture conditions. Circulating miR-15a can travel through the circulation and play a role in diabetic retinopathy progression by their transfer to retinal cells, inducing oxidative stress and cell injury.

Diabetes also results in an impact on health mainly in its vascular complications, which include retinopathy, nephropathy, and heart disease. Diabetic retinopathy is associated with ocular increases in oxidative stress, protein glycation, growth factors, inflammatory cytokines, and cell apoptosis, all of which stimulate the shedding of membrane MVs from retinal or vascular cells. In fact, the presence of MVs from platelets, endothelial and retinal cells has been described in human vitreous samples of patients with diabetic retinopathy. Also, these MVs stimulate in vitro endothelial proliferation and in vivo new-vessel formation in a Matrigel plug model. This suggests a role of MVs from vitreous samples of patients with diabetic retinopathy 
in retinal angiogenesis by mechanisms involving VEGF (48). Also, it has been reported that miR-130a and miR-145 are enriched, while miR-155 and miR-424 reduced, in urinary exosomes from T1DM patients with microalbuminuria. In the same way, levels of miR-145 in urinary exosomes are increased in an animal model of diabetic nephropathy induced by streptozotocin. Furthermore, exposure of cultured mesangial cells to high glucose increases miR-145 content in both mesangial cells and mesangial cells derived exosomes, providing a potential mechanism for diabetes-induced miR-145 overexpression (17).

On the other hand, some studies have provided evidence of the role of EVs in the connection between diabetes and heart diseases. Actually, maternal exosomes from diabetic pregnant C57BL/6 mice could cross the maternal-fetal barrier and infiltrate into the embryonic organs/tissues, including the heart, during embryonic development. Furthermore, exosomes from the maternal diabetic mice display upregulation of 126 miRNAs and downregulation of 92 miRNAs. Among these miRNAs, miR-23, miR-30, miR-99, miR-133 are found to be involved in cardiac development. This suggests that maternal exosomes from diabetic mice contribute to the cardiac development deficiency possibly by the transfer of miRNAs. Nonetheless, the relationship between the aberrant miRNAs and the pathways related to cardiac development (such as Notch, Pitx2, Wnt, NKX2.5 and GATA4) is still unknown (271). In addition, in diabetic patients, abnormal regulation of lipid uptake or its intracellular metabolism in cardiomyocytes may be one of the mechanisms underlying cardiomyopathy. Myocardial steatosis, defined as the accumulation of neutral lipids in the myocardium, has been observed in T2DM patients (225). In fact, circulating miR-1 and miR-133a levels are significantly elevated in T2DM patients compared to healthy subjects. Also, high-fat diet-fed mice with myocardial steatosis have elevated levels of circulating miR-1 and miR-133a compared to control animals. Moreover, exosomes released from lipid-loaded HL-1 cardiomyocytes are 
enriched in miR-1 and miR-133a. These data suggest an association between exosomal miR-1 and miR-133a levels and myocardial steatosis in T2DM patients (105).

\section{EVs in OBESITY (Table 2 and 3)}

Defined as an excessive fat accumulation that may impair health and reduce life expectancy, obesity has become a true global epidemic, and worldwide obesity has more than doubled since 1980. Obesity causes are complex: besides nutrition, lack of physical activity and genetics, many environmental factors, such insufficient sleep or endocrine disruptors seem to be also involved in the development of this chronic disease (158). Undeniably, obesity is favored by the modern lifestyle of industrialized countries, which is associated with an obesogenic environment leading to an imbalance between both energy intake and expenditure. Thus, when the former surpasses the second, excess fat will settle in peripheral tissues. One of the major anomalies characterizing people with obesity is inflammation related to the progressive accumulation of immune cells, particularly macrophages, in adipose tissue (31). It is associated with an abnormal production of adipokines which will contribute to generating complications in the other organs (147). Thus, obesity increases the likelihood of various diseases, particularly CVD like stroke, T2DM, obstructive sleep apnea (reviewed by (236)) but also certain types of cancer (173) and depression (192).

Changes to diet and exercising, and medications to reduce appetite or decrease fat absorption are the main treatments for obesity (340). If all these treatments are not sufficient, bariatric surgery may be performed to reduce stomach volume or bowel length. Currently, new approaches are needed to prevent and treat obesity development to stop the global epidemic. For this, accumulated evidence has shown that EVs could be an interesting target.

Several studies have reported that patients with overweight, and also those with obesity, display enhanced circulating levels of procoagulant MVs expressing tissue factor, derived from platelets, endothelial cells and leukocytes, when compared with normal weight healthy subjects 
$(43,282)$. Whereas Stepanian and colleagues (282) show that MV counts do not significantly vary in subjects who lost $25 \%$ of their excess weight, several studies have provided evidence that weight loss reduces EV rates in obese subjects. Indeed, Murakami's group has described that levels of platelet-derived MVs are significantly reduced after weight loss (218). In addition, it has been shown that, at one month after bariatric surgery, the decrease in body mass index (BMI) is associated with the improvement of glycaemia and reduction in endothelial-, plateletand monocyte-derived MVs reflecting a diminished inflammation (50). More recently, it has been shown that, one year after gastrectomy, the decrease of BMI is correlated with a decline of circulating MVs from endothelial, platelet, leukocyte origins, and those expressing tissue factor and CD36. Moreover, the reductions of leukocyte-derived and CD36 ${ }^{+} \mathrm{MVs}$ are significantly correlated with hs-CRP decrease (42). All these studies suggest that overweight and obesity are directly involved in the modulation of levels and subsets of circulating MVs (Figure 7).

Among the circulating EVs, adipocyte-derived exosomes (235) have been also described. Thus, it has been reported increased levels of exosomes expressing adiponectin in blood from $o b / o b$ mice when compared with wild-type mice suggesting that adipocytes release important amounts of EVs during obesity (235). In addition, in vitro secretion of adipocyte-derived EVs is enhanced following an exposure to different biological stimuli, such TNF- $\alpha$ and palmitic acid, related to the chronic inflammation state associated with obesity (76). All these results shed light on the fact that EVs, and particularly adipocyte-derived EVs, can be considered as true biomarkers of obesity.

Moreover, EVs could participate in the establishment of metabolic alterations. In fact, circulating MVs from obese insulin-resistant rats induce ROS production and vascular cell adhesion molecule (VCAM)-1 expression in cardiac endothelial cells (120) (Figure 7). Moreover, injection of adipose tissue-derived exosomes from obese mice in lean mice leads to 
the development of an insulin resistance, linked to the polarization of macrophages to an inflammatory phenotype (71). Indeed, it has been shown that adipocyte-derived exosomes from obese mice induce pro-inflammatory macrophage phenotype through secreted miR-155 (347) (Figure 7). Thus, EVs could participate to the imbalance in the pro-inflammatory-to-antiinflammatory macrophage ratio in adipose tissue, which causes chronic inflammation and local insulin resistance in obesity.

The changes of miRNA patterns in EVs are also described in obese patients, suggesting that EVs can carry other miRNAs which may participate to the development of complications of obesity. Indeed, in adipocyte-derived exosomes from young lean and obese patients, 55 miRNAs are differentially expressed. Transforming growth factor (TGF)- $\beta$ and Wnt/ $\beta$-catenin signaling emerged as top canonical pathways targeted by these miRNAs. These pathways appear to be important in the development and progression of chronic inflammation and fibrotic disease (86). Moreover, Hubal and colleagues (130) have also shown that pattern of miRNA from adipocyte-derived exosomes change after 1-year of gastric bypass surgery and are correlated to improved post-surgery insulin resistance. Finally, in circulating exosomes of patients with metabolic troubles, a significant dysregulation of seven miRNAs associated with risks involved in the manifestation of the metabolic syndrome has been reported when compared with exosomes from healthy subjects. Among them, miR-197, miR-23a, and miR509-5p are correlated with BMI and may be considered as potential contributors of dyslipidemia in metabolic syndrome (154) (Figure 7).

\section{EVs in ATHEROSCLEROSIS (Table 2 and 3)}

Atherosclerosis is the underlying pathology of CVD. The main risk factors for atherosclerosis are T2DM (257), hypertension (242), hyperlipidemia, hypercholesterolemia, sleep apnea (307) and obesity/metabolic syndrome (218). Atherosclerosis is considered to be a chronic inflammatory disease that affects large- and medium-sized arterial vessels, leading to the 
formation of atherosclerotic plaques (253). Typical human atherosclerotic lesions contain different cell types, including smooth muscle cells (SMCs), endothelial cells, fibroblasts, foam cells and macrophages which are involved in the inflammation and the development of the plaque. In the last years, several studies have highlighted the role of EVs, particularly MVs, during the initiation and the progression of atherosclerotic lesion due to EV capacity to interact with the cellular components of vessels.

MVs are produced and accumulated in the human atherosclerotic plaques, particularly, from leukocytes; this process induces endothelial dysfunction and leukocyte recruitment (250). Mechanisms leading to MV formation in atherosclerotic plaques are unknown; however, lipids oxidation or modification, oxidative stress and pro-inflammatory cytokines may locally contribute to MV release from vascular cells or monocytes (90). Likewise, exosomes are present in human atherosclerotic plaques; however, no data is available of the mechanisms that allow regulating exosome presence in the plaque lesion (reviewed by (30)). In this context, EVs affect different biological pathways involved in atherosclerosis such as inflammation, endothelial dysfunction, thrombosis, neovascularization and calcification.

\section{A. EVs and atherosclerotic type I/ II and III lesions}

In the earliest stage of the atherosclerosis, the lesion is classified as type I/ II and type III and is characterized by a near-normal wall thickness and diffuse intimal thickening without calcification (325). EVs are related with some processes in early atherosclerotic lesion including endothelial dysfunction, inflammation, ROS production and monocyte-macrophage adhesion.

EVs: relationship with endothelial dysfunction: Under physiological conditions such as high shear stress or an increase in blood flow, there is an increase of * NO release by endothelial cells (121) that negatively regulates endothelial ATP-binding cassette (ABC) A1 expression, limiting membrane remodeling and PS exposure, but also stabilizing actin at the membrane (Figure 8). 
Both mechanisms concur to limit MV release. However, under pathological conditions such as atherosclerosis, low shear stress increases endothelial ROCK and ERK1/2 activation. This is associated with decreased eNOS, resulting in the loss of the *NO-mediated repression of ABCA1, leading to membrane remodeling and MV release (324) (Figure 8).

Oxidative theory of atherosclerosis includes a primary accumulation of low density lipoprotein (LDL) levels and their oxidation (ox-LDL) in the sub-endothelial matrix (323) leading to endothelial dysfunction, monocyte-macrophage adhesion (195), ROS production (92), and secretion of pro-inflammatory cytokines and growth factors (24). Endothelial permeability is increased when hemodynamic forces and endothelial shear stress are disturbed, allowing LDL diffusion through endothelial cell junctions $(250,295)$. Then, LDL undergoes several modifications, including oxidation, lipolysis, proteolysis, or aggregation. Some evidence suggests that MVs derived from endothelial cells, platelets and leukocytes might contribute to endothelial dysfunction (reviewed by (90)) (Figure 9). It has been shown that MVs derived from metabolic syndrome patients, but not from healthy individuals, induce a decrease of * NO production, leading to endothelial dysfunction. It is associated with a decrease of eNOS activity due to an increase of eNOS phosphorylation at the inhibitory site (Thr495), in human cultured endothelial cells (4). In fact, a temporal cross talk between the endoplasmic reticulum and mitochondria takes place in human endothelial cells treated with the MVs from metabolic syndrome patients. In that way, MVs increase cytosolic and mitochondrial ROS contributing to a decreased bioavailability of ${ }^{*} \mathrm{NO}$. Likewise, MVs activate the three canonical unfolded protein response pathways involving PERK and eIF2a activation, XBP1 splicing and nuclear ATF6 translocation human aortic endothelial cells (258). Additionally, MVs from metabolic syndrome patients are able to activate nSMase, which has been directly related to endothelial dysfunction. Inhibition of nSMase strongly blocks MV-induced endoplasmic reticulum stress and improves both eNOS activity and *NO production. In addition, neutralization of Fas-ligand, 
carried by MVs, abolishes the effects induced by metabolic syndrome MVs (258). Moreover, in diabetic mimic conditions, endothelial-derived MVs lead to an impairment of endotheliumdependent relaxation evoked by acetylcholine, in aortic rings from $\mathrm{ApoE}^{-/-}$mice. Indeed, these MVs possess a pro-oxidant role by triggering ROS production in endothelial cells and the subsequent activation of $\mathrm{p} 38$. A specific inhibition of $\mathrm{p} 38$ prevents the effects mediated by MVs (141). Finally, the interaction between ROS and NO sets up a feedback loop which results in further endothelial dysfunction and inflammation.

EVs: Inflammation and monocyte-macrophage adhesion (Figure 9): Animal and in vitro studies have suggested that oxidative stress and hypercholesterolemia might lead to both monocyte activation and enhanced accumulation of ox-LDL, which induce endothelial dysfunction (226). Ox-LDL induces the release of MVs from pro-inflammatory monocytes and up-regulation of CD36, chemokine receptors, as well as, pro-inflammatory factors through CD36-dependent pathways. Likewise, it has been described an association between the atherosclerosis progress in subjects with heterozygous familial hypercholesterolemia and their circulating levels of MVs derived from monocytes. This suggests a link between lipoprotein-associated oxidative stress, monocyte-macrophage activation and MV release that might reflect some of the underlying mechanisms involved in the atherosclerotic process (226).

In vitro experiments show that MVs can promote adhesion of monocytes to the endothelium, a crucial step for subsequent leukocyte diapedesis. MVs derived from endothelial cells, platelets or leukocytes can promote monocyte rolling and adhesion as well as the release of proinflammatory cytokines (reviewed by (90)). Injection of circulating MVs from metabolic syndrome patients into mice induces pro-inflammatory cytokine production in the aorta, mainly IL-6 and monocyte chemoattractant protein-1 (3). Circulating MVs from obstructive sleep apnea syndrome patients increase the expression of pro-inflammatory proteins such as Eselectin, integrin $\alpha 5$ and ICAM-1 in human endothelial cells. This may initiate atherogenic 
processes in these patients (243). Likewise, injection of MVs derived from endothelial cells from human coronary arteries increases monocyte and macrophage infiltration in atherosclerotic lesions in $\mathrm{ApoE}^{-/-}$mice. This is associated with an enhancement of the adhesion protein expression, ICAM-1 and VCAM-1, in blood vessels (141). MVs isolated from human atherosclerotic plaques enhance inflammatory responses by favoring the adhesion of monocytes to endothelial cells via the transfer of ICAM-1 molecules leading to atherosclerotic plaque progression (250). Indeed, the ICAM-1 expression on EVs isolated from patients with coronary heart disease is remarkably higher than in healthy controls (125).

EVs: SMC migration and proliferation (Figure 9): The proliferation and migration of SMCs from the tunica media to the sub-endothelial region, also known as neointima formation, lead to vessel thickening and occlusion (24) playing a crucial role in vascular remodeling. Under physiologic conditions, intercellular signals between endothelial cells and SMCs are required for the upkeep of the vascular function and remodeling. In fact, EVs can transfer miR-143/145 from endothelial cells to SMCs. This is regulated by the endothelial Krüppel-like factor (KLF)2 expression which leads to an enhanced repression of miR-143/145 target genes and dedifferentiation-associated gene expression (122). In addition, it has been suggested that miR146a and KLF4 present a feedback loop to regulate each other expression and SMC proliferation. miR-146a promotes SMC proliferation and migration by targeting KLF4 and regulating the miR-146a promoter. Finally, the transfection of antisense miR-146a oligonucleotide into balloon-injured rat carotid arteries markedly decreases neointimal hyperplasia (287).

Accumulating evidence demonstrates that pericytes may play a key role in vascular pathogenesis including atherosclerosis (136). Indeed, during atherosclerosis, intimal pericytes may participate in the recruitment of inflammatory cells by producing signaling molecules and play a role in the antigen presentation (135). It has been shown that MVs derived from high 
glucose-treated endothelial cells transfer miR-503 to pericytes and, subsequently, inhibit VEGF expression, resulting in impaired pericyte migration and proliferation (46). On the other hand, MVs from TNF- $\alpha$-treated endothelial cells carry out miR-146a-5p which plays an important role in modulating SMC function, increasing the proliferation and migration of these cells. miR$146 \mathrm{a}-5 \mathrm{p}$ has been associated with the activation of the Mek1/2/ERK1/2 pathway and caspase3/Bcl-2 regulation (231). Furthermore, foam cell-derived EVs from atherosclerotic patients could promote SMC migration and adhesion. These may be mediated by regulating the actin cytoskeleton and focal adhesion pathways after the integration of EVs into SMCs and the subsequent downstream activation of ERK and Akt (227). Altogether these results indicate that EVs from different origins (endothelial cells or foam cells) can alter SMC function by increasing their proliferation, suggesting that EVs can be active mediators in the development of the neo-intima during atherosclerosis.

\section{B. EVs and atherosclerotic type IV to VIII lesions}

In advanced atherosclerotic stage, type IV/V lesions are characterized by the accumulation of lipids and the formation of the lipid or necrotic core. Type VI lesion is a complex plaque with possible surface defect, hemorrhages or thrombus. Finally, type VII lesion is a calcified plaque and type VIII is a fibrotic plaque $(123,325)$. As a consequence of all these processes, including chronic inflammatory response, plaque grows into confluent necrotic cores characterized by a great infiltration of macrophages and apoptosis of foam cells and SMCs.

EVs: Foam cells and "fatty streaks", extracellular matrix synthesis and necrotic cores: Several findings indicate that EVs are implicated in the advanced stages of atherosclerosis but their effect on sub-endothelial LDL modification has not been directly evaluated. LDL and EVs have been implicated in CVD though their relationship has not been well established. Recently, it has been reported that circulating EV levels increase significantly after a high-fat meal in healthy individuals. Even more important, it has been shown that these EVs (after identification 
by annexin $\mathrm{V}$ and anti-CD41 for MVs or anti-CD9 and anti-CD63 for exosomes), are enriched with high quantities of apoB lipoproteins, and low amounts of apoCII and ApoE. These results highlight that both types of circulating EVs, MVs and exosomes, might contain significant amount of lipoproteins related with LDL (278). MVs derived from human coronary endothelial cells exposed to high glucose concentrations induce atherosclerotic plaque formation in $\mathrm{ApoE}^{-}$ ${ }^{1-}$ mice after 8-weeks of treatment. This lesion is characterized by a larger necrotic core as a marker for plaque instability (141). In human carotid plaque, MVs derived from activated or apoptotic leukocytes are mostly concentrated as the result of decreased macrophage phagocytic activity in lesions (142).

Neovascularization of the plaque: As atherosclerosis progresses, the intima thickens and oxygen diffusion is impaired which favors the neovascularization of the plaque (40). Molecular mechanisms responsible for angiogenesis are predominantly related to hypoxia, inflammation and activation of the Toll-like receptor (211). Indeed, that accumulation of EVs within the atherosclerotic plaque may represent an endogenous signal of neovascularization and vulnerability. Even more, MVs isolated from human atherosclerotic lesions, which express CD40L, induce endothelial cell proliferation and promote in vivo angiogenesis, through mechanism involving VEGF and PI3K/Akt (185).

Formation of complex plaque with possible surface defect, hemorrhage or thrombus: The density of intra-plaque neo-vessels increases the risk of rupture and intra-plaque hemorrhage, which is the most frequent cause of thrombosis and cardiovascular complications (24). Circulating MVs might contribute to platelet deposition and thrombus formation under plaque ruptures, damage of vascular lumen or vascular stenosis. MVs are more abundant in atherosclerotic plaques than in plasma, playing an important role in the pro-coagulant activity of the lipid core. Among MVs, leukocyte-derived MVs are the major subset in patients with unstable carotid plaque compared with patients with stable plaque. MVs have been associated 
with plaque vulnerability in patients with high-grade carotid stenosis (261). Interestingly, mildly-ox-high density lipoprotein (HDL) are able to antagonize agonist-induced platelet aggregation by inhibiting the release of pro-coagulant platelet-derived EVs. This may be the result of more efficient phospholipid and sphingolipid platelet remodeling mediated by HDL binding to CD36 or scavenger receptor-B1 in the absence of ABCA1 on platelets (291).

The pro-coagulant effects of MVs and thrombus formation have been correlated with the exposure of PS, and the expression of tissue factor, as well as other surface molecules. Moreover, von Willebrand factor expressed in endothelial-derived MVs binds to platelets and platelet-derived MVs to promote coagulation. Tissue factor on the surface of MVs can function as blood-borne tissue factor to initiate the clotting process (337). MVs exposing coagulant tissue factor are detected in acute coronary syndromes (reviewed by (97)). Circulating MVs and specifically platelet-derived MVs from patients with coronary artery disease enhance platelet aggregation, coagulation, and thrombosis on atherosclerotic and damaged vessels (284). Actually, platelet-derived MVs induce an increase in platelet and fibrin deposition on human atherosclerotic plaques (284). In contrast, only low numbers of platelet-derived exosomes expose a negatively charged lipid such as PS suggesting that exosomes do not display a coagulant activity (119).

Plaque calcification: Calcification of atherosclerotic plaque lesions is the latest stage of atherosclerosis. Vascular calcification is a predictor of CVD and a major determinant of atherosclerotic plaque stability (342). EVs have been identified in calcified human aortic valves and medial arterial calcifications, as well as in atherosclerotic intimal plaques. Emerging evidence suggests that vascular wall cells, including SMCs and macrophages, release calcifying EVs. They are susceptible to aggregate in the extracellular matrix and to form the calcific plaque (132) suggesting that MVs may initiate the mineralization processes, and may induce the rupture of vulnerable plaques. EVs released by SMCs and macrophages in the vessel wall 
interact with fibrillar collagen, which might lead to the calcification. Mineralization of SMCs generates MVs, which enhance calcification in vitro. Furthermore, mineralization in SMCs requires active MVs and an interaction of the MVs with type I collagen (50). Additionally, during the early stages of calcification, MVs released from macrophages and SMCs may contribute to the calcification process. In vitro and in vivo studies have proposed the concept of an inflammation-dependent calcification paradigm. It suggests that macrophage infiltration and inflammation proceed to the calcification. Activated pro-inflammatory pathways induce osteogenic transformation of SMCs and the release of MVs from macrophages and SMCs (reviewed by (224)).

SMC-derived EVs enriched in alkaline phosphatase, members of the annexin family, and MMP2 play a role in the process of matrix calcification, releasing required substrates and forming intermediates known to trigger calcium phosphate precipitation (152). In fact, annexins 2, 5, and 6 in MVs might contribute to the formation of nucleation complex. They facilitate calcium influx and mineralization by binding to PS and forming ion channels in the MV membrane (224). On the other hand, collagen receptor discoidin domain receptor-1 (DDR-1) regulates collagen deposition and release of calcifying EVs by SMCs through the TGF- $\beta$ pathway. DDR1 is a connection between SMC-induced fibrosis and EV-mediated calcification in early-stage atherosclerotic plaque formation. By restricting TGF- $\beta 1$ release in SMCs, DDR-1 suppresses phosphorylation of pro-atherogenic p38 and increases phospho-Smad3, resulting in attenuated fibrosis and calcifying EV release (172). Finally, miR-30, miR-125b, miR-143, miR-145 and miR-155 influence the expression of a specific set of osteogenic markers such as Smad1, RUNX-2, ALP and osterix and altered concentrations of these miRNAs in EVs result in changes in calcium and MAPK signaling pathways implicated in SMC-mediated calcification $(23,171)$ (Figure 10). 


\section{NEURODEGENERATIVE DISEASES and EVs (Table 2 and 3)}

The central nervous system (CNS) is made of neurons and glial cells comprising astrocytes, oligodendrocytes, microglia and ependymal cells. All these cells are able to release vesicles into the extracellular space and recent evidences indicate that cells utilize EVs to exchange signals with neighboring cells or to dispose of unwanted proteins. Thus, in the CNS, EVs provide an important mode in intercellular communication in particular in neuroglia communication, but are, also more and more, implicated in the progression of neurodegenerative diseases associated with the misfolded protein.

\section{A. Characteristics of EVs from CNS (Figure 11)}

Exosomes from neuronal cells: Release of EVs from neurons with the characteristics of exosomes was first demonstrated in 2006 by Fauré and colleagues (84) using cultured cortical neurons from rat embryos. This exosomal release is regulated by glutamatergic synaptic activity and exosomes contain the cell adhesion molecule L1, the glycosylphosphatidylinositol (GPI)anchored prion protein and AMPA-type glutamate receptor subunits GluR2/3 (174). Further studies have shown that neuronal exosomes may also contain proteins associated with neurodegenerative disorders. Following treatments with alkalizing drugs, exosomes from primary neuronal culture cells and differentiated neuroblastoma contain amyloid precursor protein (APP), which is central to the pathogenesis of Alzheimer disease (AD), as well its derivatives, the amyloid intracellular domain and the APP C-terminal fragments (322). Neurons also have the capacity to release exosomes with possible neuroprotective effects. Cystatin C, a protein implicated in the processes of neuronal repair of the nervous system (62) is secreted by neurons in association with exosomes (98). Nedd4 family-interacting protein, an adaptor protein required for the secretion of Nedd4, an ubiquitin ligase important for protein degradation, is detectable in exosomes secreted from primary neurons (245). 
Through neuronal exosomes secretion, miR-124a can be transferred into astrocytes where it significantly increases the expression of glutamate transporter GLT1, an essential transporter for synaptic modulation (209). Exosomes are also implicated in the miRNA release from depolarized neurons (103). By example, miR-29, miR-99a and miR-125a are increased and functionally active in the synaptosome supernatant after depolarization in a calcium-dependent manner (336). Since the release of exosomes from neurons can be modulated by synaptic activity, exosomes can play a key role in synaptic function and in interneuronal communication. Exosomes from glial cells: In the absence of neurons, primary cultures of oligodendrocytes release exosomes which, in addition to cholesterol and phosphatidylcholine, are enriched in the classic myelin lipids such as galactosylceramide and sulfatide (169). Oligodendroglial exosomes are also characterized by the presence of major myelin proteins; although the relative abundance does not exactly reflect the stoichiometry of the myelin membrane as myelin basic protein, PLP, myelin oligodendrocyte glycoprotein and 2', 3'-cyclic nucleotide 3'phosphodiesterase. Moreover, a proteomic analysis of these exosomes identifies a plethora of chaperones and enzymes involved in the management of the oxidative stress (169).

Astrocytes, the most abundant glial cells, are housekeeper of the CNS providing variety of supportive functions to neurons (320). Astrocytes secrete exosomes that contain functional excitatory amino-acid transporters (EAAT)-1 and EAAT2 that are vital for neurotransmission. Importantly, the enrichment of EAAT-1, and probably also EAAT2, into exosomes is under the positive control of PKC (106). Interestingly, mtDNA (111) and miRNAs (175) have also been found in these exosomes. Exosomes are also released from astrocytes in the management of oxidative stress. Cultured astrocytes subjected to hyperthermia release an increasing amount of HSP70 associated with exosomes (296). Synapsin-I, an oligomannose binding protein, playing an important role in modulating nervous system development, is present in exosomes isolated 
from astrocyte-enriched cultures derived from the cortex of neonatal mice and treated with hydrogen peroxide (329).

Microglia cells are tissue-resident macrophages in the CNS that play an important role in managing synaptic development and connectivity besides their function of primary mediators of the CNS immune defense system. Exosomes isolated from the culture supernatant of N9, a well characterized-murine microglial cell line, are rich in chaperones, tetraspanins or membrane receptors previously reported in B cells and DC-derived exosomes, the lactate transporter MCT1 and the enkephalin-degrading- aminopeptidase CD13 (237).

MVs from brain cells: Besides exosomes, both neurons (265) and astrocytes (244) release shed MVs that contain fibroblast growth factor-2 and VEGF. Recent evidence also demonstrates that glial cells release MVs upon appropriate stimulation. For example, activation of astrocytes via the activation of the ATP receptor $\mathrm{P} 2 \mathrm{X}_{7}$ results in an increased release of MVs containing the proinflammatory cytokine IL-1beta (25). The signaling pathway downstream of $\mathrm{P} 2 \mathrm{X}_{7}$ receptor involves p38-dependent activation of acid SMase and is accompanied by the translocation of the enzyme to the outer membrane leaflet. This results in sphingomyelin breakdown and ceramide generation that facilitate membrane blebbing. Upon stimulation by ATP, the N9 murine microglial cell release MVs containing IL-1beta (26). In both cases, the MV formation seems to be the predominant mechanism of IL-1beta secretion in glial cells.

\section{B. Functional roles of EVs in CNS}

A reciprocal communication between the different classes of brain cells is determinant in the development and physiology of the human nervous system. In recent years, EVs have emerged as a novel and critical form of communication in the nervous system (reviewed in $(18,248$, 264). However, most studies evaluating the EV function are performed in cell cultures and need in vivo confirmation. An unresolved question indeed relates to the role of the recipient cells in 
a possible selection of the receiving cargo. Moreover, the majority of these studies focused on exosomes. In this part, we summarize the possible physiological roles of EVs in the CNS.

EVs from neuronal cells: The basal level of exosomes released from mature cortical neurons is very low. In contrast, treatment of neurons with antagonists of the GABAA receptor, which indirectly activates glutamatergic synapses, rapidly and massively increases the secretion of exosomes. The addition of antagonists of glutamate receptors AMPA or ADMA inhibits this increase confirming that glutamatergic synapse activation triggers exosomal release (174). These exosomes contain AMPA-type glutamate receptor subunits GluR2/3 and the loss of AMPA receptors upon extensive synaptic activation could be a mean to regulate excitability by controlling the number of post synaptic glutamate receptors. In addition, recent work reports that exosomes released upon synaptic activation are specifically transferred to neurons (52). By analyzing the binding of exosomes to target cells, these authors demonstrate that exosomes from neuroblastoma cells indiscriminately bind to neurons and glial cells, whereas exosomes secreted from stimulated cortical neurons bind neurons only.

During depolarization, neurons also release exosomes enriched with functionally specific miRNAs and the synaptic-plasticity-associated protein MAP1b (103). As depolarization is associated with a neurite restricted decrease in miRNA, it is plausible that the exosomal miRNA may be an efficient way for cells to rapidly eliminate miRNA activity. Interestingly, Konopka and colleagues (164) recently reported that miRNA depletion enhances learning and memory in mice. It is therefore tempting to speculate that miRNA exosomal release could be an important regulatory component to facilitate synaptic plasticity.

Additionally, exosomes released by neurons may also contribute to the function of the nervous system by modifying supporting cells such as astrocytes. For example, exosomal transfer of neuronal miR-124a is able to regulate the expression of astroglial glutamate transporter-1 (209). 
The mechanism of neuronal exosomal miRNA release is unclear and seems not directly linked to neuronal activity.

EVs from oligodendrocytes: Oligodendrocyte exosomes are able to functionally transfer their content to neurons. More in detail, the transfer of superoxide dismutase (SOD) and, catalase is associated with increased resistance of neurons against oxidative stress and starvation (95) improving the cellular viability. Oligodendrocyte exosomes may also promote physiological responses in neurons. After application of exosomes, analysis of neuronal electrical activity reveals an increase in the firing rate of neurons (94). Moreover, treatment of cultured neurons with oligodendroglial exosomes activates pro-survival activating pathways such as Akt and ERK to influence neuronal gene expression (94). In addition, oligodendroglial exosomes can act in an autocrine fashion to inhibit myelin membrane sheath formation (16).The signal responsible for the exosome release is unknown but it may involve change in intracellular calcium level (169). These exosomes appear to control the growth properties of the cell and the myelin formation (16). These results support the idea that neurons may control terminal differentiation of oligodendrocytes by regulating the release of autoinhibitory exosomes from oligodendrocytes.

Finally, it has been shown that oligodendrocyte exosomes are specifically and efficiently taken up by microglia both in vitro and in vivo (89). Internalization of oligodendrocyte-derived exosomes seems to occur without inflammatory reactions. By such a mechanism, microglia could take part in the clearance of oligodendrocyte myelin components produced in excess in an immunologically "silent" manner.

EVs from astrocytes: Astrocyte-derived MVs carry factors as growth factor 2 and VEGF, known to contribute to regulating angiogenesis and neurogenesis. Astrocytes also release exosomes containing synapsin-I, a lectin-like protein that promotes neurite outgrowth and neuronal survival (329). Interestingly, it is observed that isolated exosomes from astrocyte- 
enriched cell cultures are able to release synapsin-I in the medium in presence of high $\mathrm{K}^{+}$ concentrations $(75-80 \mathrm{mM})$. Since these $\mathrm{K}^{+}$concentrations are similar to that recorded during propagation of spreading depression waves, this suggests that, under condition of high neuronal activity, synapsin-I might play a neuroprotective role by modulating the interaction between neurons and glia.

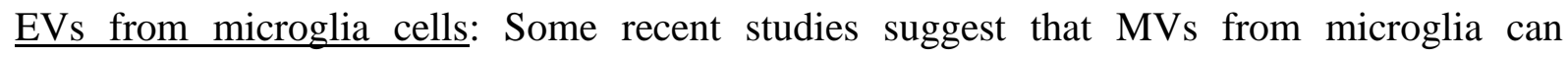
physiologically influence synaptic activity. Treatment of 14-day-old cultured hippocampal neurons with MVs generated either from microglia cell culture or from the N9 microglia cell line enhances spontaneous and evoked excitatory transmission (9). MVs mainly act at the presynaptic site by increasing the probability of synaptic vesicle release. Both SMase and ceramidase activities are required for the presynaptic action of MVs indicating that sphingosine production from sphingomyelin plays a crucial role in the effect. Consistent with this finding, it is reported that sphingosine, but not ceramide, can enhance vesicle exocytosis in brain synaptosomes by activating vesicle-associated membrane protein-2 to form SNARE complex assembly (65). However, additional studies are warranted to better understand the signaling pathway linking MVs to sphingolipid metabolism in neurons.

Microglia-derived MVs are also identified as an additional vehicle for the transporting of lipophilic compounds in the brain like endocannabinoids (96). Endocannabinoids are synthetized in the post synaptic compartment of neurons and retrogradely act to inhibit GABA (inhibitory neurotransmitter) or glutamate (excitatory neuro transmitter) release. Vesicular endocannabinoids are biologically active, and exposure of hippocampal neurons to microgliaderived MVs induces a significant decrease of miniature inhibitory postsynaptic currents mimicking the effect of an agonist of the presynaptic type-1 cannabinoid receptor (CB1). Thus, MVs are able to stimulate CB1 and inhibit presynaptic transmission in GABAergic neurons. However, the suppression of GABAergic tone does not contribute to the increase in excitatory 
transmission elicited by MVs and described above (96). Collectively, these data suggest that microglia MVs may be involved in the modulation of the excitation/inhibition balance.

Microglia also releases exosomes that contain the lactate transporter MCT1. Since exosomes contain all the enzymes necessary for glycolysis and lactate production, lactate release through MCT1 could function as an auxiliary source of energy for neurons. Microglial exosomes also display CD13, an aminopeptidase responsible for enkephalin cleavage. Neurons express CD13 on the presynaptic membrane, but the presence of active CD13 in such a mobile particle could be physiologically advantageous to control the catabolism of enkephalins released at distance from synapses (237).

\section{EVs as biomarkers of neurodegenerative diseases}

For tissues not accessible to direct examination such as the CNS, analysis of EVs released in the blood or in the CSF by neural and non-neural cells has been proposed as a promising diagnostic/prognostic markers for neurological disorders (for review (151)). In cerebrovascular disorders, it is suggested that endothelial- or platelet-derived MVs could represent one useful marker to stratify and identify patients in which initial thrombolysis treatment of the acute phase of ischemic stroke may not be indicated (57). In the diagnosis and treatment of inflammatory diseases of CNS, analysis of exosomes in the CSF may also help diagnostic. For instance, it has been recently reported that exosomal proteome analysis of CSF detects distinct biosignatures of neuromyelitis optica and multiple sclerosis (183), two disorders that are often indistinguishable by their clinical features (36). Reliable markers are also urgently needed to improve the diagnosis of AD and Parkinson's disease (PD) before the appearance of clinical symptoms (157). In CSF, Tau phosphorylated at Thr-181, an established biomarker for AD, has been shown to be significantly enriched relative to total Tau in the exosomal fraction in the early stages of AD (259). Circulating exosomes contain proteins such as cathepsin D, Lamp-1, the levels of which are significantly higher in the preclinical AD, ten years before diagnosis 
(101). To improve the specificity of exosome analysis in these diseases, isolation methodologies are developed to obtain plasma EVs enriched for neuronal origin (219). By analyzing such enriched exosomes, it would be possible to identify AD patients at a preclinical state, to predict the conversion from mild cognitive impairment to dementia (333) or to differentiate AD from frontotemporal dementia (102). Furthermore, whereas exosomes levels of synaptophysin, synaptopodin, synaptotagmin-2 and neurogranin are lower in patients with frontotemporal dementia and AD than in controls, levels of growth-associated protein 43 and synapsin 1 are reduced in AD patients only (102). Using the same approach, plasma exosomes containing elevated levels of $\alpha$-synuclein are detected in PD patients when compared to healthy subjects (271). Expression of miRNA in exosomes might be useful for the diagnosis of PD (45) and AD (315). However, further work is still required to make exosome utilization a reality in the clinics. In particular, the procedures to selectively isolate exosomes crossing the blood-brain barrier from brain into circulation need to be improved.

\section{Implication of EVs in neurological disorders}

The involvement of EVs in neurological disorders including neurodegenerative diseases, brain cancer, and neuro-inflammation has drawn particular attention in recent years. Indeed, it was proposed that exosomes might participate in the progression and the dissemination of the diseases. In particular, proteins associated with neurodegenerative diseases such as AD, PD and amyotrophic lateral sclerosis (ALS) have been shown to be released by cells in association with EVs.

Prion disease: Prions are infectious agents that are responsible for transmissible neurodegenerative diseases such as Creutzfeldt-Jakob disease of humans or bovine spongiform encephalopathy of cattle. The infectious particle is the abnormal protein isoform (PrPSc) of the host-encoded cellular prion protein (PrP). Prion diseases are caused by misfolded forms of PrP that can induce the misfolded state in preexisting normally folded protein of the same type. 
Misfolded proteins trigger a chain reaction of refolding and self-aggregation, spreading the pathophysiological status to other cells and resulting in a formation of stable protein aggregates with a fibrillary amyloid-like structure (283). The precise mechanisms by which prions are transmitted from cell to cell remain to be fully elucidated. Fevrier and colleagues (87) suggest that exosomes may contribute to intercellular membrane exchange and the spread of prions. Through the analysis of two distinct cellular models expressing ovine PrP (rabbit epithelial cells and mouse neuroglial cells), they found that normal PrP and PrPSc are released by cells in association with exosomes and that intracerebral inoculation of these exosomes causes clinical disease in mice. Vella and colleagues (318) have provided the first evidence on the transmission of exosome-associated PrPSc to heterologous cell types in addition to homologous cell types. Recently, it has been demonstrated that the MVB is the major internal site of prion conversion (341) and that stimulation of the release of exosomes increases the infectiousness of PrPSc (112). Moreover, PrPSc is detected in EVs obtained from plasma samples from preclinical and clinically sick mice (255). Together, these studies highlight the potential role of exosomes in prion transmission.

Alzheimer' disease (Figure 12): AD is characterized by the deposition in the brain of the 40-42 amino acid amyloid- $\beta$ peptide $(\mathrm{A} \beta)$ in extracellular plaques and of the microtubule-binding protein Tau in intracellular neurofibrillary tangles. $A \beta$ is produced via the sequential enzymatic cleavage of the amyloid precursor protein (APP) by two proteases, $\beta$ and $\gamma$ secretases. Hela cells expressing the Swedish mutant of APP and N2a neuroblastoma cells provide evidence that A $\beta$ peptides are produced in the early endosome and are directed to MVBs. Furthermore, a small portion of $A \beta(<1 \%)$ is secreted into the extracellular medium bound to exosomes upon fusion of MVB with the plasma membrane (249). In addition, subsequent studies demonstrated that APP, APP metabolites and key enzymes that cleave full-length APP are secreted in exosomes using APP overexpressing cell lines $(270,322)$. Because exosomal markers such as ALIX and 
flotillins have been found to accumulate in amyloid plaques (249), it has been suggested that exosomes might participate in the pathogenesis of AD. Neurotoxicity of exosomes in $\mathrm{AD}$ is consistent with recent evidence indicating that prevention of neuronal exosome secretion is associated with lower amyloid plaque load (73) and improvement of cognition in the 5XFAD mouse model of $\mathrm{AD}$ (74). In these studies, the reduction of exosomes secretion is obtained by pharmacological inhibition of nSMase2, a critical enzyme for exosome biogenesis, or by generating genetically nSMase2-deficient mice. However, the exact role of exosomes in AD remains controversial (144). Several studies have indeed reported that exosomes may also have a protective function. Yuyama and colleagues (343) initially demonstrated that exosomes released from neuroblastoma $\mathrm{N} 2 \mathrm{a}$ can bind extracellular soluble $\mathrm{A} \beta$, promoting $\mathrm{A} \beta$ fibril formation on their surface and incorporation in microglia for lysosomal degradation. In a more recent study, they show that exosomes isolated from primary neuron cultures have also the capability to capture $A \beta$ and, clearly provide evidence that, intracerebral infusion of these exosomes can lead to decrease A $\beta$ accumulation in the brains of APP transgenic mice (344). Thus, the binding of $A \beta$ to neuronal exosome might be a way to increase $A \beta$ clearance by microglia leading them to hypothesize that the decrease in exosome secretion observed in aging could contribute to the plaque formation (344). Furthermore, An and colleagues (8) have demonstrated that, in rats, the intracerebroventricularly infusion of exosomes from N2a cells or healthy CSF can prevent the synaptic plasticity disruption caused by injection of A $\beta$ derived from $\mathrm{AD}$ brain extracts. Mechanistically, the sequestration of $\mathrm{A} \beta$ and mostly the generation of fibrillar $A \beta$ at the exosomal surface may explain the protective function attributed to exosomes by reducing the level of the most neurotoxic species of $A \beta$, the oligomeric forms of $A \beta(8,83)$. Notably, it has been reported that PrPc associated with exosomes from neuronal cell lines (N2a and SH-SY5Y) accelerates fibrillization of $\mathrm{A} \beta$ (83) suggesting a protective role of exosomal PrPc in AD. Nevertheless, it has recently demonstrated that MVs released by cultured microglia 
strongly increase $A \beta$ neurotoxicity in vitro by promoting the formation of soluble toxic forms of $\mathrm{A} \beta$ from extracellular insoluble aggregates and that microglial MVs also contain toxic forms generated from internalized $A \beta$ (144). Taken together, these results indicate that the action of EVs on AD may vary between vesicle populations and support the concept that the EVs may have a "double-edged sword effect" on the process of AD depending on the cell origins, the relative abundance of EVs, and the condition of their formation (335).

Intracellular neurofibrillary tangles consisting of hyperphosphorylated Tau are the second major hallmarks of AD. Exosomes are proposed to be a vehicle for spreading Tau (Figure 13). Saman and colleagues (259) first reported that Tau can be exported via an exosome-mediated mechanism in the M1C neuroblastoma tauopathy model. Moreover, it has been reported that exosomes released by cultured primary neurons or by N2a cells overexpressing different Tau constructs contribute to the transmission of Tau from neuron to neuron via a trans-synaptic pathway (330). However, exosomes containing Tau or phosphorylated Tau have been found to be released by astrocytes (51) and microglia (11), suggesting also the possibility of an exosynaptic propagation of Tau. By using an adeno-associated virus based model exhibiting rapid Tau propagation, it has been observed that depletion of microglia suppresses the propagation of Tau (11). Since microglia spread Tau via exosomes secretion, it has been proposed that microglia phagocytose neuron-contained Tau and then, secrete Tau in exosomes which, in turn, efficiently transmit Tau to neurons.

Parkinson's disease: PD is a neurodegenerative disease clinically characterized by tremor, bradykinesia and postural instability in which the aggregation of protein $\alpha$-synuclein has been found to be central in the progression of the disease. Analysis of the distribution pattern of $\alpha-$ synuclein aggregates has led to the deduction that PD may start in either the olfactory bulbs or the enteric nervous system before spreading to the midbrain and neocortex (33). Using an inducible $\alpha$-synuclein SH-SY5Y cell line, Emmanouilidou's group (79) has shown that $\alpha$ - 
synuclein can be exported out of the cells via an exosomal pathway. This finding, confirmed by others (for review (317)), suggests that exosomes might play a role in the transmission of PD. Although exosomal $\alpha$-synuclein only represents a small pool of the total extracellular $\alpha$ synuclein, several studies have highlighted the importance of this fraction to provide a platform for the propagation of PD (64) and to catalyze the aggregation of free $\alpha$-synuclein (110). Moreover, it has been observed that, in vitro, decreasing lysosomal activity promotes the exosome formation (6). Interestingly, impairment of the autophagy-lysosome pathway is a hallmark of sporadic and genetic forms of PD suggesting that in vivo exosome release may be increased in PD. Thus, exosome is the most studied mode of $\alpha$-synuclein spread (313). Amyotrophic lateral sclerosis: ALS is a fatal neurodegenerative disease characterized by the progressive loss of motor neurons in the brain, brainstem and spinal cord. SOD1 and TDP-43 are two proteins mutated in the familial forms of ALS and, both of them have been found to be associated with exosomes suggesting that exosomes could propagate the proliferation of misfolded SOD1 (108, 273) and TDP43 (134). By example, when human TDP-43-transfected mouse neuroblastoma N2a cells are exposed to exosomes from ALS, but not from healthy brain, TDP-43 redistributes in the cytoplasm, suggesting that TDP-43 may propagate via exosomes. However, the inhibition of exosomes secretion using GW4869, an inhibitor of nSMase2, provokes the formation of TDP-43 aggregates in N2a cells and exacerbates pathological defects in TDP-43A315T transgenic mice (134). Thus, it seems that in the transgenic mouse model, exosome secretion may also protect the cells by eliminating unwanted protein products.

\section{EVs AND CANCER (Table 2 and 3)}

Tumor cells as well as tumor microenvironment cells are prone to produce EVs, that are involved in both tumorigenesis and cancer progression. Moreover, exosomes derived from cancer cells are able to transfer pathophysiological information to normal "healthy" cells favoring their transformation into malignant cells. Also, cells from tumor microenvironment 
generate EVs which increase angiogenesis in order to induce new blood vessel generation necessary to supply oxygen and nutriments facilitating the growth of cancer cells. Also, EV levels can be used as biomarkers of cancer progression and efficacy of antitumor treatments. Due to the huge number of data concerning EVs on cancer, in this part of this review, we will analyze some works showing the potential role of EVs (i) as biomarkers of cancer progression and (ii) as shuttles of information involved in the growth of tumors.

\section{A. EVs as biomarkers for cancer diagnosis and prognosis}

Elevated levels of EVs have been reported in different biofluids from patients with solid or nonsolid tumors (for review see $(32,104)$ ) (Figure 14). In particular, elevated levels of CD41 ${ }^{+} \mathrm{MVs}$ from platelets, and $\mathrm{CD} 14^{+}$and $\mathrm{CD} 62 \mathrm{P}^{+} \mathrm{MVs}$ from monocytes and activated platelets have been detected in patients with gastric (161) and lung cancer (150), respectively. Notably, plasma levels of $\mathrm{CD} 41^{+} \mathrm{MVs}$ are markedly correlated with the advanced stage of gastric cancer and with the prediction of distant metastasis (161). Also, levels of glioblastoma-derived exosomes expressing epidermal growth factor receptor (EGFR)vIII mRNA are correlated with the severity of this cancer (275) and, interestingly, can predict the efficacy of in vivo treatment with the alkylating agent, temozolomide (269). Analysis of the subsets of circulating MVs in patients with advanced non-small cell lung cancer (NSCLC) shows that circulating levels of MVs from platelets $\left(\mathrm{CD} 31^{+} \mathrm{CD} 42 \mathrm{~b}^{+}\right)$and endothelial cells $\left(\mathrm{CD} 31^{+} \mathrm{CD} 42 \mathrm{~b}^{-}\right)$are significantly higher in NSCLC patients than in control subjects, and return to control levels at 3 months after surgical intervention (308). However, only $\mathrm{CD} 1^{+} \mathrm{CD} 42 \mathrm{~b}^{-}$Annexin $\mathrm{V}^{-} \mathrm{MVs}$ from activated endothelial cells are significantly correlated with liver metastasis, disease progression after the complete course of first-line treatment, and one-year mortality suggesting that this MV subset may be used as a biomarker predictive of one-year morality in end stage-NSCLC patients (328). Raimondo and colleagues (247) have analyzed the proteins of urinary exosomes obtained from renal cell carcinoma patients. They identify 9 overexpressed proteins including MMP-9, 
ceruloplasmin, podocalyxin, Dickkopf related protein 4 and carbonic anhydrase IX, whereas 5 proteins (aquaporin-1, MMP inducer, neprilysin, dipeptidase 1 and syntenin-1) are less abundant. However, further studies are needed in order to establish whether the urinary levels of these markers are modified depending on the patient's outcome.

Concerning the non-solid tumors, the characterization of EVs from peripheral blood of patients with hematological malignancies highlights the fact that markers of EVs are specific for each pathology. Indeed, high levels of $\mathrm{CD} 19^{+}$EVs are detected in B cell neoplasms, CD38 ${ }^{+}$EVs in multiple myeloma (MM), $\mathrm{CD}^{+} 3^{+} \mathrm{EVs}$ in myeloid tumors, and CD30 ${ }^{+} \mathrm{EVs}$ in Hodgkin's lymphoma (39). In agreement with these data, other authors have described comparable results in patients or in animal models $(20,21,68,228)$. The study of miRNA carried by EVs in the prognosis of cancer is promising. By analyzing the profile of miRNA into exosomes from normal and MM-derived exosomes, Roccaro and colleagues (252) have shown that levels of miR-15a are significantly decreased in MM-derived exosomes, suggestive of a tumorsuppressive role of exosome-associated miR-15a. Also, two miRNAs, let-7b and miR-18a, in circulating exosomes can predict progression-free survival and overall survival in patients with newly diagnosed MM (198). Similarly, in patients with NSCLC, it has been proposed that plasma exosomes rich in miR-21 and miR-4257 could be potential biomarkers to predict tumor recurrence (70). Remarkably, miR-21 is associated with tumor size and tumor-node-metastasis stage, while miR-4257 shows an association with histological subtypes, lymphatic invasion and tumor-node-metastasis stage. Moreover, in patients receiving curative resection, high exosomal miR-21 or miR-4257 levels are correlated with lower disease-free survival rates than those with low exosomal miR-4257 levels. This suggests that plasma exosomal miR-21 and miR-4257 expression has a potential as a predictive biomarker for recurrence in NSCLC patients. miR-21 associated to exosomes is also a useful biomarker for the prediction of recurrence and poor prognosis in colorectal cancer patients with tumor-node-metastasis stage II, III, or IV (309). In 
another study, it has been shown that, in colon cancer patients developing liver metastases, expression of miR-328 into exosomes is greater in plasma from mesenteric veins than in peripheral veins indicating a possible role of miR-328 in the development of liver metastases (208).

Finally, the analysis of the 36 most abundant lipid species in urinary exosomes of prostate cancer patients reveals that nine lipids species are different to those of healthy patients. Whereas levels of PS and phosphatidylethanolamine are decreased in exosomes from prostate cancer patients, phosphatidylcholine, hexosylceramide and lactosylceramide are enhanced. These data underscore the potential of specific molecular lipid species in urinary exosomes as biomarkers for prostate cancer (276). Altogether, these data suggest that the detection of specific proteins, miRNAs or even lipids in EVs can be used as non-invasive predictor methods of cancer outcome or response to therapy (32).

\section{B. EVs as shuttle of information involved in the growth of tumors}

The implication of EVs on malignant transformation of cells: Choi and colleagues (53) have compiled information concerning the mechanisms by which EVs can modulate oncogenic transformation. Indeed, EVs from solid or non-solid tumors carry transforming molecules including oncoproteins (such as RAS, EGFR, Akt, TAX), oncogenic RNA and miRNA or even oncogenic DNA sequences. For instance, adult T-cell leukemia/lymphoma cells release exosomes containing the transactivator of $\mathrm{pX} \mathrm{TAX}$, an oncoprotein able to activate the expression of viral and cellular genes involved in several pathways including the permanent activation of the NF- $\mathrm{B}$ pathway (327). When delivered to MSCs, these exosomes induce phenotypic changes favoring cell proliferation and creating a more favorable environment for leukemia (78). Also, exosomes from prostate cancer cells overexpressing both miR-125b and miR-130b, involved in the down-regulation of the tumor repressors, reprogram adipose stem cells from cancer patients by conferring genetic instability and oncogenic transformation, and 
reproducing aggressive tumors in mice (1) (Figure 15). Other authors have shown that after injection of exosomes carrying breakpoint cluster region/abelson (BCR/ABL) DNA and generated from human erythroleukemic cells K562, mice display symptoms characteristic of chronic myeloid leukemia (38). Moreover, they have detected both BCR/ABL mRNA and protein into mouse neutrophils. Interestingly, these effects are directly associated with the transfer of BCR/ABL DNA since inhibition of de novo synthesis of BCR/ABL protein prevents the abnormalities caused by K562 EVs in mice. In patients with B-cell chronic lymphocytic leukemia, it has been shown that plasma MVs, mainly from platelets and B cells, not only activate the Akt/mTOR/p70S6K/HIF-1 $\alpha$ axis in bone marrow stromal cells but also transfer, into these cells, the protein kinase receptor Axl in its phosphorylated form (99).

The ability of EVs to transform target cells is largely dependent of the susceptibility to EV uptake. Lee and colleagues (184) have shown that several biological barriers protect normal cells from horizontal transformation by extracellular trafficking of the H-ras oncogene. Indeed, epithelial cells and astrocytes are resistant to EV uptake, whereas primary and immortalized fibroblasts are susceptible to the EV uptake, retention of H-ras DNA and phenotypic transformation. Notably, uptake of H-ras-containing EVs stimulates but fails to transform primary endothelial cells. Altogether these data suggest EVs derived from cancer cells contribute to cellular transformation; however, the horizontal transfer of oncogenic information through EVs is limited depending on target cells.

The implication of EVs on the proliferation of tumor cells: In MM, exosomes isolated from bone marrow-derived MSCs induce in vivo tumor growth in mice and promote dissemination of tumor cells and metastasis to distant bone marrow niches (252). Analysis of miRNA content indicates that miR-15a is down-modulated in exosomes isolated from bone marrow-derived MSCs. The role of miR-15 in MM progression was confirmed by loss and gain of function studies. Indeed, transfection with pre-miR-15a of primary normal bone marrow-derived MSCs 
generates exosomes displaying decreased proliferative activity, and inversely, inhibition of miR-15a in exosomes from normal bone marrow-derived MSCs increases MM proliferation (252). Similarly, in vitro studies have shown that exosomes from leukemia stem cells promote proliferation and migration and inhibit apoptosis of acute myeloid leukemia cells; these effects are associated with miR-34a down-expression since when exosomes are enriched in miR-34a these effects are prevented (331).

Furthermore, exosomes and MVs from glioblastoma express chloride intracellular channel 1 (CLIC1), which has been involved in tumor growth (268). CLIC1-containing EVs stimulate in vitro glioblastoma cell proliferation, migration, and in vivo tumor growth and, these effects are significantly decreased by treatment of glioblastoma cells with EVs derived from CLIC1silenced cells. These findings suggest that CLIC1 carried by EVs may be a novel regulator of glioblastoma growth but the exact mechanism by which CLIC1 acts is not elucidated (268).

Through the transfer of receptors that platelet-derived MVs express at their surface, they are able to increase adhesion, proliferation, and survival of malignant hematopoietic cells by the activation of several kinase signaling cascades including MAPK p42/44, PI3K/Akt, and STAT proteins. The biological effects of MVs derived from platelets are only partly reduced by heat inactivation or trypsin digest, indicating that proteins and lipids of MVs are responsible for their biological activity (15).

EVs from tumor cells are actively involved in tumor angiogenesis: Angiogenesis is a key step in solid tumor progression since unceasing growth of this type of tumor requires (i) a large quantity of oxygen and nutrients, and (ii) removal of metabolite wastes. For this new formation of vessels, tumor cells and tumor environment cells release pro-angiogenic factors, mainly VEGF (for review see (160)).

EVs, mainly exosomes, from epithelial ovarian cancer cells are rich in CD147, an extracellular MMP inducer (Figure 15). This type of EVs promotes an angiogenic phenotype of cultured 
human endothelial cells characterized by the increase of MMP-1 and MMP-2 expressions and the formation of capillary-like structures (204). In addition, the treatment of ovarian cancer cells with small interfering RNA against CD147 suppressed the angiogenic potential of EVs suggesting the direct implication of this protein in the pro-angiogenic effects of EVs from ovarian cancer cells (204). Interestingly, in vitro studies have shown that EVs from CSF, but not from blood, from glioblastoma patients promote endothelial migration and proliferation leading to angiogenesis by a $\beta$-catenin/Akt pathway (187). Isolation and characterization by transcriptional microarray analysis of exosomes released by human SW480 colorectal cancer cell line show that exosomes are enriched in 241 mRNAs related to cell cycle processes when compared to parent cells. Moreover, when human umbilical vein endothelial cells (HUVECs) are treated with human SW480 colorectal cancer-derived exosomes, endothelial cells are in metaphase and cytokinesis with mitotic spindle formation reflecting enhanced proliferation which is an essential step in neovascularization (124).

Since hypoxia is proposed as a driving force of cancer progression, Hsu's group (127) has characterized the effects of EVs (exosomes) released from lung cancer cells exposed to hypoxia $\left(1 \% \mathrm{O}_{2}\right)$ on endothelial cells. These exosomes affect HUVEC function by increasing migration and tube formation, endothelial permeability and transendothelial migration of cancer cells. These effects are mediated by miR-23a carried by exosomes from hypoxic lung cancer cells suggesting that exosomal miR-23a may be a promising strategy for lung cancer treatment (127). EVs from non-tumor cell origins are also able to modulate tumor angiogenesis. In particular, human platelet-derived MVs have been described to increase angiogenesis, but also proliferation and survival of leukemic cells as well as metastasis, in lung cancer (139). These MVs are able to induce the release of pro-angiogenic factors such as VEGF, MMP-9 and IL-8 in HUVECs (139). 
Taken together, these data show that EVs from tumor cells, but also those from tumor environment cells, display pro-angiogenic properties enhancing the ability of endothelial cells to form new vessels in order to allow the tumor growth.

Role of EVs on metastasis: Tumor cells have the ability to migrate, to access the blood or lymphatic routes, circulate and reach distant zones from the primary tumor to form metastasis. In a very elegant study, and by combining high-resolution intravital imaging with a Cre recombinase-based method, Zomer and colleagues (351) have shown the spread of metastatic behavior through EVs in living mice, and directly visualized the release of EVs by highly metastatic human MDA-MB-231 mammary tumor cells. These EVs induce changes in tumor cells with low potential malignant, enhancing their migratory behavior and metastatic capacity (351).

The exosomes from mouse pancreatic ductal adenocarcinomas induce liver pre-metastatic niche formation in mice and, consequently, increase the liver metastatic burden. Interestingly, these exosomes are taken up by Kupffer cells and, then, release TGF $\beta$ leading to the activation of hepatic stellate cells. These events account for the recruitment of bone marrow-derived macrophages to the liver, providing a favorable niche for liver metastasis. Furthermore, these effects seem to be dependent on exosome-associated migration inhibitory factor (61). Metastatic murine and human breast cancer cell lines, as well as sera of mice bearing metastatic tumors, display miR-200-enriched EVs (180). Notably, these EVs, via the transfer of miR-200 to non-metastatic cells, alter gene expression and promote mesenchymal-to-epithelial transition. Besides, EVs from human xenograft models expressing miR-200, promote metastasis. Other authors have shown that exosomes from MDA-MB-231 breast cancer metastatic cell line downregulate tight junction protein zonula occludens (ZO)-1 and increase endothelial permeability leading to alteration of the barrier function of endothelial monolayers by a mechanism dependent on the presence of miR-105 into exosomes (349). In addition, the 
pathophysiological relevance of these findings has been demonstrated by the injection of miR105-enriched exosomes into mice. Indeed, increased miR-105 levels are detected in lung and brain of mice, which is accompanied by reduced ZO-1 expression in endothelial cells, enhanced vascular permeability and metastasis (349). Also, circulating miR-105 levels correlate with metastasis in early-stage breast cancer patients. These authors suggest the developing of personalized therapeutics based on a combination of miR-105 with other circulating miRNAs and/or proteins, allowing the selection of breast cancer patients with high risk for metastasis. In this respect, it has been described that exosomes from breast cancer patients contain the RNA-induced silencing loading complex proteins, Dicer, TAR RNA binding protein, and $\mathrm{AGO} 2$, which process pre-miRNAs into mature miRNAs. Consequently, cancer exosomes alter the transcriptome of target cells in a Dicer-dependent manner, which stimulates non-tumorigenic epithelial cells to form tumors (202).

As described above for their pro-angiogenic potential, platelet-derived MVs can also enhance the invasive capacity of breast cancer cells (138). Although Janowska-Wieczorek and colleagues have only performed in vitro experiments, they have demonstrated that human platelet-derived MVs enhance activation of AKT and ERK1/2 pathways and stimulate the production of MMPs in invasive breast cancer cell lines as well as their chemoinvasion across the reconstituted basement membrane Matrigel. These results underline the problems associated with platelet transfusion to cancer patients.

Other actions of EVs from tumor cells: Cancer is commonly associated with a hypercoagulable state leading to an elevated risk of thrombosis and venous thromboembolism (93). Since EVs, mainly MVs, carry pro-coagulant factors such as tissue factor and/or PS $(76,153,181)$, it is possible that they can be involved in the thrombus generation. Indeed, although exosomes from melanoma cells are less prone to generate thrombin and fibrin than MVs, it is necessary to 
emphasize the potential of both types of EVs to contribute to the pro-thrombotic state of cancer patients (214).

MVs from prostatic carcinoma cell lines (PC3 and LnCaP) modify normal fibroblast function as evidenced by the promotion of MMP-9 expression and ERK1/2 phosphorylation, the increase of tissue factor expression and PS exposure and acquire partial resistance to apoptosis. The data highlight the potential pro-coagulant role of EVs in cancer. Furthermore, prostatic carcinoma cell line-derived MVs induce migration of fibroblasts that, in their turn, release MVs promoting migration and invasion of cancer cells by a mechanism mediated, at least in part, by CX3CR1 (47).

Finally, EVs have also been related to the development of resistance of cancer cells that is associated to poor outcome of patients. The mechanisms by which resistance occurs have not completely elucidated, but some evidence show that inhibition of EV generation by methotrexate or an inhibitor of peptidylarginine deiminases sensitizes prostate cancer cells to chemotherapy $(143,159)$. Recently, it has been shown that the transfer of functional miR-21 by EVs from macrophages associated with tumors to gastric cancer cells induces cisplatin resistance. Once exosome-associated miR-21 enters into gastric cancer cells, it is able to modulate the PTEN/PI3K/Akt signaling pathway and enhances the Bcl-2 anti-apoptotic protein in gastric cancer cells, without affecting $\mathrm{ABC}$ transporter genes. The authors conclude that targeting exosomal miR-21 from tumor-associated macrophages may be a promising adjuvant therapeutic strategy for gastric cancer patients, especially those developing resistance to cisplatin (348). By contrast, other studies have described the presence of $\mathrm{ABC}$ transporters in exosomes released from breast and prostate cancer cells treated with docetaxel $(60,194)$ suggesting that the involvement of these transporters carried by EVs on multidrug resistance developed by cancer cells may be dependent on the type of tumor. 


\section{EVS as THERAPEUTIC TOOLS}

As discussed previously, there is an emerging literature concerning the role of EVs on pathological processes such as diabetes, obesity, CVD or neurodegenerative diseases, and cancer. Since the past decades, new therapeutic strategies in the field of nanomedicine have been developed using the nanostructures as drug delivery systems in order to treat specifically these diseases. Synthetic nanoparticles, liposomes or adenovirus have been produced; however, the use of these nanoparticles is limited. On the one hand, their membrane composition does not facilitate the crossover between cells (77) and, on the other hand, repeated injections of these nanoparticles induce undesired inflammatory responses. Therefore, the use of EVs as drug delivery systems in order to increase the specificity and efficiency of the treatment seems to be an interesting breakthrough.

\section{A. EVs as tools for drug delivery (Figure 16)}

After administration, the intrinsic characteristics of EVs allow the delivery of endogenous or exogenous molecules into target cells and tissues. Thus, (i) the membrane of EVs protects their encapsulated content against degradation, (ii) their small size decreases their clearance and allows that they passively enter in tissues, and (iii) the modification of the membrane surface enhances their ability to target several tissues (165). Altogether, specifically targeted drug delivery systems via EVs may increase the efficacy of therapies for CVD, cancer or neurodegenerative diseases.

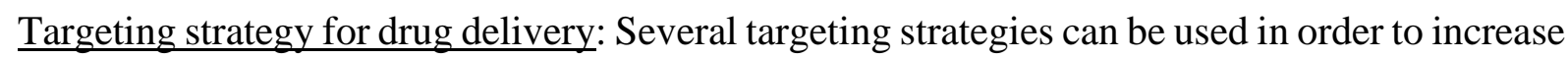
the ability of EVs to interact with specific cells. In fact, Alvarez-Erviti and colleagues (7), have bioengineered the Lamp2b to express the peptide rabies virus glycoprotein (RVG) directly below the signal peptide sequence to target either brain or tumor tissues. Indeed, RVG binds to acetylcholine receptors in neurons, microglia, and oligodendrocytes after intravenous injection allowing a target delivery of EV content. This approach enables the correct insertion of the 
protein into the exosome membrane and prevents the cleavage of important regions in the targeting peptide sequence. Another strategy concerns the fusion of nanobody DNA sequences with GPI-anchor peptide sequences in N2a cells resulting in the insertion of nanobodies into EV membranes. Due to this modification, cell targeting specificity is increased as demonstrated by the enhancement of the association of EVs with EGFR-expressing tumor cells, while interactions with EGFR-negative cells are unaltered (165). Alternative strategies to enhance targeting of EVs consist to stable conjugation of targeting ligands to the surface of isolated EVs by using chemical linkers such as N-hydroxy succinimidyl ester reactive groups, or by the postinsertion technique, once EVs are generated, by fusion with the distal ends of polyethylene glycol-phospholipids (165).

Therapeutic cargo and methods for loading EVs: The current interest in EVs derives from their ability to deliver innovative therapies to specific target cells. This strategy consists to load EVs with a substantial amount of pharmacological drugs efficient to act on target cells. Several loading strategies depending on the type of cargo have been described.

Simple incubation of exosomes with the cargo is a method which has proven efficient results in the loading of EVs thanks to the particular characteristics of the bilayer membrane. For example, exosomes can deliver anti-inflammatory drugs such as curcumin to activate myeloid cells in vivo. Thus, in a lipopolysaccharide (LPS)-induced septic shock mouse model, curcumin carried by exosomes from murine macrophage cell line decreases IL- 6 and TNF- $\alpha$ levels in sera (287). Another study compares nanovesicles in a context of creating chemotherapeutic for malignant tumors and find that doxorubicin-loaded exosomes reduce more tumor growth than bioinspired exosome-mimetic nanovesicles (137). A commercial transfection reagent is also used in order to load EVs but this approach is inadequate for an efficient loading in a therapeutic purpose. Hence, electroporation is a safe method which can be used in a clinical setting but could alter EV integrity. For instance, RVG-loaded exosomes are charged with GAPDH siRNA 
by electroporation (7). Another alternative corresponds to the direct transfection or pharmacological treatment of cells producing EVs. In this way, enrichment of human blood cells and THP-1 cells with synthetic miR-150 enhances the packaging into MVs which are able to reduce c-Myb expression and enhance human microvascular endothelial cell migration. These results indicate that transfection of miR-150 into cells enable the secretion of MVs which can modulate recipient cell function and regulate gene expression (346). Also, adeno-associated viruses (AAVs) are more efficient for delivering cargo into recipient cells when encapsulated in EVs than free AAVs (196). Moreover, it has been demonstrated that the treatment of tumor cells with chemotherapeutic drugs such as doxorubicin induces the release of doxorubicin-rich exosomes, thus these exosomes can be collected and exploited to kill tumor cells (294). However, these techniques can promote adverse effects on the exosomes integrity and their cargoes, by inducing aggregation, for example (166). Finally, pharmacologic treatment of parental cells is also efficient to load generated exosomes with drugs. For instance, when HepG2 cells are incubated with different anticancer agents, such as paclitaxel, etoposide, irinotecan or cisplatin, released exosomes display strong anti-proliferative activity on the human pancreatic cell line CFPAC-1 (193). Also, pharmacologic treatment of human T cells with the apoptotic inductor actinomycin D induces the generation of MVs with antiproliferative and anti-angiogenic properties that have been proposed to be used in lung carcinoma (338). Interestingly, when human T cells are treated with a cocktail of mitogens and actinomycin D, the generated MVs are rich in Sonic hedgehog and display in vitro and in vivo pro-angiogenic actions $(22,279)$. Indeed, these MVs harboring Sonic hedgehog may represent new therapeutic tools in diseases related with failed angiogenesis such as peripheral ischemia or diabetes (199) (Figure 17).

Choice of donor cell type: The use of EVs produced from tumor cells is controverted by the fact that they induce inflammatory reaction during administration (80). To avoid this 
undesirable effect, some studies produce EVs with immunogenic properties from DCs at their immature state. Immature DCs produce large quantities of exosomes, that are immunologically inert, lacking T-cell activators such as MHC-I, MHC-II and CD86 (246). In this respect, exosomes from immature DCs promote graft survival (234) and reduce inflammation in animal models of inflammatory bowel disease (339). Moreover, because EVs are natural transporters, they are less susceptible to trigger immune responses and exert toxicity. Also, it has been demonstrated that EVs from progenitor or MSCs have regenerative properties, particularly they reach injured sites $(162,168)$, promote functional recovery and modulate immune responses. Moreover, in a model mouse myocardial ischemia/reperfusion injury, exosomes from MSCs increase ATP levels, decrease oxidative stress and activate PI3K/Akt pathway to enhance the myocardial viability and prevent adverse remodeling (10). Also, in a liver injury mouse model, it has been demonstrated that MSC-derived exosomes can trigger hepatoprotective effects against toxin-induced injury, through an activation of proliferative and regenerative responses (293). Several studies promote the advantageous use of MSC-derived EVs, instead of stem cells, because they do not replicate and are not trap into lungs after intravenous administration (133).

Recently, it has been described that bovine milk can serve as a source of exosomes that act as a carrier for chemotherapeutic agents showing no adverse immune and inflammatory response. Notably, exosomes from milk are biocompatible and represent excellent candidates, in terms of cost-effectiveness, to enhance oral bioavailability, improve efficacy and safety of drugs (217). After the discovery of exosomes in animal cells, exosomes have also been isolated from several edible plants (145). Oral administration of exosome-like nanoparticles isolated from the grape juice by ultracentrifugation on a sucrose gradient leads to protection in a mouse model of dextran sulphate sodium-induced colitis. Moreover, these exosomes can be used as immune 
modulators in the intestine and for oral delivery of small molecule drugs to attenuate inflammatory responses in human disease (326).

Administration of EVs: EVs have to be stable and capable of delivering their content through the classic administration routes (intravenous, oral...) but also by unusual ways in order to address their cargo more specifically. In the case of malignancies, EVs are mostly administrated by intravenous injection. This method is especially adapted in porous blood vessels and to a defective lymphatic drainage. For example, tumor-bearing mice intravenously treated with exosomes loaded with doxorubicin, show an inhibition of the tumor growth. Moreover, the capacity of these vesicles to express the 9-amino acid cyclic peptide iRGD (sequence: CRGDKGPDC) peptide allows an efficient targeting to the tumor tissue and distribution of doxorubicin without any toxicity (304). In the case of accessible tumors, intratumoral injections are used and provide a secure specific delivery of the therapeutic molecules. Because of their protein and lipid composition, exosomes loaded with doxorubicin intratumorally injected into mice are more efficient internalized by tumor cells than liposomes and allow an effective liberation of doxorubicin inducing a complete suppression of tumor growth (277).

The biodistribution of DiR (DiOC18)-labeled milk exosomes administrated to mice differs depending on the type of administration (217). Indeed, DiR-labeled milk exosomes predominate in the liver after intravenous injection whereas the distribution of these exosomes is uniform in the other organs. A novel approach for treating brain inflammatory-related diseases consists to intranasally administrate exosomes loaded with curcumin in a context of LPS-induced injured brain model in mice. This strategy enables a rapid delivery of exosomeencapsulated drug to the brain, mainly into microglial cells and induce their apoptosis (350). Intraventricular administration of folate receptor-positive EVs is also performed in mouse brain parenchyma in order to restore a functional folate receptor which allows cerebral folate transport (109). Another type of strategy is rising up in order to improve the uptake of EVs by 
cells through the merge of exosomes with liposomes conferring a complex lipid composition to the bilayer membrane. This approach allows an optimization of the exosome surface properties in order to decrease its immunogenicity and increase its colloidal stability, thus improving its half-life in blood. Using the freeze-thaw method which is a simple physiochemical process, exosomes and liposomes membranes fuse causing significant structural and functional changes allowing distinct types of interaction between the hybrid exosomes and the target cell (262). This membrane-engineering method represents a new strategy to load exogenous hydrophobic lipids either hydrophilic cargoes within the exosomes as drug delivery systems.

\section{B. EVs as therapeutic tools in pathophysiological contexts}

As described above, natural or modified EVs can be used as therapeutic tools by modifying the phenotype and function of target cells in order to correct a dysfunction or treat cells with drugs. Here, we propose several examples of the use of EVs as therapeutic tools.

Cardiovascular diseases: EVs possess a potential interest in cardiac regenerative therapies. It has been evidenced that the MSC secretome, mainly exosomes, trigger the beneficial regenerative effects of MSCs by reducing infarct size in animal models of myocardial ischemia/reperfusion $(177,178)$. Moreover, exosomes derived from MSCs inhibit vascular remodeling and hypertension after an intravenous injection in a mouse model of pulmonary hypertension by the inhibition of STAT3 signaling in pulmonary artery endothelial cells (182). In a model of mouse diabetic hindlimb ischemia, exosomes from induced pluripotent stem cells derived from MSCs are able to promote angiogenesis and protect limb from ischemic injury (128).

On the other hand, EVs, specifically enriched in Sonic hedgehog obtained by pharmacological treatment of human T lymphocytes, display protective properties on cardiovascular cells (200). Their pro-angiogenic capacities have illustrated after an intravenous injection in a mouse model hindlimb ischemia (22). In mice, these EVs are able to improve endothelial function by 
increasing *NO release. Also, EVs carrying Sonic hedgehog reduce oxidative stress through the induction of antioxidant messages in HUVECs (280). More in detail, these EVs express antioxidant enzymes, catalase, and isoforms of the superoxide dismutase (Cu/Zn-SOD, MnSOD and extracellular SOD). Furthermore, their effects are associated with the ability to increase the expression of Mn-SOD, but not the other isoforms of SOD, in endothelial cells, through the internalization process (280) (Figure 17).

CNS pathologies: The modulation of neurological disorders by EVs has been recently described. For example, exosomes from MSCs promote endogenous angiogenesis, neurogenesis and reduce inflammation in a rat model of traumatic brain injury contributing of a partial functional recovery (345). It has been demonstrated that EVs from microglia, which are implicated in the defense during inflammation, spread inflammatory reactions throughout the brain by diffusing inflammatory signals and upregulating the expression of enhancing genes inflammation $(241,319)$. A strategy using EVs against AD is proposed in order to enhance the level of nephrilysin which is the most important $A \beta$ degrading enzyme in the brain. Indeed, active nephrilysin carried by exosomes from human adipose tissue-derived MSCs decreases A $\beta$ secretion and its intracellular levels into neuroblastoma cells (156). Moreover, in vivo systemic administration of EVs from DCs, previously enriched in an exogenous siRNA, induce a knockdown of $\beta$-site APP cleaving enzyme I, a therapeutic target in AD, in the mouse brain (7). In a PD mouse model, intranasal administration of catalase-loaded macrophage exosomes induces significant neuroprotective effects reflected by the reduction in microgliosis as measured by $\mathrm{CD} 11 \mathrm{~b}$ expression and the decrease in astrocytosis as demonstrated by the decrease of glial fibrillary acidic protein levels. This leads to an increase in survival of dopaminergic neurons. Interestingly, the neuroprotection is greater when exosomes are loaded with catalase by permeabilization with saponin than by sonication (113). This new exosome- 
based technology allows protecting catalase from a rapid degradation and then, preserving catalase therapeutic activity, leading to improve brain delivery.

Cancer: Some clinical trials are conducted to analyze the efficacy of exosomes as cell-free vaccine in patients with a late-stage of cancer and demonstrated the feasibility and the good tolerance of these vesicles $(63,80,212)$. In addition, antiangiogenic therapy has been demonstrated to have a potential effect in altering the pro-angiogenic properties of EVs which can be used as a novel approach to decrease tumor-associated vasculature and tumor resistance (114). Also, EVs laden with chemotherapeutic molecules such as paclitaxel show high anticancer efficacy against different types of cancer including lung metastasis (163), and prostate cancer (256) representing a novel nanoformulation for these antitumor molecules.

\section{FUTURE DIRECTIONS}

The main disadvantage in using EVs as biomarkers and/or tools against diseases is the lack of gold standards for isolation techniques (107). To address this problem, the International Society for Extracellular Vesicles (ISEV) gives directives to isolate and characterize EVs, as accurately as possible. However, it recognizes there is no protocol standard, and invite the researchers to be cautious about the interpretation of results (191). Also, in order to use EVs in a clinical context as therapeutic tools, characterization of their content has to be exhaustive and, at the same time, easy to perform and not expensive. Only if the scientific community successes to homogenize the parameters of isolation of EVs and their characterization that EVs could be considered as excellent biomarkers for diagnosis and prognosis with a particular interest in the development of tools for theragnosis in a personalized medicine-based strategy. 


\section{Acknowledgements}

This work was supported by Institut National de la Santé et de la Recherche Médicale (INSERM), Université d'Angers, and Centre Hospitalo-Universitaire d'Angers. MM and MV are recipients of doctoral fellowships from INSERM and Conseil Régional du Pays de la Loire. LP is recipient of a postdoctoral fellowship from Angers Loire Métropole. 


\section{List of Abbreviations}

Adeno-associated virus, AAV; ADP ribosylation factor 6, ARF6; ALG-2-interacting protein X, ALIX; Alzheimer's disease, AD; Amyloid- $\beta$ peptide, A $\beta$; Amyloid precursor protein, APP; Amyotrophic lateral sclerosis, ALS; ATP-binding cassette, ABC; Body mass index, BMI; Breakpoint cluster region/abelson (BCR/ABL); Cannabinoid receptor 1, CB1; Cardiovascular diseases, CVD; Central nervous system, CNS; Cerebrospinal fluid, CSF; Chloride intracellular channel 1, CLIC1; Dendritic cells, DCs; Discoidin domain receptor-1, DDR-1; Endosomal sorting complex required for transport, ESCRT; Endothelial nitric oxide synthase, eNOS; Epidermal growth factor receptor, EGFR; Excitatory amino-acid transporter, EAAT; Extracellular signal-regulated kinase, ERK; Extracellular vesicles, EVs; Glycosylphosphatidylinositol, GPI; Heat shock protein, HSP; High density lipoprotein, HDL; Human umbilical vein endothelial cells, HUVECs; InterCellular Adhesion Molecule-1, ICAM1; Interleukin, IL; Intraluminal vesicles, ILVs; Krüppel-like factor, KLF; Lipopolysaccharide, LPS; Low density lipoprotein, LDL; Lymphocyte function-associated antigen 1, LFA-1; Lysosomal-associated membrane protein, Lamp; Major histocompatibility complex, MHC; Matrix metalloproteinase, MMPs; Mesenchymal stem cells, MSCs; Microvesicles, MVs; Milk fat globule-epidermal growth factor 8, Mfge8; Mitochondrial DNA, mtDNA; Multiple myeloma, MM; Multivesicular bodies, MVBs; Nanoparticle tracking analysis, NTA; Neutral sphingomyelinase, nSMase; Nitric oxide, ${ }^{*} \mathrm{NO}$; Non-alcoholic steatohepatitis, NASH; Nonsmall cell lung cancer, NSCLC; Nuclear factor kappa B, NF-кB; Parkinson's disease, PD; Phosphatidylserine, PS; Phosphoinositide-3-kinase, PI3K; Phospholipase, PL; Protein kinase C, PKC; Prion protein, PrP; Proteolipoprotein, PLP; Rabies virus glycoprotein, RVG; Reactive oxygen species, ROS; Rho-associated kinase, ROCK I; Scrapie Prion protein, PrPSc; Smooth muscle cells, SMCs; Soluble N-ethylmaleimide sensitive factor attachment protein receptor, SNARE; Superoxide dismutase, SOD; Transforming growth factor, TGF; Tumor necrosis 
factor, TNF; Tumor susceptibility gene 101, TSG101; Type 1 diabetes mellitus, T1DM; Type 2 diabetes mellitus, T2DM; Vascular cell adhesion molecule, VCAM; Vascular endothelial growth factor, VEGF; Zonula occludens, ZO 


\section{References}

1. Abd Elmageed ZY, Yang Y, Thomas R, Ranjan M, Mondal D, Moroz K, Fang Z, Rezk BM, Moparty K, Sikka SC, Sartor O, Abdel-Mageed AB. Neoplastic reprogramming of patientderived adipose stem cells by prostate cancer cell-associated exosomes. Stem Cells 32: 983997, 2014.

2. Abels ER, Breakefield XO. Introduction to extracellular vesicles: biogenesis, RNA cargo selection, content, release, and uptake. Cell Mol Neurobiol 36: 301-312, 2016.

3. Agouni A, Ducluzeau P-H, Benameur T, Faure S, Sladkova M, Duluc L, Leftheriotis G, Pechanova O, Delibegovic M, Martinez MC, Andriantsitohaina R. Microparticles from patients with metabolic syndrome induce vascular hypo-reactivity via Fas/Fas-ligand pathway in mice. PloS One 6: e27809, 2011.

4. Agouni A, Lagrue-Lak-Hal AH, Ducluzeau PH, Mostefai HA, Draunet-Busson C, Leftheriotis G, Heymes C, Martinez MC, Andriantsitohaina R. Endothelial dysfunction caused by circulating microparticles from patients with metabolic syndrome. Am J Pathol 173: 1210$1219,2008$.

5. Alexy T, Rooney K, Weber M, Gray WD, Searles CD. TNF- $\alpha$ alters the release and transfer of microparticle-encapsulated miRNAs from endothelial cells. Physiol Genomics 46: 833-840, 2014.

6. Alvarez-Erviti L, Seow Y, Schapira AH, Gardiner C, Sargent IL, Wood MJA, Cooper JM. Lysosomal dysfunction increases exosome-mediated alpha-synuclein release and transmission. Neurobiol Dis 42: 360-367, 2011.

7. Alvarez-Erviti L, Seow Y, Yin H, Betts C, Lakhal S, Wood MJA. Delivery of siRNA to the mouse brain by systemic injection of targeted exosomes. Nat Biotechnol 29: 341-345, 2011.

8. An K, Klyubin I, Kim Y, Jung JH, Mably AJ, O’Dowd ST, Lynch T, Kanmert D, Lemere CA, Finan GM, Park JW, Kim T-W, Walsh DM, Rowan MJ, Kim J-H. Exosomes neutralize synaptic-plasticity-disrupting activity of A $\beta$ assemblies in vivo. Mol Brain 6: 47, 2013.

9. Antonucci F, Turola E, Riganti L, Caleo M, Gabrielli M, Perrotta C, Novellino L, Clementi E, Giussani P, Viani P, Matteoli M, Verderio C. Microvesicles released from microglia stimulate synaptic activity via enhanced sphingolipid metabolism. EMBO J 31: 1231-1240, 2012.

10. Arslan F, Lai RC, Smeets MB, Akeroyd L, Choo A, Aguor ENE, Timmers L, van Rijen HV, Doevendans PA, Pasterkamp G, Lim SK, de Kleijn DP. Mesenchymal stem cell-derived exosomes increase ATP levels, decrease oxidative stress and activate PI3K/Akt pathway to enhance myocardial viability and prevent adverse remodeling after myocardial ischemia/reperfusion injury. Stem Cell Res 10: 301-312, 2013.

11. Asai H, Ikezu S, Tsunoda S, Medalla M, Luebke J, Haydar T, Wolozin B, Butovsky O, Kügler S, Ikezu T. Depletion of microglia and inhibition of exosome synthesis halt tau propagation. Nat Neurosci 18: 1584-1593, 2015. 
12. Atai NA, Balaj L, Veen H van, Breakefield XO, Jarzyna PA, Noorden CJFV, Skog J, Maguire CA. Heparin blocks transfer of extracellular vesicles between donor and recipient cells. J Neurooncol 115: 343-351, 2013.

13. Badimon L, Suades R, Fuentes E, Palomo I, Padró T. Role of platelet-derived microvesicles as crosstalk mediators in atherothrombosis and future pharmacology targets: a link between inflammation, atherosclerosis, and thrombosis. Front Pharmacol 7, 2016.

14. Baietti MF, Zhang Z, Mortier E, Melchior A, Degeest G, Geeraerts A, Ivarsson Y, Depoortere F, Coomans C, Vermeiren E, Zimmermann P, David G. Syndecan-syntenin-ALIX regulates the biogenesis of exosomes. Nat Cell Biol 14: 677-685, 2012.

15. Baj-Krzyworzeka M, Majka M, Pratico D, Ratajczak J, Vilaire G, Kijowski J, Reca R, Janowska-Wieczorek A, Ratajczak MZ. Platelet-derived microparticles stimulate proliferation, survival, adhesion, and chemotaxis of hematopoietic cells. Exp Hematol 30: 450-459, 2002.

16. Bakhti M, Winter C, Simons M. Inhibition of myelin membrane sheath formation by oligodendrocyte-derived exosome-like vesicles. J Biol Chem 286: 787-796, 2011.

17. Barutta F, Tricarico M, Corbelli A, Annaratone L, Pinach S, Grimaldi S, Bruno G, Cimino D, Taverna D, Deregibus MC, Rastaldi MP, Perin PC, Gruden G. Urinary exosomal microRNAs in incipient diabetic nephropathy. PloS One 8: e73798, 2013.

18. Basso M, Bonetto V. Extracellular vesicles and a novel form of communication in the brain. Front Neurosci 10: 127, 2016.

19. Belle van TL, Coppieters KT, von Herrath MG. Type 1 diabetes: etiology, immunology, and therapeutic strategies. Physiol Rev 91: 79-118, 2011.

20. Belov L, Matic KJ, Hallal S, Best OG, Mulligan SP, Christopherson RI. Extensive surface protein profiles of extracellular vesicles from cancer cells may provide diagnostic signatures from blood samples. J Extracell Vesicles 5: 25355, 2016.

21. Benameur T, Chappard D, Fioleau E, Andriantsitohaina R, Martinez MC, Clere N, Marchand-Libouban H. Plasma cells release membrane microparticles in a mouse model of multiple myeloma. Micron 54-55: 75-81, 2013.

22. Benameur T, Soleti R, Porro C, Andriantsitohaina R, Martínez MC. Microparticles carrying Sonic hedgehog favor neovascularization through the activation of nitric oxide pathway in mice. PloS One 5: e12688, 2010.

23. Benjamin EJ, Blaha MJ, Chiuve SE, Cushman M, Das SR, Deo R, de Ferranti SD, Floyd J, Fornage M, Gillespie C, Isasi CR, Jiménez MC, Jordan LC, Judd SE, Lackland D, Lichtman JH, Lisabeth L, Liu S, Longenecker CT, Mackey RH, Matsushita K, Mozaffarian D, Mussolino ME, Nasir K, Neumar RW, Palaniappan L, Pandey DK, Thiagarajan RR, Reeves MJ, Ritchey M, Rodriguez CJ, Roth GA, Rosamond WD, Sasson C, Towfighi A, Tsao CW, Turner MB, Virani SS, Voeks JH, Willey JZ, Wilkins JT, Wu JH, Alger HM, Wong SS, Muntner P, American Heart Association Statistics Committee and Stroke Statistics Subcommittee. Heart Disease and Stroke Statistics-2017 Update: a report from the American Heart Association. Circulation 135: e146-e603, 2017. 
24. Bentzon JF, Otsuka F, Virmani R, Falk E. Mechanisms of plaque formation and rupture. Circ Res 114: 1852-1866, 2014.

25. Bianco F, Perrotta C, Novellino L, Francolini M, Riganti L, Menna E, Saglietti L, Schuchman EH, Furlan R, Clementi E, Matteoli M, Verderio C. Acid sphingomyelinase activity triggers microparticle release from glial cells. EMBO J 28: 1043-1054, 2009.

26. Bianco F, Pravettoni E, Colombo A, Schenk U, Möller T, Matteoli M, Verderio C. Astrocyte-derived ATP induces vesicle shedding and IL-1 beta release from microglia. $J$ Immunol 1950 174: 7268-7277, 2005.

27. Blanc L, Vidal M. New insights into the function of Rab GTPases in the context of exosomal secretion. Small GTPases 1-12, 2017.

28. Blans K, Hansen MS, Sørensen LV, Hvam ML, Howard KA, Möller A, Wiking L, Larsen LB, Rasmussen JT. Pellet-free isolation of human and bovine milk extracellular vesicles by size-exclusion chromatography. J Extracell Vesicles 6, 2017.

29. Bochmann I, Ebstein F, Lehmann A, Wohlschlaeger J, Sixt SU, Kloetzel P-M, Dahlmann B. T lymphocytes export proteasomes by way of microparticles: a possible mechanism for generation of extracellular proteasomes. J Cell Mol Med 18: 59-68, 2014.

30. Boulanger CM, Loyer X, Rautou P-E, Amabile N. Extracellular vesicles in coronary artery disease. Nat Rev Cardiol 14: 259-272, 2017.

31. Boutens L, Stienstra R. Adipose tissue macrophages: going off track during obesity. Diabetologia 59: 879-894, 2016.

32. Boyiadzis M, Whiteside TL. The emerging roles of tumor-derived exosomes in hematological malignancies. Leukemia 31:1259-1268, 2017

33. Braak H, Rüb U, Gai WP, Del Tredici K. Idiopathic Parkinson's disease: possible routes by which vulnerable neuronal types may be subject to neuroinvasion by an unknown pathogen. J Neural Transm 110: 517-536, 2003.

34. Brianza-Padilla M, Carbó R, Arana JC, Vázquez-Palacios G, Ballinas-Verdugo MA, Cardoso-Saldaña GC, Palacio AG, Juárez-Vicuña Y, Sánchez F, Martínez-Martínez E, Huang F, Sánchez-Muñoz F, Bojalil R. Inflammation related microRNAs are modulated in total plasma and in extracellular vesicles from rats with chronic ingestion of sucrose. BioMed Res Int 2016, 2016.

35. Brown MD, Feairheller DL, Thakkar S, Veerabhadrappa P, Park J-Y. Racial differences in tumor necrosis factor- $\alpha$-induced endothelial microparticles and interleukin-6 production. Vasc Health Risk Manag 7: 541-550, 2011.

36. Brownlee WJ, Hardy TA, Fazekas F, Miller DH. Diagnosis of multiple sclerosis: progress and challenges. Lancet 389: 1336-1346, 2017.

37. Buschow SI, Nolte-'t Hoen ENM, Van Niel G, Pols MS, Ten Broeke T, Lauwen M, Ossendorp F, Melief CJM, Raposo G, Wubbolts R, Wauben MHM, Stoorvogel W. MHC II in Dendritic cells is targeted to lysosomes or T cell-induced exosomes via distinct multivesicular body pathways. Traffic 10: 1528-1542, 2009. 
38. Cai J, Wu G, Tan X, Han Y, Chen C, Li C, Wang N, Zou X, Chen X, Zhou F, He D, Zhou L, Jose PA, Zeng C. Transferred BCR/ABL DNA from K562 extracellular vesicles causes chronic myeloid leukemia in immunodeficient mice. PloS One 9: e105200, 2014.

39. Caivano A, Laurenzana I, De Luca L, La Rocca F, Simeon V, Trino S, D'Auria F, Traficante A, Maietti M, Izzo T, D’Arena G, Mansueto G, Pietrantuono G, Laurenti L, Musto P, Del Vecchio L. High serum levels of extracellular vesicles expressing malignancy-related markers are released in patients with various types of hematological neoplastic disorders. Tumour Biol 36: 9739-9752, 2015.

40. Camaré C, Pucelle M, Nègre-Salvayre A, Salvayre R. Angiogenesis in the atherosclerotic plaque. Redox Biol 12: 18, 2017.

41. Campbell LE, Nelson J, Gibbons E, Judd AM, Bell JD. Membrane properties involved in calcium-stimulated microparticle release from the plasma membranes of S49 lymphoma cells. ScientificWorldJournal 2014: 537192, 2014.

42. Campello E, Zabeo E, Radu CM, Spiezia L, Foletto M, Prevedello L, Gavasso S, Bulato C, Vettor R, Simioni P. Dynamics of circulating microparticles in obesity after weight loss. Intern Emerg Med 11: 695-702, 2016.

43. Campello E, Zabeo E, Radu CM, Spiezia L, Gavasso S, Fadin M, Woodhams B, Vettor R, Simioni P. Hypercoagulability in overweight and obese subjects who are asymptomatic for thrombotic events. Thromb Haemost 113: 85-96, 2015.

44. Cantaluppi V, Biancone L, Figliolini F, Beltramo S, Medica D, Deregibus MC, Galimi F, Romagnoli R, Salizzoni M, Tetta C, Segoloni GP, Camussi G. Microvesicles derived from endothelial progenitor cells enhance neoangiogenesis of human pancreatic islets. Cell Transplant 21: 1305-1320, 2012.

45. Cao X-Y, Lu J-M, Zhao Z-Q, Li M-C, Lu T, An X-S, Xue L-J. MicroRNA biomarkers of Parkinson's disease in serum exosome-like microvesicles. Neurosci Lett 644: 94-99, 2017.

46. Caporali A, Meloni M, Nailor A, Mitić T, Shantikumar S, Riu F, Sala-Newby GB, Rose L, Besnier M, Katare R, Voellenkle C, Verkade P, Martelli F, Madeddu P, Emanueli C. p75(NTR)dependent activation of NF- $\mathrm{KB}$ regulates microRNA-503 transcription and pericyte-endothelial crosstalk in diabetes after limb ischaemia. Nat Commun 6: 8024, 2015.

47. Castellana D, Zobairi F, Martinez MC, Panaro MA, Mitolo V, Freyssinet J-M, Kunzelmann C. Membrane microvesicles as actors in the establishment of a favorable prostatic tumoral niche: a role for activated fibroblasts and CX3CL1-CX3CR1 axis. Cancer Res 69: 785-793, 2009.

48. Chahed S, Leroyer AS, Benzerroug M, Gaucher D, Georgescu A, Picaud S, Silvestre J-S, Gaudric A, Tedgui A, Massin P, Boulanger CM. Increased vitreous shedding of microparticles in proliferative diabetic retinopathy stimulates endothelial proliferation. Diabetes 59: 694-701, 2010.

49. Chen NX, O'Neill KD, Chen X, Moe SM. Annexin-mediated matrix vesicle calcification in vascular smooth muscle cells. J Bone Miner Res 23: 1798-1805, 2008. 
50. Cheng V, Kashyap SR, Schauer PR, Kirwan JP, McCrae KR. Restoration of glycemic control in patients with type 2 diabetes mellitus after bariatric surgery is associated with reduction in microparticles. Surg Obes Relat Dis 9: 207-212, 2013.

51. Chiarini A, Armato U, Gardenal E, Gui L, Dal Prà I. Amyloid $\beta$-exposed human astrocytes overproduce phospho-tau and overrelease it within exosomes, effects suppressed by calcilytic NPS 2143-further implications for Alzheimer's therapy. Front Neurosci 11: 217, 2017.

52. Chivet M, Javalet C, Laulagnier K, Blot B, Hemming FJ, Sadoul R. Exosomes secreted by cortical neurons upon glutamatergic synapse activation specifically interact with neurons. $J$ Extracell Vesicles 3: 24722, 2014.

53. Choi D, Lee TH, Spinelli C, Chennakrishnaiah S, D'Asti E, Rak J. Extracellular vesicle communication pathways as regulatory targets of oncogenic transformation. Semin Cell Dev Biol 67: 11-22, 2017.

54. Clayton A, Court J, Navabi H, Adams M, Mason MD, Hobot JA, Newman GR, Jasani B. Analysis of antigen presenting cell derived exosomes, based on immuno-magnetic isolation and flow cytometry. J Immunol Methods 247: 163-174, 2001.

55. Cocucci E, Racchetti G, Meldolesi J. Shedding microvesicles: artefacts no more. Trends Cell Biol 19: 43-51, 2009.

56. Coleman ML, Sahai EA, Yeo M, Bosch M, Dewar A, Olson MF. Membrane blebbing during apoptosis results from caspase-mediated activation of ROCK I. Nat Cell Biol 3: 339$345,2001$.

57. Colombo E, Borgiani B, Verderio C, Furlan R. Microvesicles: novel biomarkers for neurological disorders. Front Physiol 3: 63, 2012.

58. Colombo M, Raposo G, Théry C. Biogenesis, secretion, and intercellular interactions of exosomes and other extracellular vesicles. Annu Rev Cell Dev Biol 30: 255-289, 2014.

59. Conde-Vancells J, Rodriguez-Suarez E, Embade N, Gil D, Matthiesen R, Valle M, Elortza F, Lu SC, Mato JM, Falcon-Perez JM. Characterization and comprehensive proteome profiling of exosomes secreted by hepatocytes. J Proteome Res 7: 5157, 2008.

60. Corcoran C, Rani S, O’Brien K, O’Neill A, Prencipe M, Sheikh R, Webb G, McDermott $\mathrm{R}$, Watson W, Crown J, O'Driscoll L. Docetaxel-resistance in prostate cancer: evaluating associated phenotypic changes and potential for resistance transfer via exosomes. PloS One 7: e50999, 2012.

61. Costa-Silva B, Aiello NM, Ocean AJ, Singh S, Zhang H, Thakur BK, Becker A, Hoshino A, Mark MT, Molina H, Xiang J, Zhang T, Theilen T-M, García-Santos G, Williams C, Ararso Y, Huang Y, Rodrigues G, Shen T-L, Labori KJ, Lothe IMB, Kure EH, Hernandez J, Doussot A, Ebbesen SH, Grandgenett PM, Hollingsworth MA, Jain M, Mallya K, Batra SK, Jarnagin WR, Schwartz RE, Matei I, Peinado H, Stanger BZ, Bromberg J, Lyden D. Pancreatic cancer exosomes initiate pre-metastatic niche formation in the liver. Nat Cell Biol 17: 816-826, 2015.

62. D'Adamio L. Role of cystatin $\mathrm{C}$ in neuroprotection and its therapeutic implications. Am J Pathol 177: 2163-2165, 2010. 
63. Dai S, Wei D, Wu Z, Zhou X, Wei X, Huang H, Li G. Phase I clinical trial of autologous ascites-derived exosomes combined with GM-CSF for colorectal cancer. Mol Ther 16: 782790, 2008.

64. Danzer KM, Kranich LR, Ruf WP, Cagsal-Getkin O, Winslow AR, Zhu L, Vanderburg CR, McLean PJ. Exosomal cell-to-cell transmission of alpha synuclein oligomers. Mol Neurodegener 7: 42, 2012.

65. Darios F, Wasser C, Shakirzyanova A, Giniatullin A, Goodman K, Munoz-Bravo JL, Raingo J, Jorgacevski J, Kreft M, Zorec R, Rosa JM, Gandia L, Gutiérrez LM, Binz T, Giniatullin R, Kavalali ET, Davletov B. Sphingosine facilitates SNARE complex assembly and activates synaptic vesicle exocytosis. Neuron 62: 683-694, 2009.

66. Dasgupta SK, Abdel-Monem H, Niravath P, Le A, Bellera RV, Langlois K, Nagata S, Rumbaut RE, Thiagarajan P. Lactadherin and clearance of platelet-derived microvesicles. Blood 113:1332-1339, 2009.

67. Dasgupta SK, Le A, Chavakis T, Rumbaut RE, Thiagarajan P. Developmental endothelial locus-1 (Del-1) mediates clearance of platelet microparticles by the endothelium. Circulation 125:1664-1672, 2012.

68. De Luca L, D’Arena G, Simeon V, Trino S, Laurenzana I, Caivano A, La Rocca F, Villani O, Mansueto G, Deaglio S, Innocenti I, Laurenti L, Molica S, Pietrantuono G, De Stradis A, Del Vecchio L, Musto P. Characterization and prognostic relevance of circulating microvesicles in chronic lymphocytic leukemia. Leuk Lymphoma 58: 1424-1432, 2017.

69. Dean WL, Lee MJ, Cummins TD, Schultz DJ, Powell DW. Proteomic and functional characterisation of platelet microparticle size classes. Thromb Haemost 102: 711-718, 2009.

70. Dejima H, Iinuma H, Kanaoka R, Matsutani N, Kawamura M. Exosomal microRNA in plasma as a non-invasive biomarker for the recurrence of non-small cell lung cancer. Oncol Lett 13: 1256-1263, 2017.

71. Deng Z, Poliakov A, Hardy RW, Clements R, Liu C, Liu Y, Wang J, Xiang X, Zhang S, Zhuang X, Shah SV, Sun D, Michalek S, Grizzle WE, Garvey T, Mobley J, Zhang H-G. Adipose tissue exosome-like vesicles mediate activation of macrophage-induced insulin resistance. Diabetes 58: 2498-2505, 2009.

72. Diehl P, Fricke A, Sander L, Stamm J, Bassler N, Htun N, Ziemann M, Helbing T, El-Osta A, Jowett JBM, Peter K. Microparticles: major transport vehicles for distinct microRNAs in circulation. Cardiovasc Res 93: 633-644, 2012.

73. Dinkins MB, Dasgupta S, Wang G, Zhu G, Bieberich E. Exosome reduction in vivo is associated with lower amyloid plaque load in the 5XFAD mouse model of Alzheimer's disease. Neurobiol Aging 35: 1792-1800, 2014.

74. Dinkins MB, Enasko J, Hernandez C, Wang G, Kong J, Helwa I, Liu Y, Terry AV, Bieberich E. Neutral sphingomyelinase-2 deficiency ameliorates Alzheimer's disease pathology and improves cognition in the 5XFAD mouse. J Neurosci 36: 8653-8667, 2016. 
75. Dragovic RA, Gardiner C, Brooks AS, Tannetta DS, Ferguson DJP, Hole P, Carr B, Redman CWG, Harris AL, Dobson PJ, Harrison P, Sargent IL. Sizing and phenotyping of cellular vesicles using nanoparticle tracking analysis. Nanomedicine 7: 780-788, 2011.

76. Durcin M, Fleury A, Taillebois E, Hilairet G, Krupova Z, Henry C, Truchet S, Trötzmüller M, Köfeler H, Mabilleau G, Hue O, Andriantsitohaina R, Martin P, Le Lay S. Characterisation of adipocyte-derived extracellular vesicle subtypes identifies distinct protein and lipid signatures for large and small extracellular vesicles. J Extracell Vesicles 6, 2017.

77. El Andaloussi S, Lakhal S, Mäger I, Wood MJA. Exosomes for targeted siRNA delivery across biological barriers. Adv Drug Deliv Rev 65: 391-397, 2013.

78. El-Saghir J, Nassar F, Tawil N, El-Sabban M. ATL-derived exosomes modulate mesenchymal stem cells: potential role in leukemia progression. Retrovirology 13: 73, 2016.

79. Emmanouilidou E, Melachroinou K, Roumeliotis T, Garbis SD, Ntzouni M, Margaritis LH, Stefanis L, Vekrellis K. Cell-produced alpha-synuclein is secreted in a calcium-dependent manner by exosomes and impacts neuronal survival. J Neurosci 30: 6838-6851, 2010.

80. Escudier B, Dorval T, Chaput N, André F, Caby M-P, Novault S, Flament C, Leboulaire C, Borg C, Amigorena S, Boccaccio C, Bonnerot C, Dhellin O, Movassagh M, Piperno S, Robert C, Serra V, Valente N, Le Pecq J-B, Spatz A, Lantz O, Tursz T, Angevin E, Zitvogel L. Vaccination of metastatic melanoma patients with autologous dendritic cell (DC) derivedexosomes: results of the first phase I clinical trial. J Transl Med 3: 10, 2005.

81. Esposito K, Maiorino MI, Di Palo C, Gicchino M, Petrizzo M, Bellastella G, Saccomanno F, Giugliano D. Effects of pioglitazone versus metformin on circulating endothelial microparticles and progenitor cells in patients with newly diagnosed type 2 diabetes--a randomized controlled trial. Diabetes Obes Metab 13: 439-445, 2011.

82. Fader CM, Sánchez DG, Mestre MB, Colombo MI. TI-VAMP/VAMP7 and VAMP3/cellubrevin: two v-SNARE proteins involved in specific steps of the autophagy/multivesicular body pathways. Biochim Biophys Acta 1793: 1901-1916, 2009.

83. Falker C, Hartmann A, Guett I, Dohler F, Altmeppen H, Betzel C, Schubert R, Thurm D, Wegwitz F, Joshi P, Verderio C, Krasemann S, Glatzel M. Exosomal cellular prion protein drives fibrillization of amyloid beta and counteracts amyloid beta-mediated neurotoxicity. $J$ Neurochem 137: 88-100, 2016.

84. Fauré J, Lachenal G, Court M, Hirrlinger J, Chatellard-Causse C, Blot B, Grange J, Schoehn G, Goldberg Y, Boyer V, Kirchhoff F, Raposo G, Garin J, Sadoul R. Exosomes are released by cultured cortical neurones. Mol Cell Neurosci 31: 642-648, 2006.

85. Feng D, Zhao W-L, Ye Y-Y, Bai X-C, Liu R-Q, Chang L-F, Zhou Q, Sui S-F. Cellular internalization of exosomes occurs through phagocytosis. Traffic 11: 675-687, 2010.

86. Ferrante SC, Nadler EP, Pillai DK, Hubal MJ, Wang Z, Wang JM, Gordish-Dressman H, Koeck E, Sevilla S, Wiles AA, Freishtat RJ. Adipocyte-derived exosomal miRNAs: a novel mechanism for obesity-related disease. Pediatr Res 77: 447-454, 2015.

87. Fevrier B, Vilette D, Archer F, Loew D, Faigle W, Vidal M, Laude H, Raposo G. Cells release prions in association with exosomes. Proc Natl Acad Sci USA 101: 9683-9688, 2004. 
88. Figliolini F, Cantaluppi V, De Lena M, Beltramo S, Romagnoli R, Salizzoni M, Melzi R, Nano R, Piemonti L, Tetta C, Biancone L, Camussi G. Isolation, characterization and potential role in beta cell-endothelium cross-talk of extracellular vesicles released from human pancreatic islets. PloS One 9: e102521, 2014.

89. Fitzner D, Schnaars M, van Rossum D, Krishnamoorthy G, Dibaj P, Bakhti M, Regen T, Hanisch U-K, Simons M. Selective transfer of exosomes from oligodendrocytes to microglia by macropinocytosis. J Cell Sci 124: 447-458, 2011.

90. Flamant $\mathrm{S}$, Tamarat R. Extracellular vesicles and vascular injury: new insights for radiation exposure. Radiat Res 186: 203-218, 2016.

91. Flaumenhaft R, Dilks JR, Richardson J, Alden E, Patel-Hett SR, Battinelli E, Klement GL, Sola-Visner M, Italiano JE. Megakaryocyte-derived microparticles: direct visualization and distinction from platelet-derived microparticles. Blood 113: 1112-1121, 2009.

92. Förstermann U, Xia N, Li H. Roles of vascular oxidative stress and nitric oxide in the pathogenesis of atherosclerosis. Circ Res 120: 713-735, 2017.

93. Franco AT, Corken A, Ware J. Platelets at the interface of thrombosis, inflammation, and cancer. Blood 126: 582-588, 2015.

94. Fröhlich D, Kuo WP, Frühbeis C, Sun J-J, Zehendner CM, Luhmann HJ, Pinto S, Toedling J, Trotter J, Krämer-Albers E-M. Multifaceted effects of oligodendroglial exosomes on neurons: impact on neuronal firing rate, signal transduction and gene regulation. Philos Trans R Soc Lond B Biol Sci 369, 2014.

95. Frühbeis C, Fröhlich D, Kuo WP, Amphornrat J, Thilemann S, Saab AS, Kirchhoff F, Möbius W, Goebbels S, Nave K-A, Schneider A, Simons M, Klugmann M, Trotter J, KrämerAlbers E-M. Neurotransmitter-triggered transfer of exosomes mediates oligodendrocyteneuron communication. PLoS Biol 11: e1001604, 2013.

96. Gabrielli M, Battista N, Riganti L, Prada I, Antonucci F, Cantone L, Matteoli M, Maccarrone M, Verderio C. Active endocannabinoids are secreted on extracellular membrane vesicles. EMBO Rep 16: 213-220, 2015.

97. Gaceb A, Martinez MC, Andriantsitohaina R. Extracellular vesicles: new players in cardiovascular diseases. Int J Biochem Cell Biol 50: 24-28, 2014.

98. Ghidoni R, Paterlini A, Albertini V, Glionna M, Monti E, Schiaffonati L, Benussi L, Levy $\mathrm{E}$, Binetti G. Cystatin C is released in association with exosomes: a new tool of neuronal communication which is unbalanced in Alzheimer's disease. Neurobiol Aging 32: 1435-1442, 2011.

99. Ghosh AK, Secreto CR, Knox TR, Ding W, Mukhopadhyay D, Kay NE. Circulating microvesicles in B-cell chronic lymphocytic leukemia can stimulate marrow stromal cells: implications for disease progression. Blood 115: 1755-1764, 2010.

100. Ghossoub R, Lembo F, Rubio A, Gaillard CB, Bouchet J, Vitale N, Slavík J, Machala M, Zimmermann P. Syntenin-ALIX exosome biogenesis and budding into multivesicular bodies are controlled by ARF6 and PLD2. Nat Commun 5: 3477, 2014. 
101. Goetzl EJ, Boxer A, Schwartz JB, Abner EL, Petersen RC, Miller BL, Kapogiannis D. Altered lysosomal proteins in neural-derived plasma exosomes in preclinical Alzheimer disease. Neurology 85: 40-47, 2015.

102. Goetzl EJ, Kapogiannis D, Schwartz JB, Lobach IV, Goetzl L, Abner EL, Jicha GA, Karydas AM, Boxer A, Miller BL. Decreased synaptic proteins in neuronal exosomes of frontotemporal dementia and Alzheimer's disease. FASEB J 30: 4141-4148, 2016.

103. Goldie BJ, Dun MD, Lin M, Smith ND, Verrills NM, Dayas CV, Cairns MJ. Activityassociated miRNA are packaged in Map1b-enriched exosomes released from depolarized neurons. Nucleic Acids Res 42: 9195-9208, 2014.

104. Gong J, Jaiswal R, Dalla P, Luk F, Bebawy M. Microparticles in cancer: A review of recent developments and the potential for clinical application. Semin Cell Dev Biol 40: 35-40, 2015.

105. Gonzalo-Calvo de D, van der Meer RW, Rijzewijk LJ, Smit JWA, Revuelta-Lopez E, Nasarre L, Escola-Gil JC, Lamb HJ, Llorente-Cortes V. Serum microRNA-1 and microRNA133a levels reflect myocardial steatosis in uncomplicated type 2 diabetes. Sci Rep 7: 47, 2017.

106. Gosselin R-D, Meylan P, Decosterd I. Extracellular microvesicles from astrocytes contain functional glutamate transporters: regulation by protein kinase $\mathrm{C}$ and cell activation. Front Cell Neurosci 7: 251, 2013.

107. Gould SJ, Raposo G. As we wait: coping with an imperfect nomenclature for extracellular vesicles. J Extracell Vesicles 2, 2013.

108. Grad LI, Yerbury JJ, Turner BJ, Guest WC, Pokrishevsky E, O'Neill MA, Yanai A, Silverman JM, Zeineddine R, Corcoran L, Kumita JR, Luheshi LM, Yousefi M, Coleman BM, Hill AF, Plotkin SS, Mackenzie IR, Cashman NR. Intercellular propagated misfolding of wildtype $\mathrm{Cu} / \mathrm{Zn}$ superoxide dismutase occurs via exosome-dependent and -independent mechanisms. Proc Natl Acad Sci USA 111:3620-3625, 2014.

109. Grapp M, Wrede A, Schweizer M, Hüwel S, Galla H-J, Snaidero N, Simons M, Bückers J, Low PS, Urlaub H, Gärtner J, Steinfeld R. Choroid plexus transcytosis and exosome shuttling deliver folate into brain parenchyma. Nat Commun 4: 2123, 2013.

110. Grey M, Dunning CJ, Gaspar R, Grey C, Brundin P, Sparr E, Linse S. Acceleration of $\alpha$-synuclein aggregation by exosomes. J Biol Chem 290: 2969-2982, 2015.

111. Guescini M, Genedani S, Stocchi V, Agnati LF. Astrocytes and glioblastoma cells release exosomes carrying mtDNA. J Neural Transm (Vienna) 117: 1-4, 2010.

112. Guo BB, Bellingham SA, Hill AF. Stimulating the release of exosomes increases the intercellular transfer of prions. J Biol Chem 291: 5128-5137, 2016.

113. Haney MJ, Klyachko NL, Zhao Y, Gupta R, Plotnikova EG, He Z, Patel T, Piroyan A, Sokolsky M, Kabanov AV, Batrakova EV. Exosomes as drug delivery vehicles for Parkinson's disease therapy. J Control Release 207:18-30, 2015. 
114. Hannafon BN, Carpenter KJ, Berry WL, Janknecht R, Dooley WC, Ding W-Q. Exosome-mediated microRNA signaling from breast cancer cells is altered by the antiangiogenesis agent docosahexaenoic acid (DHA). Mol Cancer 14: 133, 2015.

115. Haraszti RA, Didiot M-C, Sapp E, Leszyk J, Shaffer SA, Rockwell HE, Gao F, Narain NR, DiFiglia M, Kiebish MA, Aronin N, Khvorova A. High-resolution proteomic and lipidomic analysis of exosomes and microvesicles from different cell sources. J Extracell Vesicles 5, 2016.

116. Harding C, Heuser J, Stahl P. Receptor-mediated endocytosis of transferrin and recycling of the transferrin receptor in rat reticulocytes. J Cell Biol 97: 329-339, 1983.

117. Hargett LA, Bauer NN. On the origin of microparticles: From "platelet dust" to mediators of intercellular communication. Pulm Circ 3: 329-340, 2013.

118. Hauser P, Wang S, Didenko VV. Apoptotic bodies: selective detection in extracellular vesicles. Methods Mol Biol 1554: 193-200, 2017.

119. Heijnen HF, Schiel AE, Fijnheer R, Geuze HJ, Sixma JJ. Activated platelets release two types of membrane vesicles: microvesicles by surface shedding and exosomes derived from exocytosis of multivesicular bodies and alpha-granules. Blood 94: 3791-3799, 1999.

120. Heinrich LF, Andersen DK, Cleasby ME, Lawson C. Long-term high fat feeding of rats results in increased numbers of circulating microvesicles with pro-inflammatory effects on endothelial cells. Br J Nutr 113: 1704-1711, 2015.

121. Heiss C, Rodriguez-Mateos A, Kelm M. Central role of eNOS in the maintenance of endothelial homeostasis. Antioxid Redox Signal 22: 1230-1242, 2015.

122. Hergenreider E, Heydt S, Tréguer K, Boettger T, Horrevoets AJG, Zeiher AM, Scheffer MP, Frangakis AS, Yin X, Mayr M, Braun T, Urbich C, Boon RA, Dimmeler S. Atheroprotective communication between endothelial cells and smooth muscle cells through miRNAs. Nat Cell Biol 14: 249-256, 2012.

123. Hetterich H, Webber N, Willner M, Herzen J, Birnbacher L, Hipp A, Marschner M, Auweter SD, Habbel C, Schüller U, Bamberg F, Ertl-Wagner B, Pfeiffer F, Saam T. AHA classification of coronary and carotid atherosclerotic plaques by grating-based phase-contrast computed tomography. Eur Radiol 26: 3223-3233, 2016.

124. Hong BS, Cho J-H, Kim H, Choi E-J, Rho S, Kim J, Kim JH, Choi D-S, Kim Y-K, Hwang D, Gho YS. Colorectal cancer cell-derived microvesicles are enriched in cell cyclerelated mRNAs that promote proliferation of endothelial cells. BMC Genomics 10: 556, 2009.

125. Hosseinkhani B, van den Akker N, D'Haen J, Gagliardi M, Struys T, Lambrichts I, Waltenberger J, Nelissen I, Hooyberghs J, Molin DGM, Michiels L. Direct detection of nanoscale extracellular vesicles derived from inflammation-triggered endothelial cells using surface plasmon resonance. Nanomedicine 13:1663-1671, 2017

126. Hsu C, Morohashi Y, Yoshimura S-I, Manrique-Hoyos N, Jung S, Lauterbach MA, Bakhti M, Grønborg M, Möbius W, Rhee J, Barr FA, Simons M. Regulation of exosome secretion by Rab35 and its GTPase-activating proteins TBC1D10A-C. J Cell Biol 189: 223$232,2010$. 
127. Hsu Y-L, Hung J-Y, Chang W-A, Lin Y-S, Pan Y-C, Tsai P-H, Wu C-Y, Kuo P-L. Hypoxic lung cancer-secreted exosomal miR-23a increased angiogenesis and vascular permeability by targeting prolyl hydroxylase and tight junction protein $\mathrm{ZO}-1$. Oncogene 36 : 4929-4942, 2017.

128. Hu G, Li Q, Niu X, Hu B, Liu J, Zhou S, Guo S, Lang H, Zhang C, Wang Y, Deng Z. Exosomes secreted by human-induced pluripotent stem cell-derived mesenchymal stem cells attenuate limb ischemia by promoting angiogenesis in mice. Stem Cell Res Ther 6: 10, 2015.

129. Huang-Doran I, Zhang C-Y, Vidal-Puig A. Extracellular vesicles: Novel mediators of cell communication in metabolic disease. Trends Endocrinol Metab 28: 3-18, 2017.

130. Hubal MJ, Nadler EP, Ferrante SC, Barberio MD, Suh J-H, Wang J, Dohm GL, Pories WJ, Mietus-Snyder M, Freishtat RJ. Circulating adipocyte-derived exosomal MicroRNAs associated with decreased insulin resistance after gastric bypass. Obes Silver Spring 25: 102$110,2017$.

131. Hulsmans M, Holvoet P. MicroRNA-containing microvesicles regulating inflammation in association with atherosclerotic disease. Cardiovasc Res 100: 7-18, 2013.

132. Hutcheson JD, Goettsch C, Bertazzo S, Maldonado N, Ruiz JL, Goh W, Yabusaki K, Faits T, Bouten C, Franck G, Quillard T, Libby P, Aikawa M, Weinbaum S, Aikawa E. Genesis and growth of extracellular-vesicle-derived microcalcification in atherosclerotic plaques. Nat Mater 15: 335-343, 2016.

133. Hwang DW, Choi H, Jang SC, Yoo MY, Park JY, Choi NE, Oh HJ, Ha S, Lee Y-S, Jeong JM, Gho YS, Lee DS. Noninvasive imaging of radiolabeled exosome-mimetic nanovesicle using (99m)Tc-HMPAO. Sci Rep 5: 15636, 2015.

134. Iguchi Y, Eid L, Parent M, Soucy G, Bareil C, Riku Y, Kawai K, Takagi S, Yoshida M, Katsuno M, Sobue G, Julien J-P. Exosome secretion is a key pathway for clearance of pathological TDP-43. Brain J Neurol 139: 3187-3201, 2016.

135. Ivanova EA, Bobryshev YV, Orekhov AN. Intimal pericytes as the second line of immune defence in atherosclerosis. World J Cardiol 7:583-593, 2015.

136. Ivanova EA, Orekhov AN. Cellular model of atherogenesis based on pluripotent vascular wall pericytes. Stem Cells Int 2016: 7321404, 2016.

137. Jang SC, Kim OY, Yoon CM, Choi D-S, Roh T-Y, Park J, Nilsson J, Lötvall J, Kim Y$\mathrm{K}$, Gho YS. Bioinspired exosome-mimetic nanovesicles for targeted delivery of chemotherapeutics to malignant tumors. ACS Nano 7: 7698-7710, 2013.

138. Janowska-Wieczorek A, Marquez-Curtis LA, Wysoczynski M, Ratajczak MZ. Enhancing effect of platelet-derived microvesicles on the invasive potential of breast cancer cells. Transfusion 46: 1199-1209, 2006.

139. Janowska-Wieczorek A, Wysoczynski M, Kijowski J, Marquez-Curtis L, Machalinski B, Ratajczak J, Ratajczak MZ. Microvesicles derived from activated platelets induce metastasis and angiogenesis in lung cancer. Int J Cancer 113: 752-760, 2005. 
140. Jansen F, Yang X, Hoyer FF, Paul K, Heiermann N, Becher MU, Abu Hussein N, Kebschull M, Bedorf J, Franklin BS, Latz E, Nickenig G, Werner N. Endothelial microparticle uptake in target cells is annexin I/phosphatidylserine receptor dependent and prevents apoptosis. Arterioscler Thromb Vasc Biol 32:1925-1935, 2012.

141. Jansen F, Yang X, Franklin BS, Hoelscher M, Schmitz T, Bedorf J, Nickenig G, Werner N. High glucose condition increases NADPH oxidase activity in endothelial microparticles that promote vascular inflammation. Cardiovasc Res 98: 94-106, 2013.

142. Jansen F, Yang X, Hoelscher M, Cattelan A, Schmitz T, Proebsting S, Wenzel D, Vosen S, Franklin BS, Fleischmann BK, Nickenig G, Werner N. Endothelial microparticle-mediated transfer of MicroRNA-126 promotes vascular endothelial cell repair via SPRED1 and is abrogated in glucose-damaged endothelial microparticles. Circulation 128: 2026-2038, 2013.

143. Jorfi S, Ansa-Addo EA, Kholia S, Stratton D, Valley S, Lange S, Inal J. Inhibition of microvesiculation sensitizes prostate cancer cells to chemotherapy and reduces docetaxel dose required to limit tumor growth in vivo. Sci Rep 5: 13006, 2015.

144. Joshi P, Benussi L, Furlan R, Ghidoni R, Verderio C. Extracellular vesicles in Alzheimer's disease: friends or foes? Focus on aß-vesicle interaction. Int J Mol Sci 16: 4800$4813,2015$.

145. Ju S, Mu J, Dokland T, Zhuang X, Wang Q, Jiang H, Xiang X, Deng Z-B, Wang B, Zhang L, Roth M, Welti R, Mobley J, Jun Y, Miller D, Zhang H-G. Grape exosome-like nanoparticles induce intestinal stem cells and protect mice from DSS-induced colitis. Mol Ther 21: 1345-1357, 2013.

146. Juan T, Fürthauer M. [The ESCRT complex: from endosomal transport to the development of multicellular organisms]. Biol Aujourdhui 209: 111-124, 2015.

147. Jung UJ, Choi M-S. Obesity and Its Metabolic Complications: The Role of adipokines and the relationship between obesity, inflammation, insulin resistance, dyslipidemia and nonalcoholic fatty liver disease. Int J Mol Sci 15: 6184-6223, 2014.

148. Kahn SE, Hull RL, Utzschneider KM. Mechanisms linking obesity to insulin resistance and type 2 diabetes. Nature 444: 840-846, 2006.

149. Kamalden TA, Macgregor-Das AM, Kannan SM, Dunkerly-Eyring B, Khaliddin N, Xu Z, Fusco AP, Yazib SA, Chow RC, Duh EJ, Halushka MK, Steenbergen C, Das S. Exosomal microRNA-15a transfer from the pancreas augments diabetic complications by inducing oxidative stress. Antioxid Redox Signal 27: 913-930, 2017.

150. Kanazawa S, Nomura S, Kuwana M, Muramatsu M, Yamaguchi K, Fukuhara S. Monocyte-derived microparticles may be a sign of vascular complication in patients with lung cancer. Lung Cancer 39: 145-149, 2003.

151. Kanninen KM, Bister N, Koistinaho J, Malm T. Exosomes as new diagnostic tools in CNS diseases. Biochim Biophys Acta 1862: 403-410, 2016.

152. Kapustin AN, Davies JD, Reynolds JL, McNair R, Jones GT, Sidibe A, Schurgers LJ, Skepper JN, Proudfoot D, Mayr M, Shanahan CM. Calcium regulates key components of 
vascular smooth muscle cell-derived matrix vesicles to enhance mineralization. Circ Res 109: e1-12, 2011.

153. Kapustin AN, Schoppet M, Schurgers LJ, Reynolds JL, McNair R, Heiss A, JahnenDechent W, Hackeng TM, Schlieper G, Harrison P, Shanahan CM. Prothrombin loading of vascular smooth muscle cell-derived exosomes regulates coagulation and calcification. Arterioscler Thromb Vasc Biol 37: e22-e32, 2017.

154. Karolina DS, Tavintharan S, Armugam A, Sepramaniam S, Pek SLT, Wong MTK, Lim SC, Sum CF, Jeyaseelan K. Circulating miRNA profiles in patients with metabolic syndrome. J Clin Endocrinol Metab 97: E2271-E2276, 2012.

155. Kastorini C-M, Panagiotakos DB. Dietary patterns and prevention of type 2 diabetes: from research to clinical practice; a systematic review. Curr Diabetes Rev 5: 221-227, 2009.

156. Katsuda T, Tsuchiya R, Kosaka N, Yoshioka Y, Takagaki K, Oki K, Takeshita F, Sakai Y, Kuroda M, Ochiya T. Human adipose tissue-derived mesenchymal stem cells secrete functional neprilysin-bound exosomes. Sci Rep 3: 1197, 2013.

157. Kawikova I, Askenase PW. Diagnostic and therapeutic potentials of exosomes in CNS diseases. Brain Res 1617: 63-71, 2015.

158. Keith SW, Redden DT, Katzmarzyk PT, Boggiano MM, Hanlon EC, Benca RM, Ruden D, Pietrobelli A, Barger JL, Fontaine KR, Wang C, Aronne LJ, Wright SM, Baskin M, Dhurandhar NV, Lijoi MC, Grilo CM, DeLuca M, Westfall AO, Allison DB. Putative contributors to the secular increase in obesity: exploring the roads less traveled. Int J Obes 2005 30: 1585-1594, 2006.

159. Kholia S, Jorfi S, Thompson PR, Causey CP, Nicholas AP, Inal JM, Lange S. A novel role for peptidylarginine deiminases in microvesicle release reveals therapeutic potential of PAD inhibition in sensitizing prostate cancer cells to chemotherapy. $J$ Extracell Vesicles 4: 26192, 2015.

160. Kholia S, Ranghino A, Garnieri P, Lopatina T, Deregibus MC, Rispoli P, Brizzi MF, Camussi G. Extracellular vesicles as new players in angiogenesis. Vascul Pharmacol 86: 6470, 2016.

161. Kim HK, Song KS, Park YS, Kang YH, Lee YJ, Lee KR, Kim HK, Ryu KW, Bae JM, Kim S. Elevated levels of circulating platelet microparticles, VEGF, IL-6 and RANTES in patients with gastric cancer: possible role of a metastasis predictor. Eur J Cancer 39: 184-191, 2003.

162. Kim SM, Jeong CH, Woo JS, Ryu CH, Lee J-H, Jeun S-S. In vivo near-infrared imaging for the tracking of systemically delivered mesenchymal stem cells: tropism for brain tumors and biodistribution. Int J Nanomedicine 11: 13-23, 2016.

163. Kim MS, Haney MJ, Zhao Y, Yuan D, Deygen I, Klyachko NL, Kabanov AV, Batrakova EV. Engineering macrophage-derived exosomes for targeted paclitaxel delivery to pulmonary metastases: in vitro and in vivo evaluations. Nanomedicine 14: 195-204, 2018.

164. Konopka W, Kiryk A, Novak M, Herwerth M, Parkitna JR, Wawrzyniak M, Kowarsch A, Michaluk P, Dzwonek J, Arnsperger T, Wilczynski G, Merkenschlager M, Theis FJ, Köhr 
G, Kaczmarek L, Schütz G. MicroRNA loss enhances learning and memory in mice. J Neurosci 30: 14835-14842, 2010.

165. Kooijmans SAA, Schiffelers RM, Zarovni N, Vago R. Modulation of tissue tropism and biological activity of exosomes and other extracellular vesicles: New nanotools for cancer treatment. Pharmacol Res 111: 487-500, 2016.

166. Kooijmans SAA, Stremersch S, Braeckmans K, de Smedt SC, Hendrix A, Wood MJA, Schiffelers RM, Raemdonck K, Vader P. Electroporation-induced siRNA precipitation obscures the efficiency of siRNA loading into extracellular vesicles. J Control Release 172: 229-238, 2013.

167. Kowal J, Arras G, Colombo M, Jouve M, Morath JP, Primdal-Bengtson B, Dingli F, Loew D, Tkach M, Théry C. Proteomic comparison defines novel markers to characterize heterogeneous populations of extracellular vesicle subtypes. Proc Natl Acad Sci USA 113: E968-E977, 2016.

168. Kraitchman DL, Tatsumi M, Gilson WD, Ishimori T, Kedziorek D, Walczak P, Segars WP, Chen HH, Fritzges D, Izbudak I, Young RG, Marcelino M, Pittenger MF, Solaiyappan M, Boston RC, Tsui BMW, Wahl RL, Bulte JWM. Dynamic imaging of allogeneic mesenchymal stem cells trafficking to myocardial infarction. Circulation 112: 1451-1461, 2005.

169. Krämer-Albers E-M, Bretz N, Tenzer S, Winterstein C, Möbius W, Berger H, Nave KA, Schild H, Trotter J. Oligodendrocytes secrete exosomes containing major myelin and stressprotective proteins: Trophic support for axons? Proteomics Clin Appl 1: 1446-1461, 2007.

170. Kranendonk MEG, de Kleijn DPV, Kalkhoven E, Kanhai DA, Uiterwaal CSPM, van der Graaf Y, Pasterkamp G, Visseren FLJ, SMART Study Group. Extracellular vesicle markers in relation to obesity and metabolic complications in patients with manifest cardiovascular disease. Cardiovasc Diabetol 13: 37, 2014.

171. Krohn JB, Hutcheson JD, Martínez-Martínez E, Aikawa E. Extracellular vesicles in cardiovascular calcification: expanding current paradigms. J Physiol 594: 2895-2903, 2016.

172. Krohn JB, Hutcheson JD, Martínez-Martínez E, Irvin WS, Bouten CVC, Bertazzo S, Bendeck MP, Aikawa E. Discoidin Domain Receptor-1 regulates calcific extracellular vesicle release in vascular smooth muscle cell fibrocalcific response via Transforming Growth Factor$\beta$ signaling. Arterioscler Thromb Vasc Biol 36: 525-533, 2016.

173. Kyrgiou M, Kalliala I, Markozannes G, Gunter MJ, Paraskevaidis E, Gabra H, MartinHirsch P, Tsilidis KK. Adiposity and cancer at major anatomical sites: umbrella review of the literature. BMJ 356: j477, 2017.

174. Lachenal G, Pernet-Gallay K, Chivet M, Hemming FJ, Belly A, Bodon G, Blot B, Haase G, Goldberg Y, Sadoul R. Release of exosomes from differentiated neurons and its regulation by synaptic glutamatergic activity. Mol Cell Neurosci 46: 409-418, 2011.

175. Lafourcade C, Ramírez JP, Luarte A, Fernández A, Wyneken U. MiRNAs in astrocytederived exosomes as possible mediators of neuronal plasticity. J Exp Neurosci 10: 1-9, 2016. 
176. Lai CP, Mardini O, Ericsson M, Prabhakar S, Maguire C, Chen JW, Tannous BA, Breakefield XO. Dynamic biodistribution of extracellular vesicles in vivo using a multimodal imaging reporter. ACS Nano 8: 483-494, 2014.

177. Lai CP-K, Breakefield XO. Role of exosomes/microvesicles in the nervous system and use in emerging therapies. Front Physiol 3: 228, 2012.

178. Lai RC, Chen TS, Lim SK. Mesenchymal stem cell exosome: a novel stem cell-based therapy for cardiovascular disease. Regen Med 6: 481-492, 2011.

179. Laulagnier K, Motta C, Hamdi S, Roy S, Fauvelle F, Pageaux J-F, Kobayashi T, Salles J-P, Perret B, Bonnerot C, Record M. Mast cell- and dendritic cell-derived exosomes display a specific lipid composition and an unusual membrane organization. Biochem J 380: 161-171, 2004

180. Le MT, Hamar P, Guo C, Basar E, Perdigão-Henriques R, Balaj L, Lieberman J. miR200-containing extracellular vesicles promote breast cancer cell metastasis. J Clin Invest 124: 5109-5128, 2014.

181. Lea J, Sharma R, Yang F, Zhu H, Ward ES, Schroit AJ. Detection of phosphatidylserinepositive exosomes as a diagnostic marker for ovarian malignancies: a proof of concept study. Oncotarget 8: 14395-14407, 2017.

182. Lee C, Mitsialis SA, Aslam M, Vitali SH, Vergadi E, Konstantinou G, Sdrimas K, Fernandez-Gonzalez A, Kourembanas S. Exosomes mediate the cytoprotective action of mesenchymal stromal cells on hypoxia-induced pulmonary hypertension. Circulation 126: 2601-2611, 2012.

183. Lee J, McKinney KQ, Pavlopoulos AJ, Han MH, Kim S-H, Kim HJ, Hwang S. Exosomal proteome analysis of cerebrospinal fluid detects biosignatures of neuromyelitis optica and multiple sclerosis. Clin Chim Acta 462: 118-126, 2016.

184. Lee TH, Chennakrishnaiah S, Meehan B, Montermini L, Garnier D, D'Asti E, Hou W, Magnus N, Gayden T, Jabado N, Eppert K, Majewska L, Rak J. Barriers to horizontal cell transformation by extracellular vesicles containing oncogenic H-ras. Oncotarget 7: 5199152002, 2016.

185. Leroyer AS, Isobe H, Lesèche G, Castier Y, Wassef M, Mallat Z, Binder BR, Tedgui A, Boulanger CM. Cellular origins and thrombogenic activity of microparticles isolated from human atherosclerotic plaques. J Am Coll Cardiol 49: 772-777, 2007.

186. Li S, Wei J, Zhang C, Li X, Meng W, Mo X, Zhang Q, Liu Q, Ren K, Du R, Tian H, Li J. Cell-derived microparticles in patients with type 2 diabetes mellitus: a systematic review and meta-analysis. Cell Physiol Biochem 39: 2439-2450, 2016.

187. Liu S, Sun J, Lan Q. Glioblastoma microvesicles promote endothelial cell proliferation through Akt/beta-catenin pathway. Int J Clin Exp Pathol 7: 4857-4866, 2014.

188. Liu Y, Huang W, Zhang R, Wu J, Li L, Tang Y. Proteomic analysis of TNF- $\alpha$-activated endothelial cells and endothelial microparticles. Mol Med Rep 7: 318-326, 2013. 
189. Livaja Koshiar R, Somajo S, Norström E, Dahlbäck B. Erythrocyte-derived microparticles supporting activated protein c-mediated regulation of blood coagulation. PLoS ONE 9, 2014.

190. Llorente A, Skotland T, Sylvänne T, Kauhanen D, Róg T, Orłowski A, Vattulainen I, Ekroos K, Sandvig K. Molecular lipidomics of exosomes released by PC-3 prostate cancer cells. Biochim Biophys Acta 1831: 1302-1309, 2013.

191. Lötvall J, Hill AF, Hochberg F, Buzás EI, Di Vizio D, Gardiner C, Gho YS, Kurochkin IV, Mathivanan S, Quesenberry P, Sahoo S, Tahara H, Wauben MH, Witwer KW, Théry C. Minimal experimental requirements for definition of extracellular vesicles and their functions: a position statement from the International Society for Extracellular Vesicles. $J$ Extracell Vesicles 3, 2014.

192. Luppino FS, Wit LM de, Bouvy PF, Stijnen T, Cuijpers P, Penninx BWJH, Zitman FG. Overweight, obesity, and depression: a systematic review and meta-analysis of longitudinal studies. Arch Gen Psychiatry 67: 220-229, 2010.

193. Lv L-H, Wan Y-L, Lin Y, Zhang W, Yang M, Li G-L, Lin H-M, Shang C-Z, Chen Y-J, Min J. Anticancer drugs cause release of exosomes with heat shock proteins from human hepatocellular carcinoma cells that elicit effective natural killer cell antitumor responses in vitro. J Biol Chem 287: 15874-15885, 2012.

194. Lv M, Zhu X, Chen W, Zhong S, Hu Q, Ma T, Zhang J, Chen L, Tang J, Zhao J. Exosomes mediate drug resistance transfer in MCF-7 breast cancer cells and a probable mechanism is delivery of P-glycoprotein. Tumour Biol 35: 10773-10779, 2014.

195. Ma G, Pan B, Chen Y, Guo C, Zhao M, Zheng L, Chen B. Trimethylamine N-oxide in atherogenesis: impairing endothelial self-repair capacity and enhancing monocyte adhesion. Biosci Rep 37, 2017.

196. Maguire CA, Balaj L, Sivaraman S, Crommentuijn MHW, Ericsson M, MinchevaNilsson L, Baranov V, Gianni D, Tannous BA, Sena-Esteves M, Breakefield XO, Skog J. Microvesicle-associated AAV vector as a novel gene delivery system. Mol Ther 20: 960-971, 2012.

197. Manca S, Giraud D, Zempleni J. Bioavailability and biodistribution of fluorophorelabeled exosomes from cow's milk after intravenous and oral administration in C57B1/6J mice. FASEB J 30: Supp 690.8, 2016.

198. Manier S, Liu C-J, Avet-Loiseau H, Park J, Shi J, Campigotto F, Salem KZ, Huynh D, Glavey SV, Rivotto B, Sacco A, Roccaro AM, Bouyssou J, Minvielle S, Moreau P, Facon T, Leleu X, Weller E, Trippa L, Ghobrial IM. Prognostic role of circulating exosomal miRNAs in multiple myeloma. Blood 129: 2429-2436, 2017.

199. Martinez MC, Andriantsitohaina R. Microparticles in angiogenesis: therapeutic potential. Circ Res 109: 110-119, 2011.

200. Martínez MC, Larbret F, Zobairi F, Coulombe J, Debili N, Vainchenker W, Ruat M, Freyssinet J-M. Transfer of differentiation signal by membrane microvesicles harboring hedgehog morphogens. Blood 108: 3012-3020, 2006. 
201. Martinez MC, Tual-Chalot S, Leonetti D, Andriantsitohaina R. Microparticles: targets and tools in cardiovascular disease. Trends Pharmacol Sci 32: 659-665, 2011.

202. Melo SA, Sugimoto H, O’Connell JT, Kato N, Villanueva A, Vidal A, Qiu L, Vitkin E, Perelman LT, Melo CA, Lucci A, Ivan C, Calin GA, Kalluri R. Cancer exosomes perform cellindependent microRNA biogenesis and promote tumorigenesis. Cancer Cell 26: 707-721, 2014.

203. Michael MD, Kulkarni RN, Postic C, Previs SF, Shulman GI, Magnuson MA, Kahn CR. Loss of insulin signaling in hepatocytes leads to severe insulin resistance and progressive hepatic dysfunction. Mol Cell 6: 87-97, 2000.

204. Millimaggi D, Mari M, D’Ascenzo S, Carosa E, Jannini EA, Zucker S, Carta G, Pavan A, Dolo V. Tumor vesicle-associated CD147 modulates the angiogenic capability of endothelial cells. Neoplasia 9: 349-357, 2007.

205. Miyoshi H, Umeshita K, Sakon M, Imajoh-Ohmi S, Fujitani K, Gotoh M, Oiki E, Kambayashi J, Monden M. Calpain activation in plasma membrane bleb formation during tertbutyl hydroperoxide-induced rat hepatocyte injury. Gastroenterology 110: 1897-1904, 1996.

206. Momen-Heravi F, Balaj L, Alian S, Tigges J, Toxavidis V, Ericsson M, Distel RJ, Ivanov AR, Skog J, Kuo WP. Alternative methods for characterization of extracellular vesicles. Front Physiol 3: 354, 2012.

207. Montecalvo A, Larregina AT, Shufesky WJ, Stolz DB, Sullivan MLG, Karlsson JM, Baty CJ, Gibson GA, Erdos G, Wang Z, Milosevic J, Tkacheva OA, Divito SJ, Jordan R, LyonsWeiler J, Watkins SC, Morelli AE. Mechanism of transfer of functional microRNAs between mouse dendritic cells via exosomes. Blood 119: 756-766, 2012.

208. Monzo M, Santasusagna S, Moreno I, Martinez F, Hernández R, Muñoz C, Castellano JJ, Moreno J, Navarro A. Exosomal microRNAs isolated from plasma of mesenteric veins linked to liver metastases in resected patients with colon cancer. Oncotarget 8: 30859-30869, 2017.

209. Morel L, Regan M, Higashimori H, Ng SK, Esau C, Vidensky S, Rothstein J, Yang Y. Neuronal exosomal miRNA-dependent translational regulation of astroglial glutamate transporter GLT1. J Biol Chem 288: 7105-7116, 2013.

210. Morelli AE, Larregina AT, Shufesky WJ, Sullivan MLG, Stolz DB, Papworth GD, Zahorchak AF, Logar AJ, Wang Z, Watkins SC, Falo LD, Thomson AW. Endocytosis, intracellular sorting, and processing of exosomes by dendritic cells. Blood 104: 3257-3266, 2004.

211. Moreno PR, Purushothaman K-R, Sirol M, Levy AP, Fuster V. Neovascularization in human atherosclerosis. Circulation 113: 2245-2252, 2006.

212. Morse MA, Garst J, Osada T, Khan S, Hobeika A, Clay TM, Valente N, Shreeniwas R, Sutton MA, Delcayre A, Hsu D-H, Le Pecq J-B, Lyerly HK. A phase I study of dexosome immunotherapy in patients with advanced non-small cell lung cancer. J Transl Med 3: 9, 2005.

213. Mostefai HA, Agouni A, Carusio N, Mastronardi ML, Heymes C, Henrion D, Andriantsitohaina R, Martinez MC. Phosphatidylinositol 3-kinase and xanthine oxidase 
regulate nitric oxide and reactive oxygen species productions by apoptotic lymphocyte microparticles in endothelial cells. J Immunol 180: 5028-5035, 2008.

214. Muhsin-Sharafaldine MR, Saunderson SC, Dunn AC, Faed JM, Kleffmann T, McLellan AD. Procoagulant and immunogenic properties of melanoma exosomes, microvesicles and apoptotic vesicles. Oncotarget 7: 56279-56294, 2016.

215. Mulcahy LA, Pink RC, Carter DRF. Routes and mechanisms of extracellular vesicle uptake. J Extracell Vesicles 3, 2014.

216. Müller G. Microvesicles/exosomes as potential novel biomarkers of metabolic diseases. Diabetes Metab Syndr Obes 5: 247-282, 2012.

217. Munagala R, Aqil F, Jeyabalan J, Gupta RC. Bovine milk-derived exosomes for drug delivery. Cancer Lett 371: 48-61, 2016.

218. Murakami T, Horigome H, Tanaka K, Nakata Y, Ohkawara K, Katayama Y, Matsui A. Impact of weight reduction on production of platelet-derived microparticles and fibrinolytic parameters in obesity. Thromb Res 119: 45-53, 2007.

219. Mustapic M, Eitan E, Werner JK, Berkowitz ST, Lazaropoulos MP, Tran J, Goetzl EJ, Kapogiannis D. Plasma extracellular vesicles enriched for neuronal origin: a potential window into brain pathologic processes. Front Neurosci 11: 278, 2017.

220. Nakase I, Futaki S. Combined treatment with a pH-sensitive fusogenic peptide and cationic lipids achieves enhanced cytosolic delivery of exosomes. Sci Rep 5: 10112, 2015.

221. Nakase I, Kobayashi NB, Takatani-Nakase T, Yoshida T. Active macropinocytosis induction by stimulation of epidermal growth factor receptor and oncogenic Ras expression potentiates cellular uptake efficacy of exosomes. Sci Rep 5: 10300, 2015.

222. Nanbo A, Kawanishi E, Yoshida R, Yoshiyama H. Exosomes derived from EpsteinBarr virus-infected cells are internalized via caveola-dependent endocytosis and promote phenotypic modulation in target cells. J Virol 87: 10334-10347, 2013.

223. Neri T, Cordazzo C, Carmazzi Y, Petrini S, Balìa C, Stefanelli F, Amoruso A, Brunelleschi S, Breschi MC, Pedrinelli R, Paggiaro P, Celi A. Effects of peroxisome proliferator-activated receptor- $\gamma$ agonists on the generation of microparticles by monocytes/macrophages. Cardiovasc Res 94: 537-544, 2012.

224. New SEP, Aikawa E. Role of extracellular vesicles in de novo mineralization: an additional novel mechanism of cardiovascular calcification. Arterioscler Thromb Vasc Biol 33: 1753-1758, 2013.

225. Ng ACT, Delgado V, Bertini M, van der Meer RW, Rijzewijk LJ, Hooi Ewe S, Siebelink H-M, Smit JWA, Diamant M, Romijn JA, de Roos A, Leung DY, Lamb HJ, Bax JJ. Myocardial steatosis and biventricular strain and strain rate imaging in patients with type 2 diabetes mellitus. Circulation 122: 2538-2544, 2010.

226. Nielsen MH, Irvine H, Vedel S, Raungaard B, Beck-Nielsen H, Handberg A. The impact of lipoprotein-associated oxidative stress on cell-specific microvesicle release in patients with familial hypercholesterolemia. Oxid Med Cell Longev 2016: :2492858, 2016. 
227. Niu C, Wang X, Zhao M, Cai T, Liu P, Li J, Willard B, Zu L, Zhou E, Li Y, Pan B, Yang F, Zheng L. Macrophage foam cell-derived extracellular vesicles promote vascular smooth muscle cell migration and adhesion. J Am Heart 5: pii: e004099, 2016.

228. Oksvold MP, Kullmann A, Forfang L, Kierulf B, Li M, Brech A, Vlassov AV, Smeland EB, Neurauter A, Pedersen KW. Expression of B-cell surface antigens in subpopulations of exosomes released from B-cell lymphoma cells. Clin Ther 36: 847-862.e1, 2014.

229. Ostrowski M, Carmo NB, Krumeich S, Fanget I, Raposo G, Savina A, Moita CF, Schauer K, Hume AN, Freitas RP, Goud B, Benaroch P, Hacohen N, Fukuda M, Desnos C, Seabra MC, Darchen F, Amigorena S, Moita LF, Thery C. Rab27a and Rab27b control different steps of the exosome secretion pathway. Nat Cell Biol 12: 19-30, 2010.

230. Pan B-T, Teng K, Wu C, Adam M, Johnstone RM. Electron microscopic evidence for externalization of the transferrin receptor in vesicular form in sheep reticulocytes. $J$ Cell Biol 101: 942-948, 1985.

231. Pan Q, Liu H, Zheng C, Zhao Y, Liao X, Wang Y, Chen Y, Zhao B, Lazartigues E, Yang Y, Ma X. Microvesicles derived from inflammation-challenged endothelial cells modulate vascular smooth muscle cell functions. Front Physiol 7: 692, 2016.

232. Parolini I, Federici C, Raggi C, Lugini L, Palleschi S, De Milito A, Coscia C, Iessi E, Logozzi M, Molinari A, Colone M, Tatti M, Sargiacomo M, Fais S. Microenvironmental pH is a key factor for exosome traffic in tumor cells. J Biol Chem 284: 34211-34222, 2009.

233. Pasquet J-M, Dachary-Prigent J, Nurden AT. Calcium influx is a determining factor of calpain activation and microparticle formation in platelets. Eur J Biochem 239: 647-654, 1996.

234. Pêche H, Heslan M, Usal C, Amigorena S, Cuturi MC. Presentation of donor major histocompatibility complex antigens by bone marrow dendritic cell-derived exosomes modulates allograft rejection. Transplantation 76: 1503-1510, 2003.

235. Phoonsawat W, Aoki-Yoshida A, Tsuruta T, Sonoyama K. Adiponectin is partially associated with exosomes in mouse serum. Biochem Biophys Res Commun 448: 261-266, 2014.

236. Poirier P, Giles TD, Bray GA, Hong Y, Stern JS, Pi-Sunyer FX, Eckel RH. Obesity and cardiovascular disease: pathophysiology, evaluation, and effect of weight loss. Circulation 113: 898-918, 2006.

237. Potolicchio I, Carven GJ, Xu X, Stipp C, Riese RJ, Stern LJ, Santambrogio L. Proteomic analysis of microglia-derived exosomes: metabolic role of the aminopeptidase CD13 in neuropeptide catabolism. J Immunol 175: 2237-2243, 2005.

238. Povero D, Eguchi A, Li H, Johnson CD, Papouchado BG, Wree A, Messer K, Feldstein AE. Circulating extracellular vesicles with specific proteome and liver microRNAs are potential biomarkers for liver injury in experimental fatty liver disease. PloS One 9: e113651, 2014.

239. Povero D, Eguchi A, Niesman IR, Andronikou N, de Mollerat du Jeu X, Mulya A, Berk M, Lazic M, Thapaliya S, Parola M, Patel HH, Feldstein AE. Lipid-induced toxicity stimulates hepatocytes to release angiogenic microparticles that require Vanin-1 for uptake by endothelial cells. Sci Signal 6: ra88, 2013. 
240. Poy MN, Eliasson L, Krutzfeldt J, Kuwajima S, Ma X, Macdonald PE, Pfeffer S, Tuschl T, Rajewsky N, Rorsman P, Stoffel M. A pancreatic islet-specific microRNA regulates insulin secretion. Nature 432: 226-230, 2004.

241. Prada I, Furlan R, Matteoli M, Verderio C. Classical and unconventional pathways of vesicular release in microglia. Glia 61: 1003-1017, 2013.

242. Preston RA, Jy W, Jimenez JJ, Mauro LM, Horstman LL, Valle M, Aime G, Ahn YS. Effects of severe hypertension on endothelial and platelet microparticles. Hypertens 41: 211$217,2003$.

243. Priou P, Gagnadoux F, Tesse A, Mastronardi ML, Agouni A, Meslier N, Racineux J-L, Martinez MC, Trzepizur W, Andriantsitohaina R. Endothelial dysfunction and circulating microparticles from patients with obstructive sleep apnea. Am J Pathol 177: 974-983, 2010.

244. Proia P, Schiera G, Mineo M, Ingrassia AMR, Santoro G, Savettieri G, Di Liegro I. Astrocytes shed extracellular vesicles that contain fibroblast growth factor-2 and vascular endothelial growth factor. Int J Mol Med 21: 63-67, 2008.

245. Putz U, Howitt J, Lackovic J, Foot N, Kumar S, Silke J, Tan S-S. Nedd4 familyinteracting protein 1 (Ndfip1) is required for the exosomal secretion of Nedd4 family proteins. J Biol Chem 283: 32621-32627, 2008.

246. Quah BJ, O’Neill HC. The immunogenicity of dendritic cell-derived exosomes. Blood Cells Mol Dis 35: 94-110, 2005.

247. Raimondo F, Morosi L, Corbetta S, Chinello C, Brambilla P, Della Mina P, Villa A, Albo G, Battaglia C, Bosari S, Magni F, Pitto M. Differential protein profiling of renal cell carcinoma urinary exosomes. Mol Biosyst 9: 1220-1233, 2013.

248. Rajendran L, Bali J, Barr MM, Court FA, Krämer-Albers E-M, Picou F, Raposo G, van der Vos KE, van Niel G, Wang J, Breakefield XO. Emerging roles of extracellular vesicles in the nervous system. J Neurosci 34: 15482-15489, 2014.

249. Rajendran L, Honsho M, Zahn TR, Keller P, Geiger KD, Verkade P, Simons K. Alzheimer's disease beta-amyloid peptides are released in association with exosomes. Proc Natl Acad Sci USA 103: 11172-11177, 2006.

250. Rautou P-E, Vion A-C, Amabile N, Chironi G, Simon A, Tedgui A, Boulanger CM. Microparticles, vascular function, and atherothrombosis. Circ Res 109: 593-606, 2011.

251. Record M, Carayon K, Poirot M, Silvente-Poirot S. Exosomes as new vesicular lipid transporters involved in cell-cell communication and various pathophysiologies. Biochim Biophys Acta 1841: 108-120, 2014.

252. Roccaro AM, Sacco A, Maiso P, Azab AK, Tai Y-T, Reagan M, Azab F, Flores LM, Campigotto F, Weller E, Anderson KC, Scadden DT, Ghobrial IM. BM mesenchymal stromal cell-derived exosomes facilitate multiple myeloma progression. J Clin Invest 123: 1542-1555, 2013.

253. Ross R. Atherosclerosis--an inflammatory disease. N Engl J Med 340: 115-126, 1999. 
254. Roucourt B, Meeussen S, Bao J, Zimmermann P, David G. Heparanase activates the syndecan-syntenin-ALIX exosome pathway. Cell Res 25: 412-428, 2015.

255. Saá P, Yakovleva O, de Castro J, Vasilyeva I, De Paoli SH, Simak J, Cervenakova L. First demonstration of transmissible spongiform encephalopathy-associated prion protein (PrPTSE) in extracellular vesicles from plasma of mice infected with mouse-adapted variant Creutzfeldt-Jakob disease by in vitro amplification. J Biol Chem 289: 29247-29260, 2014.

256. Saari H, Lázaro-Ibáñez E, Viitala T, Vuorimaa-Laukkanen E, Siljander P, Yliperttula M. Microvesicle- and exosome-mediated drug delivery enhances the cytotoxicity of Paclitaxel in autologous prostate cancer cells. J Control Release 220(Pt B):727-737, 2015.

257. Sabatier F, Darmon P, Hugel B, Combes V, Sanmarco M, Velut J-G, Arnoux D, Charpiot P, Freyssinet J-M, Oliver C, Sampol J, Dignat-George F. Type 1 and type 2 diabetic patients display different patterns of cellular microparticles. Diabetes 51: 2840-2845, 2002.

258. Safiedeen Z, Rodríguez-Gómez I, Vergori L, Soleti R, Vaithilingam D, Douma I, Agouni A, Leiber D, Dubois S, Simard G, Zibara K, Andriantsitohaina R, Martínez MC. Temporal cross talk between endoplasmic reticulum and mitochondria regulates oxidative stress and mediates microparticle-induced endothelial dysfunction. Antioxid Redox Signal 26: 15-27, 2017.

259. Saman S, Kim W, Raya M, Visnick Y, Miro S, Saman S, Jackson B, McKee AC, Alvarez VE, Lee NCY, Hall GF. Exosome-associated tau is secreted in tauopathy models and is selectively phosphorylated in cerebrospinal fluid in early Alzheimer disease. $J$ Biol Chem 287: 3842-3849, 2012.

260. Samuel VT, Shulman GI. Mechanisms for insulin resistance: common threads and missing links. Cell 148: 852-871, 2012.

261. Sarlon-Bartoli G, Bennis Y, Lacroix R, Piercecchi-Marti MD, Bartoli MA, Arnaud L, Mancini J, Boudes A, Sarlon E, Thevenin B, Leroyer AS, Squarcioni C, Magnan PE, DignatGeorge F, Sabatier F. Plasmatic level of leukocyte-derived microparticles is associated with unstable plaque in asymptomatic patients with high-grade carotid stenosis. $J$ Am Coll Cardiol 62: 1436-1441, 2013.

262. Sato YT, Umezaki K, Sawada S, Mukai S, Sasaki Y, Harada N, Shiku H, Akiyoshi K. Engineering hybrid exosomes by membrane fusion with liposomes. Sci Rep 6: 21933, 2016.

263. Savina A, Fader CM, Damiani MT, Colombo MI. Rab11 promotes docking and fusion of multivesicular bodies in a calcium-dependent manner. Traffic 6: 131-143, 2005.

264. Schiera G, Di Liegro CM, Di Liegro I. Extracellular membrane vesicles as vehicles for brain cell-to-cell interactions in physiological as well as pathological conditions. BioMed Res Int 2015: 152926, 2015.

265. Schiera G, Proia P, Alberti C, Mineo M, Savettieri G, Di Liegro I. Neurons produce FGF2 and VEGF and secrete them at least in part by shedding extracellular vesicles. J Cell Mol Med 11: 1384-1394, 2007.

266. Schmidt O, Teis D. The ESCRT machinery. Curr Biol 22: R116-R120, 2012. 
267. Segura E, Nicco C, Lombard B, Véron P, Raposo G, Batteux F, Amigorena S, Théry C. ICAM-1 on exosomes from mature dendritic cells is critical for efficient naive T-cell priming. Blood 106: 216-223, 2005.

268. Setti M, Osti D, Richichi C, Ortensi B, Del Bene M, Fornasari L, Beznoussenko G, Mironov A, Rappa G, Cuomo A, Faretta M, Bonaldi T, Lorico A, Pelicci G. Extracellular vesicle-mediated transfer of CLIC1 protein is a novel mechanism for the regulation of glioblastoma growth. Oncotarget 6: 31413-31427, 2015.

269. Shao H, Chung J, Balaj L, Charest A, Bigner DD, Carter BS, Hochberg FH, Breakefield $\mathrm{XO}$, Weissleder R, Lee $\mathrm{H}$. Protein typing of circulating microvesicles allows real-time monitoring of glioblastoma therapy. Nat Med 18: 1835-1840, 2012.

270. Sharples RA, Vella LJ, Nisbet RM, Naylor R, Perez K, Barnham KJ, Masters CL, Hill AF. Inhibition of gamma-secretase causes increased secretion of amyloid precursor protein $\mathrm{C}$ terminal fragments in association with exosomes. FASEB J 22: 1469-1478, 2008.

271. Shi M, Liu C, Cook TJ, Bullock KM, Zhao Y, Ginghina C, Li Y, Aro P, Dator R, He C, Hipp MJ, Zabetian CP, Peskind ER, Hu S-C, Quinn JF, Galasko DR, Banks WA, Zhang J. Plasma exosomal $\alpha$-synuclein is likely CNS-derived and increased in Parkinson's disease. Acta Neuropathol 128: 639-650, 2014.

272. Shi R, Zhao L, Cai W, Wei M, Zhou X, Yang G, Yuan L. Maternal exosomes in diabetes contribute to the cardiac development deficiency. Biochem Biophys Res Commun 483: 602608, 2017.

273. Silverman JM, Fernando SM, Grad LI, Hill AF, Turner BJ, Yerbury JJ, Cashman NR. Disease mechanisms in ALS: misfolded SOD1 transferred through exosome-dependent and exosome-independent pathways. Cell Mol Neurobiol 36: 377-381, 2016.

274. Simoncini S, Njock M-S, Robert S, Camoin-Jau L, Sampol J, Harlé J-R, Nguyen C, Dignat-George F, Anfosso F. TRAIL/Apo2L mediates the release of procoagulant endothelial microparticles induced by thrombin in vitro: a potential mechanism linking inflammation and coagulation. Circ Res 104: 943-951, 2009.

275. Skog J, Würdinger T, van Rijn S, Meijer DH, Gainche L, Sena-Esteves M, Curry WT, Carter BS, Krichevsky AM, Breakefield XO. Glioblastoma microvesicles transport RNA and proteins that promote tumour growth and provide diagnostic biomarkers. Nat Cell Biol 10: 1470-1476, 2008.

276. Skotland T, Ekroos K, Kauhanen D, Simolin H, Seierstad T, Berge V, Sandvig K, Llorente A. Molecular lipid species in urinary exosomes as potential prostate cancer biomarkers. Eur J Cancer 70: 122-132, 2017.

277. Smyth T, Kullberg M, Malik N, Smith-Jones P, Graner MW, Anchordoquy TJ. Biodistribution and delivery efficiency of unmodified tumor-derived exosomes. $J$ Control Release 199: 145-155, 2015.

278. Sódar BW, Kittel Á, Pálóczi K, Vukman KV, Osteikoetxea X, Szabó-Taylor K, Németh A, Sperlágh B, Baranyai T, Giricz Z, Wiener Z, Turiák L, Drahos L, Pállinger É, Vékey K, Ferdinandy P, Falus A, Buzás EI. Low-density lipoprotein mimics blood plasma-derived exosomes and microvesicles during isolation and detection. Sci Rep 6: 24316, 2016. 
279. Soleti R, Benameur T, Porro C, Panaro MA, Andriantsitohaina R, Martínez MC. Microparticles harboring Sonic Hedgehog promote angiogenesis through the upregulation of adhesion proteins and proangiogenic factors. Carcinogenesis 30: 580-588, 2009.

280. Soleti R, Lauret E, Andriantsitohaina R, Carmen Martínez M. Internalization and induction of antioxidant messages by microvesicles contribute to the antiapoptotic effects on human endothelial cells. Free Radic Biol Med 53: 2159-2170, 2012.

281. Stenmark H. Rab GTPases as coordinators of vesicle traffic. Nat Rev Mol Cell Biol 10: 513-525, 2009.

282. Stepanian A, Bourguignat L, Hennou S, Coupaye M, Hajage D, Salomon L, Alessi MC, Msika S, de Prost D. Microparticle increase in severe obesity: Not related to metabolic syndrome and unchanged after massive weight loss. Obesity 21: 2236-2243, 2013.

283. Stroo E, Koopman M, Nollen EAA, Mata-Cabana A. Cellular regulation of amyloid formation in aging and disease. Front Neurosci 11: 64, 2017.

284. Suades R, Padró T, Vilahur G, Badimon L. Circulating and platelet-derived microparticles in human blood enhance thrombosis on atherosclerotic plaques. Thromb Haemost 108: 1208-1219, 2012.

285. Subra C, Grand D, Laulagnier K, Stella A, Lambeau G, Paillasse M, De Medina P, Monsarrat B, Perret B, Silvente-Poirot S, Poirot M, Record M. Exosomes account for vesiclemediated transcellular transport of activatable phospholipases and prostaglandins. J Lipid Res 51: 2105-2120, 2010.

286. Subra C, Laulagnier K, Perret B, Record M. Exosome lipidomics unravels lipid sorting at the level of multivesicular bodies. Biochimie 89: 205-212, 2007.

287. Sun D, Zhuang X, Xiang X, Liu Y, Zhang S, Liu C, Barnes S, Grizzle W, Miller D, Zhang H-G. A novel nanoparticle drug delivery system: the anti-inflammatory activity of curcumin is enhanced when encapsulated in exosomes. Mol Ther 18: 1606-1614, 2010.

288. Sun L-L, Jiang B-G, Li W-T, Zou J-J, Shi Y-Q, Liu Z-M. MicroRNA-15a positively regulates insulin synthesis by inhibiting uncoupling protein-2 expression. Diabetes Res Clin Pract 91: 94-100, 2011.

289. Svensson KJ, Belting M. Role of extracellular membrane vesicles in intercellular communication of the tumour microenvironment. Biochem Soc Trans 41: 273-276, 2013.

290. Svensson KJ, Christianson HC, Wittrup A, Bourseau-Guilmain E, Lindqvist E, Svensson LM, Mörgelin M, Belting M. Exosome uptake depends on ERK1/2-heat shock protein 27 signaling and lipid raft-mediated endocytosis negatively regulated by caveolin-1. $J$ Biol Chem 288: 17713-17724, 2013.

291. Tafelmeier M, Fischer A, Orsó E, Konovalova T, Böttcher A, Liebisch G, Matysik S, Schmitz G. Mildly oxidized HDL decrease agonist-induced platelet aggregation and release of pro-coagulant platelet extracellular vesicles. J. Steroid Biochem Mol Biol 169: 176-188, 2017 
292. Takahashi Y, Nishikawa M, Shinotsuka H, Matsui Y, Ohara S, Imai T, Takakura Y. Visualization and in vivo tracking of the exosomes of murine melanoma B16-BL6 cells in mice after intravenous injection. J Biotechnol 165: 77-84, 2013.

293. Tan CY, Lai RC, Wong W, Dan YY, Lim S-K, Ho HK. Mesenchymal stem cell-derived exosomes promote hepatic regeneration in drug-induced liver injury models. Stem Cell Res Ther 5: 76, 2014.

294. Tang K, Zhang Y, Zhang H, Xu P, Liu J, Ma J, Lv M, Li D, Katirai F, Shen G-X, Zhang G, Feng Z-H, Ye D, Huang B. Delivery of chemotherapeutic drugs in tumour cell-derived microparticles. Nat Commun 3: 1282, 2012.

295. Tarbell JM. Shear stress and the endothelial transport barrier. Cardiovasc Res 87: 320330, 2010.

296. Taylor AR, Robinson MB, Gifondorwa DJ, Tytell M, Milligan CE. Regulation of heat shock protein 70 release in astrocytes: role of signaling kinases. Dev Neurobiol 67: 1815-1829, 2007.

297. Taylor DD, Zacharias W, Gercel-Taylor C. Exosome isolation for proteomic analyses and rna profiling. Methods Mol Biol 728: 235-246, 2011

298. Terrisse AD, Puech N, Allart S, Gourdy P, Xuereb JM, Payrastre B, Sié P. Internalization of microparticles by endothelial cells promotes platelet/endothelial cell interaction under flow. J Thromb Haemost 8: 2810-2819, 2010.

299. Théry C. Exosomes: secreted vesicles and intercellular communications. F1000 Biol Rep 3, 2011.

300. Théry C, Amigorena S, Raposo G, Clayton A. Isolation and characterization of exosomes from cell culture supernatants and biological fluids. Curr Protoc Cell Biol 3: Unit $3.22,2006$.

301. Théry C, Zitvogel L, Amigorena S. Exosomes: composition, biogenesis and function. Nat Rev Immunol 2: 569-579, 2002.

302. Thomou T, Mori MA, Dreyfuss JM, Konishi M, Sakaguchi M, Wolfrum C, Rao TN, Winnay JN, Garcia-Martin R, Grinspoon SK, Gorden P, Kahn CR. Adipose-derived circulating miRNAs regulate gene expression in other tissues. Nature 542: 450-455, 2017.

303. Tian T, Zhu Y-L, Zhou Y-Y, Liang G-F, Wang Y-Y, Hu F-H, Xiao Z-D. Exosome uptake through clathrin-mediated endocytosis and macropinocytosis and mediating miR-21 delivery. J Biol Chem 289: 22258-22267, 2014.

304. Tian Y, Li S, Song J, Ji T, Zhu M, Anderson GJ, Wei J, Nie G. A doxorubicin delivery platform using engineered natural membrane vesicle exosomes for targeted tumor therapy. Biomaterials 35: 2383-2390, 2014.

305. Tokita Y, Maejima Y, Shimomura K, Takenoshita S, Ishiyama N, Akuzawa M, Shimomura Y, Nakajima K. Non-alcoholic fatty liver disease is a risk factor for type 2 diabetes in middle-aged japanese men and women. Intern Med 56: 763-771, 2017. 
306. Trajkovic K, Hsu C, Chiantia S, Rajendran L, Wenzel D, Wieland F, Schwille P, Brügger B, Simons M. Ceramide triggers budding of exosome vesicles into multivesicular endosomes. Science 319: 1244-1247, 2008.

307. Trzepizur W, Martinez MC, Priou P, Andriantsitohaina R, Gagnadoux F. Microparticles and vascular dysfunction in obstructive sleep apnoea. Eur Respir J 44: 207-216, 2014.

308. Tseng C-C, Wang C-C, Hsiao C-C, Lu H-I, Leu S, Chang H-C, Huang K-T, Fang W-F, Chen Y-M, Liu S-F, Yang C-T, Lin M-C, Yip H-K. Time courses and value of circulating microparticles in patients with operable stage non-small cell lung cancer undergoing surgical intervention. Tumour Biol 37: 11873-11882, 2016.

309. Tsukamoto M, Iinuma H, Yagi T, Matsuda K, Hashiguchi Y. Circulating exosomal microRNA-21 as a biomarker in each tumor stage of colorectal cancer. Oncology 92: 360-370, 2017.

310. Tual-Chalot S, Leonetti D, Andriantsitohaina R, Martínez MC. Microvesicles: intercellular vectors of biological messages. Mol Interv 11: 88-94, 2011.

311. Urbanelli L, Magini A, Buratta S, Brozzi A, Sagini K, Polchi A, Tancini B, Emiliani C. Signaling pathways in exosomes biogenesis, secretion and fate. Genes 4: 152-170, 2013.

312. Valadi H, Ekström K, Bossios A, Sjöstrand M, Lee JJ, Lötvall JO. Exosome-mediated transfer of mRNAs and microRNAs is a novel mechanism of genetic exchange between cells. Nat Cell Biol 9: 654-659, 2007.

313. Valdinocci D, Radford RA, Siow SM, Chung RS, Pountney DL. Potential modes of intercellular $\alpha$-synuclein transmission. Int J Mol Sci 18: pii: E469, 2017.

314.van Dommelen SM, Vader P, Lakhal S, Kooijmans SAA, van Solinge WW, Wood MJA, Schiffelers RM. Microvesicles and exosomes: Opportunities for cell-derived membrane vesicles in drug delivery. J Control Release 161: 635-644, 2012.

315. Van Giau V, An SSA. Emergence of exosomal miRNAs as a diagnostic biomarker for Alzheimer's disease. J Neurol Sci 360: 141-152, 2016.

316.van Niel G, Charrin S, Simoes S, Romao M, Rochin L, Saftig P, Marks MS, Rubinstein E, Raposo G. The tetraspanin CD63 regulates ESCRT-independent and dependent endosomal sorting during melanogenesis. Dev Cell 21: 708-721, 2011.

317. Vella LJ, Hill AF, Cheng L. Focus on Extracellular Vesicles: Exosomes and their role in protein trafficking and biomarker potential in Alzheimer's and Parkinson's disease. Int J Mol Sci 17: 173, 2016.

318. Vella LJ, Sharples RA, Lawson VA, Masters CL, Cappai R, Hill AF. Packaging of prions into exosomes is associated with a novel pathway of PrP processing. J Pathol 211: 582590, 2007.

319. Verderio C, Muzio L, Turola E, Bergami A, Novellino L, Ruffini F, Riganti L, Corradini I, Francolini M, Garzetti L, Maiorino C, Servida F, Vercelli A, Rocca M, Dalla Libera D, 
Martinelli V, Comi G, Martino G, Matteoli M, Furlan R. Myeloid microvesicles are a marker and therapeutic target for neuroinflammation. Ann Neurol 72: 610-624, 2012.

320. Verkhratsky A, Matteoli M, Parpura V, Mothet J-P, Zorec R. Astrocytes as secretory cells of the central nervous system: idiosyncrasies of vesicular secretion. EMBO J 35: 239-257, 2016.

321. Vidal M, Sainte-Marie J, Philippot JR, Bienvenue A. Asymmetric distribution of phospholipids in the membrane of vesicles released during in vitro maturation of guinea pig reticulocytes: evidence precluding a role for "aminophospholipid translocase." J Cell Physiol 140: 455-462, 1989.

322. Vingtdeux V, Hamdane M, Loyens A, Gelé P, Drobeck H, Bégard S, Galas M-C, Delacourte A, Beauvillain J-C, Buée L, Sergeant N. Alkalizing drugs induce accumulation of amyloid precursor protein by-products in luminal vesicles of multivesicular bodies. J Biol Chem 282: 18197-18205, 2007.

323. Violi F, Pignatelli P. Clinical application of NOX activity and other oxidative biomarkers in cardiovascular disease: a critical review. Antioxid Redox Signal 23: 514-532, 2015 .

324. Vion A-C, Ramkhelawon B, Loyer X, Chironi G, Devue C, Loirand G, Tedgui A, Lehoux S, Boulanger CM. Shear stress regulates endothelial microparticle release. Circ Res 112: 1323-1333, 2013.

325. Virmani R, Kolodgie FD, Burke AP, Farb A, Schwartz SM. Lessons from sudden coronary death. Arterioscler Thromb Vasc Biol 20: 1262-1275, 2000.

326. Wang B, Zhuang X, Deng Z-B, Jiang H, Mu J, Wang Q, Xiang X, Guo H, Zhang L, Dryden G, Yan J, Miller D, Zhang H-G. Targeted drug delivery to intestinal macrophages by bioactive nanovesicles released from grapefruit. Mol Ther 22: 522-534, 2014.

327. Wang C, Long W, Peng C, Hu L, Zhang Q, Wu A, Zhang X, Duan X, Wong CCL, Tanaka Y, Xia Z. HTLV-1 Tax functions as a ubiquitin E3 ligase for direct IKK activation via synthesis of mixed-linkage polyubiquitin chains. PLoS Pathog 12: e1005584, 2016.

328. Wang C-C, Tseng C-C, Hsiao C-C, Chang H-C, Chang L-T, Fang W-F, Leu S, Wang Y-H, Tsai T-H, Yang C-T, Chen C-H, Yip H-K, Ho C-K, Lin M-C. Circulating endothelialderived activated microparticle: a useful biomarker for predicting one-year mortality in patients with advanced non-small cell lung cancer. BioMed Res Int 2014: 173401, 2014.

329. Wang S, Cesca F, Loers G, Schweizer M, Buck F, Benfenati F, Schachner M, Kleene $\mathrm{R}$. Synapsin I is an oligomannose-carrying glycoprotein, acts as an oligomannose-binding lectin, and promotes neurite outgrowth and neuronal survival when released via glia-derived exosomes. J Neurosci 31: 7275-7290, 2011.

330. Wang Y, Balaji V, Kaniyappan S, Krüger L, Irsen S, Tepper K, Chandupatla R, Maetzler W, Schneider A, Mandelkow E, Mandelkow E-M. The release and trans-synaptic transmission of Tau via exosomes. Mol Neurodegener 12: 5, 2017. 
331. Wang Y, Cheng Q, Liu J, Dong M. Leukemia stem cell-released microvesicles promote the survival and migration of myeloid leukemia cells and these effects can be inhibited by microRNA34a overexpression. Stem Cells Int 2016: 9313425, 2016.

332. Wiklander OPB, Nordin JZ, O’Loughlin A, Gustafsson Y, Corso G, Mäger I, Vader P, Lee Y, Sork H, Seow Y, Heldring N, Alvarez-Erviti L, Smith CE, Le Blanc K, Macchiarini P, Jungebluth P, Wood MJA, Andaloussi SE. Extracellular vesicle in vivo biodistribution is determined by cell source, route of administration and targeting. J Extracell Vesicles 4, 2015.

333. Winston CN, Goetzl EJ, Akers JC, Carter BS, Rockenstein EM, Galasko D, Masliah E, Rissman RA. Prediction of conversion from mild cognitive impairment to dementia with neuronally derived blood exosome protein profile. Alzheimers Dement 3: 63-72, 2016.

334. Wolf $\mathrm{P}$. The nature and significance of platelet products in human plasma. $\mathrm{Br} J$ Haematol 13: 269-288, 1967.

335. Xiao T, Zhang W, Jiao B, Pan C-Z, Liu X, Shen L. The role of exosomes in the pathogenesis of Alzheimer' disease. Transl Neurodegener 6: 3, 2017.

336. Xu J, Chen Q, Zen K, Zhang C, Zhang Q. Synaptosomes secrete and uptake functionally active microRNAs via exocytosis and endocytosis pathways. J Neurochem 124: 15-25, 2013.

337. Xu M-D, Wu X-Z, Zhou Y, Xue Y, Zhang K-Q. Proteomic characteristics of circulating microparticles in patients with newly-diagnosed type 2 diabetes. Am J Transl Res 8: 209-220, 2016.

338. Yang C, Xiong W, Qiu Q, Tahiri H, Superstein R, Carret A-S, Sapieha P, Hardy P. Antiproliferative and anti-tumour effects of lymphocyte-derived microparticles are neither speciesnor tumour-type specific. J Extracell Vesicles 3, 2014.

339. Yang X, Meng S, Jiang $\mathrm{H}$, Chen $\mathrm{T}$, Wu W. Exosomes derived from interleukin-10treated dendritic cells can inhibit trinitrobenzene sulfonic acid-induced rat colitis. Scand $J$ Gastroenterol 45: 1168-1177, 2010.

340. Yanovski SZ, Yanovski JA. Long-term drug treatment for obesity: a systematic and clinical review. JAMA J Am Med Assoc 311: 74-86, 2014.

341. Yim Y-I, Park B-C, Yadavalli R, Zhao X, Eisenberg E, Greene LE. The multivesicular body is the major internal site of prion conversion. J Cell Sci 128: 1434-1443, 2015.

342. Yin M, Loyer X, Boulanger CM. Extracellular vesicles as new pharmacological targets to treat atherosclerosis. Eur J Pharmacol 763: 90-103, 2015.

343. Yuyama K, Sun H, Sakai S, Mitsutake S, Okada M, Tahara H, Furukawa J-I, Fujitani $\mathrm{N}$, Shinohara Y, Igarashi Y. Decreased amyloid- $\beta$ pathologies by intracerebral loading of glycosphingolipid-enriched exosomes in Alzheimer model mice. J Biol Chem 289: 2448824498, 2014.

344. Yuyama K, Sun H, Usuki S, Sakai S, Hanamatsu H, Mioka T, Kimura N, Okada M, Tahara H, Furukawa J, Fujitani N, Shinohara Y, Igarashi Y. A potential function for neuronal exosomes: sequestering intracerebral amyloid- $\beta$ peptide. FEBS Lett 589: 84-88, 2015. 
345. Zhang Y, Chopp M, Meng Y, Katakowski M, Xin H, Mahmood A, Xiong Y. Effect of exosomes derived from multipluripotent mesenchymal stromal cells on functional recovery and neurovascular plasticity in rats after traumatic brain injury. J Neurosurg 122: 856-867, 2015.

346. Zhang Y, Liu D, Chen X, Li J, Li L, Bian Z, Sun F, Lu J, Yin Y, Cai X, Sun Q, Wang K, Ba Y, Wang Q, Wang D, Yang J, Liu P, Xu T, Yan Q, Zhang J, Zen K, Zhang C-Y. Secreted monocytic miR-150 enhances targeted endothelial cell migration. Mol Cell 39: 133-144, 2010.

347. Zhang Y, Mei H, Chang X, Chen F, Zhu Y, Han X. Adipocyte-derived microvesicles from obese mice induce M1 macrophage phenotype through secreted miR-155. J Mol Cell Biol 8: 505-517, 2016.

348. Zheng P, Chen L, Yuan X, Luo Q, Liu Y, Xie G, Ma Y, Shen L. Exosomal transfer of tumor-associated macrophage-derived miR-21 confers cisplatin resistance in gastric cancer cells. J Exp Clin Cancer Res 36: 53, 2017.

349. Zhou W, Fong MY, Min Y, Somlo G, Liu L, Palomares MR, Yu Y, Chow A, O'Connor STF, Chin AR, Yen Y, Wang Y, Marcusson EG, Chu P, Wu J, Wu X, Li AX, Li Z, Gao H, Ren $\mathrm{X}$, Boldin MP, Lin PC, Wang SE. Cancer-secreted miR-105 destroys vascular endothelial barriers to promote metastasis. Cancer Cell 25: 501-515, 2014.

350. Zhuang X, Xiang X, Grizzle W, Sun D, Zhang S, Axtell RC, Ju S, Mu J, Zhang L, Steinman L, Miller D, Zhang H-G. Treatment of brain inflammatory diseases by delivering exosome encapsulated anti-inflammatory drugs from the nasal region to the brain. Mol Ther 19: 1769-1779, 2011.

351. Zomer A, Maynard C, Verweij FJ, Kamermans A, Schäfer R, Beerling E, Schiffelers RM, de Wit E, Berenguer J, Ellenbroek SIJ, Wurdinger T, Pegtel DM, van Rheenen J. In Vivo imaging reveals extracellular vesicle-mediated phenocopying of metastatic behavior. Cell 161: 1046-1057, 2015. 